\title{
An Analysis of New Zealand's Role in Food Insecurity in Fiji
}

\author{
By
}

\author{
Laura Barrett
}

Thesis submitted to Victoria University of Wellington in partial fulfilment of the requirements for the Degree of Master of Development Studies

School of Geography, Environment and Earth Sciences

Victoria University of Wellington

2011 



\begin{abstract}
Access to adequate food is a human right. Despite this, globally around three billion people lack access to food sufficient to allow them to live free from hunger and malnutrition. In the Pacific, despite millennia of positive nutrition, they now have some the highest rates of diabetes and obesity in the world, and 75 percent of their population are dying prematurely from non-communicable diseases (NCD's). One of the main risk factors for NCD's is an unhealthy diet. A key finding coming out of the Pacific Food Summit in 2010 was that imported foods represent a threat to Pacific food security. New Zealand is a key trader with the Pacific. It has also come under criticism in recent years over its trade of poor quality meat to the Pacific, which it has been argued is contributing to poor health outcomes there. This research seeks to look deeper into the relationship between New Zealand trade and Pacific food insecurity, using Fiji as a case study. A key foundation for this research is the 'right to food'. The right to adequate food is a fundamental right of all human beings. This is established by the Universal Declaration of Human Rights (1948) and subsequent treaties, to which all signatory countries are bound. Recently, this right is being discussed in an extraterritorial context, meaning states have obligations not only to those within their territory, but across the globe. This places obligations on states to both respect the right to food of citizens globally, and also to protect them against actions taken by those within their territory which would undermine this right. It is against this backdrop, utilising interviews, data and policy analysis, that the trade relationship between New Zealand and Fiji is analysed.
\end{abstract}




\section{Acknowledgements}

Undertaking this Masters has been an all-consuming project, both mentally and emotionally. The support of friends, family and colleagues has been invaluable in this process. I wish to pay special thanks to a few in particular, in no special order. To the 'deve girls' plus A. J, I wouldn't have started it without your encouragement, and I wouldn't have got through it without your support. To friends that have remained with me over the past two years, during which time I often missed engagements; I look forward to being a part of your lives again. To my family who made me who I am today. And to my partner Marco, who was a constant source of support and encouragement, who always believed in me, and taught me to see the race as one only with myself.

I wish to thank also my supervisor Warwick Murray, who remained encouraging even during my most wobbliest of times. Thank you also to Dennis in student support for your advice on data analysis. I only wish I had known you were there earlier. A special thank you goes to the people who participated in this research, the people I interviewed and who I consulted in the process, without whom none of this would have been possible.

Finally, to those who suffer from hunger and malnutrition because of a failure of the world to ensure the most basic right of all, that of access to sufficient healthy food; it is with hope that this research has been undertaken for a world in which this is no longer allowed to persist. 


\section{Contents}

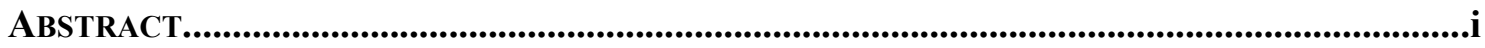

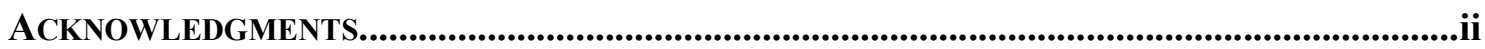

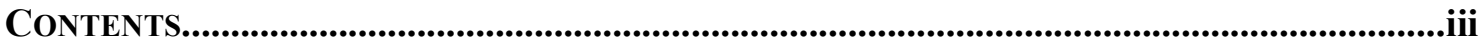

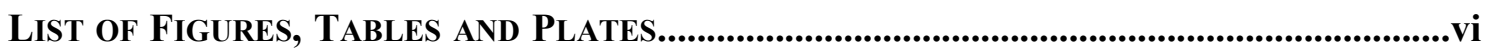

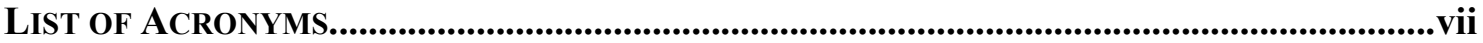

CHAPTER 1: INTRODUCTION........................................................................................................... 1

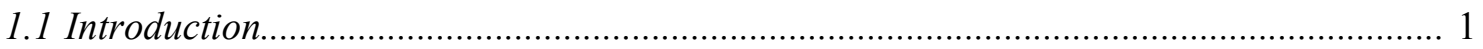

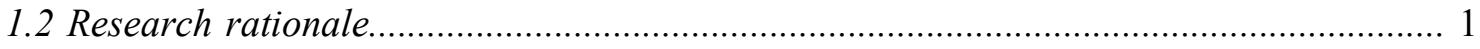

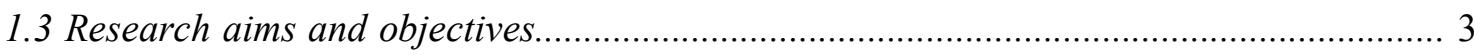

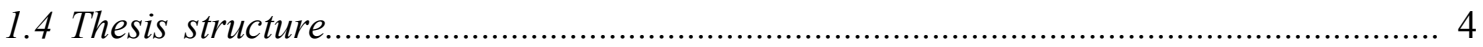

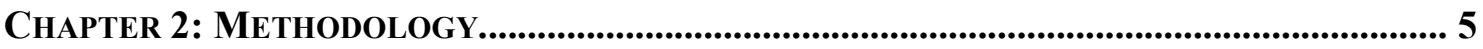

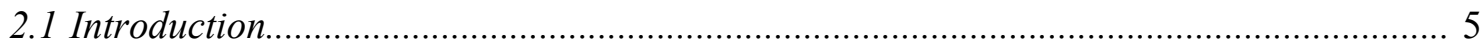

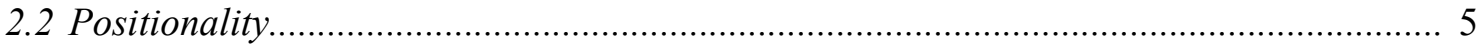

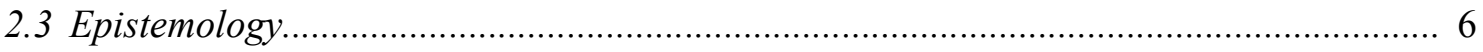

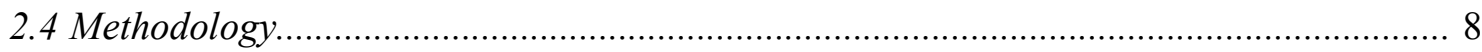

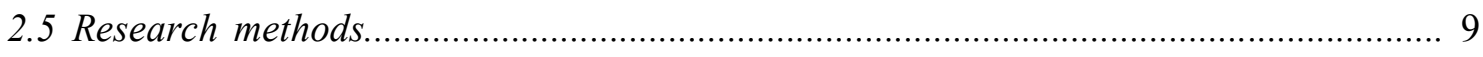

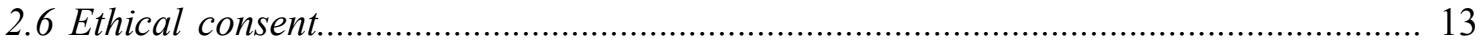

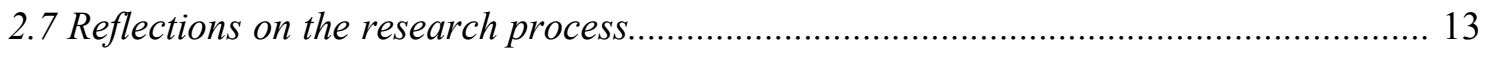

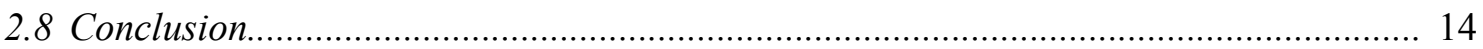

CHAPTER 3: FOOD SECURITY AND THE RIGHT TO FOOD........................................................ 16

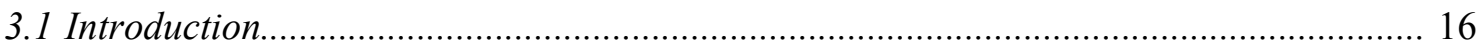

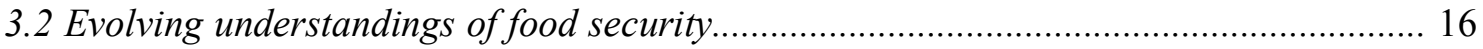

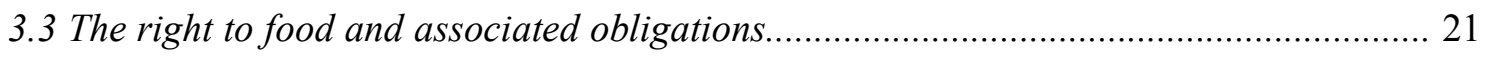

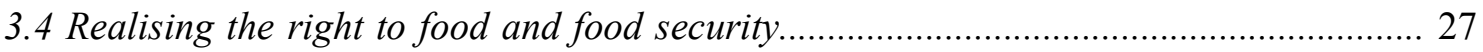

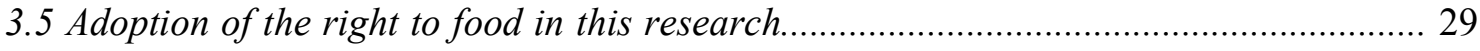

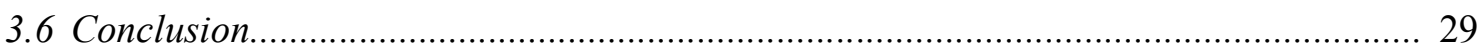


CHAPTER 4: GLOBALISATION AND FOOD SECURITY ................................................................. 31

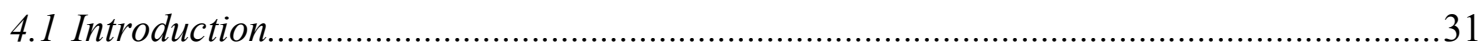

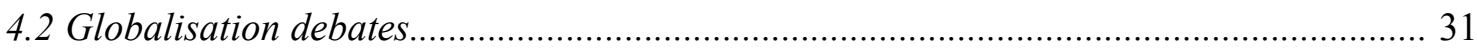

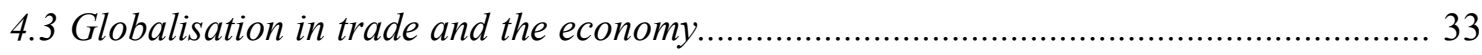

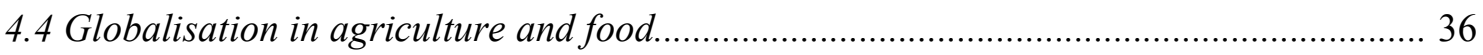

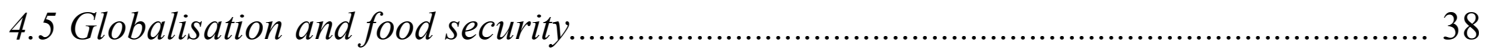

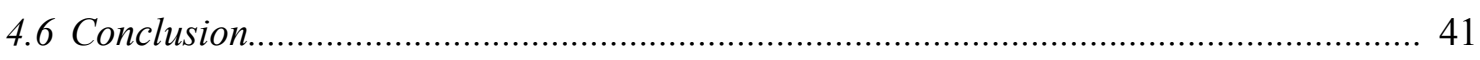

CHAPTER 5: FOOD INSECURITY IN FIJI...................................................................................... 44

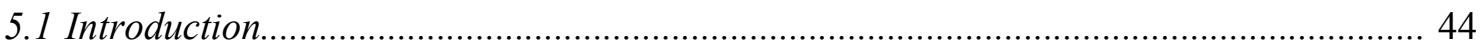

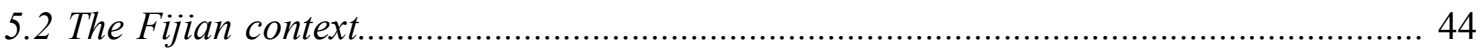

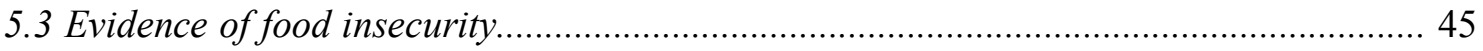

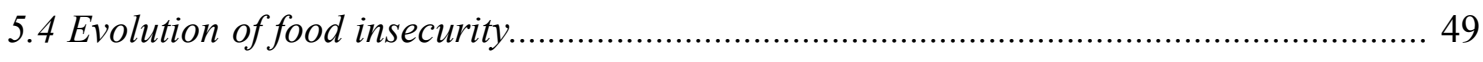

5.5 Historical causal factors in food insecurity....................................... 52

5.6 Contemporary causal factors in food insecurity - Social........................... 54

5.7 Contemporary causal factors in food insecurity - Individual ............................ 59

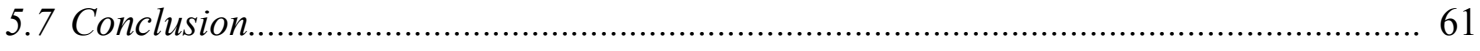

Chapter 6: TRade Between NeW ZEALANd AND FiJI............................................... 63

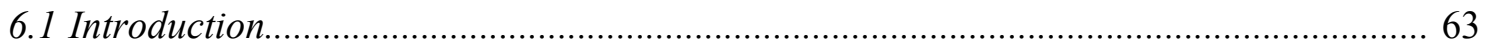

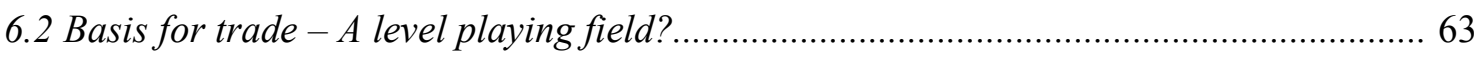

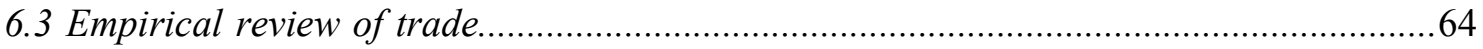

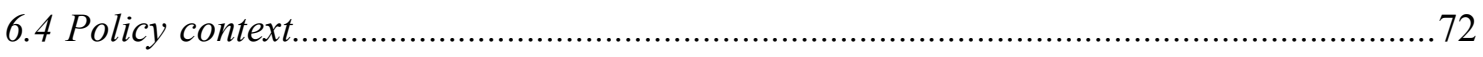

6.5 Future trade - Implications of PACER Plus............................................................ 74

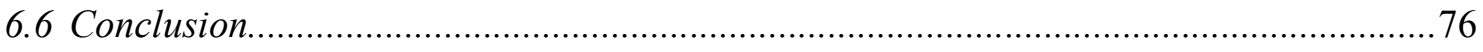

CHAPTER 7: NEW ZEALAND TRADE AND FOOD INSECURITY IN FIJI - THE LINKS................ 78

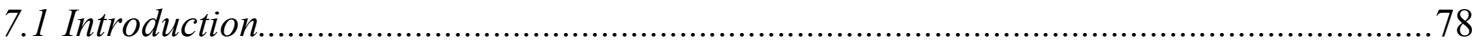

7.2 Direct impacts of New Zealand trade on food security in Fiji..................................... 80

7.3 Indirect impacts of New Zealand trade on food security in Fiji..................................... 86 
7.4 A legal and moral obligation for New Zealand to address its role in food insecurity in Fiji ............................................................................... 96

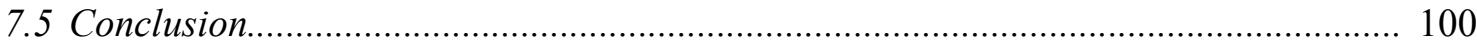

CHAPTER 8: THE NEW ZEALAND GOVERNMENT'S APPROACH TO FOOD SECURITY AND

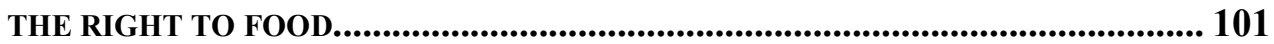

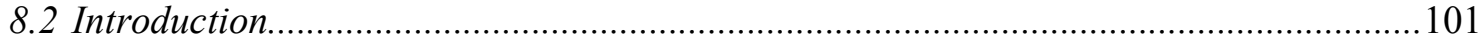

8.2 Food security and the right to food in government policy.............................. 101

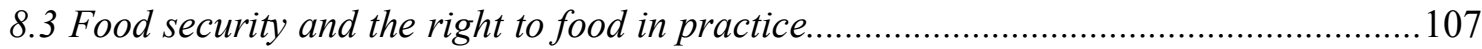

8.4 Barriers to greater prioritisation of food security and the right to food in practice...... 110

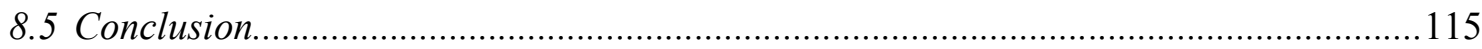

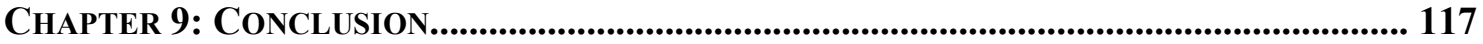

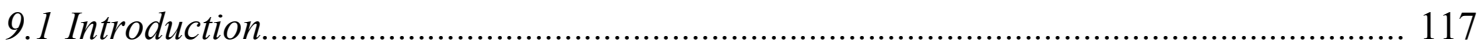

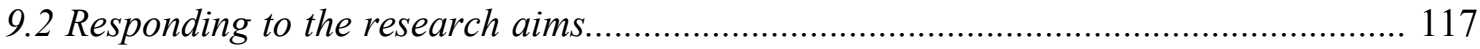

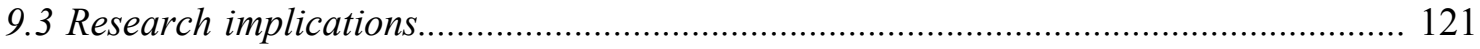

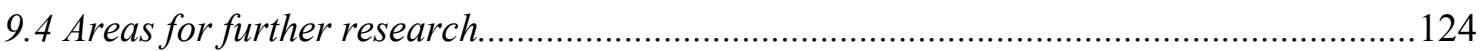

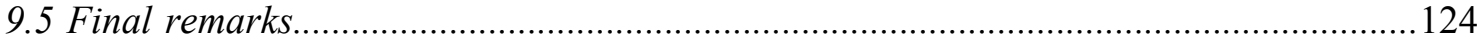

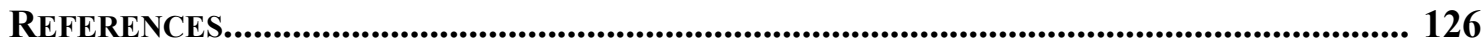

APPENDICES............................................................................................................................ 142

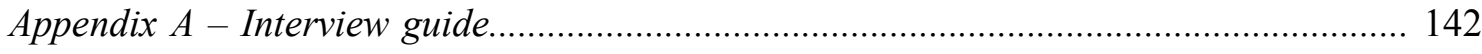

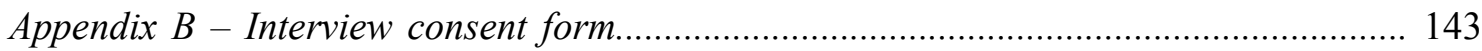

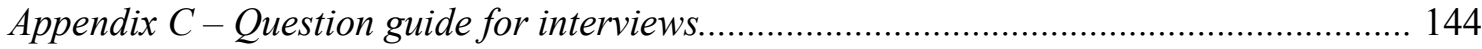

Appendix D - Guide to harmonised system categories................................................ 145

Appendix E - Foods exported from New Zealand to Fiji 2008 - 2010......................... 146

Appendix F-Meat exports New Zealand to Fiji 2008 - 2010...................................... 150 


\section{List of Figures, Tables and Plates}

\section{List of Figures}

Figure 1: Food production index Fiji 1990-2009.......................................................... 58

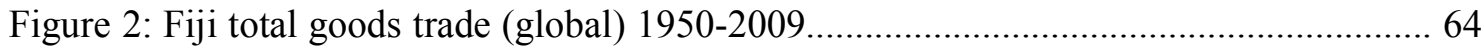

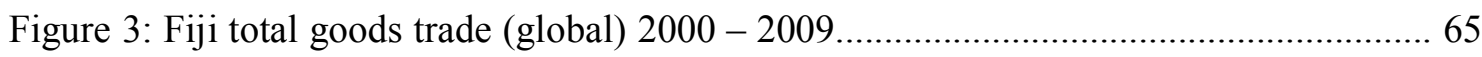

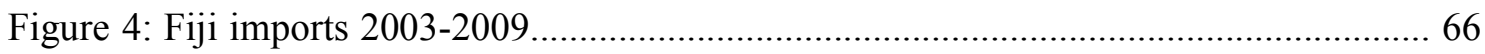

Figure 5: Goods trade between New Zealand \& Fiji 1988 - 2010................................... 67

Figure 6: New Zealand top 14 imports by category from Fiji........................ 68

Figure 7: Food exports as a proportion of total exports - New Zealand to Fiji..................... 69

Figure 8: Top three food group exports by category - New Zealand to Fiji.......................... 70

\section{List of Tables}

Table 1: Food exports by category - New Zealand to Fiji $2010 \ldots \ldots \ldots \ldots \ldots \ldots \ldots \ldots \ldots \ldots$

Table 2: Top exports by commodity - New Zealand to Fiji 2007 and 2010.................. 71

\section{List of Plates}

Plate 1: A typical supermarket aisle in Suva, Fiji................................ 51

Plate 2: Cassava planted alongside the side of a public footpath.................... 56

Plate 3: Advertisement for Fiji's 'Go Local' movement encouraging production and

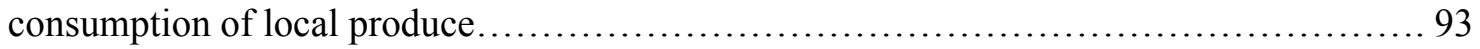




\title{
List of Acronyms
}

\author{
ADB - Asian Development Bank \\ ACP - African, Caribbean and Pacific countries \\ CEO - Chief Executive Officer \\ FAO - Food and Agriculture Organization of the United Nations \\ FSP - Food Secure Pacific \\ GATT - General Agreement on Trade and Tariffs \\ GDP - Gross Domestic Product \\ ICCPR - International Covenant on Civil and Political Rights \\ ICESCR - International Covenant on Economic Social and Cultural Rights \\ IDG - International Development Group \\ IMF - International Monetary Fund \\ MFAT - Ministry of Foreign Affairs and Trade \\ NCD - Non-communicable Disease \\ NZAID - New Zealand Agency for International Development \\ OECD - Organisation for Economic Co-operation and Development \\ PACER - Pacific Agreement on Closer Economic Relations \\ PACER Plus - Pacific Agreement on Closer Economic Relations - Plus \\ PICTA - Pacific Island Countries Trade Agreement \\ SPC - Secretariat of the Pacific Community \\ TNC - Transnational Corporation \\ UDHR - Universal Declaration of Human Rights \\ UN - United Nations \\ UNCTAD - United Nations \\ UNDP - United Nations Development Programme \\ UNESCAP - United Nations Economic and Social Commission for Asia and the Pacific \\ UNICEF - United Nations Children's Fund \\ VAT - Value added tax \\ WHO - World Health Organisation \\ WTO - World Trade Organisation
}





\section{Chapter 1: Introduction}

"Food, indeed, has a dual nature as a basic human need, as a matter of life and death, and as a commodity"

(Spitz, 2002, 75)

\subsection{INTRODUCTION}

Access to adequate food is a human right. Despite this, globally around three billion people lack access to food sufficient to allow them to live free from hunger and malnutrition. Those that suffer from this are primarily located in developing countries, however, this is an issue that the world as a whole is both implicated in and has a responsibility to address. All too often approaches to addressing global poverty and insecurity are focused on changes that need to be made in developing countries. However, this neglects the role that wealthier countries play in undermining these rights through global structures. This research thus seeks to advance awareness of the role of one developed country, New Zealand, in the deterioration of health and nutrition in a small island state, Fiji.

\subsection{RESEARCH RATIONALE}

\section{Pacific food security threatened}

The islands of the Pacific possess some of the most unique and diverse cultural and geographical heritage on Earth. Ecologically sound and communally supportive practices saw the peoples of the Pacific in good health and nutrition for millennia (Hughes, 2003). However over the last century this has become increasingly undermined. Pacific Island populations are now facing an epidemic in obesity and diabetes, with 75 percent of deaths occurring as a result of non-communicable diseases (SPC, 2009b). In response to this, addressing food security in the region has been recognised as a priority at the highest political level (FSP Working Group, 2010). In April 2010 the first Pacific Food Summit was held in order to develop a framework for action. 


\section{The role of trade in food insecurity}

One of the findings of the framework for action resulting from the Pacific Food Summit was that imported foods represent a threat to Pacific food security (FSP Working Group, 2010). Although commonly associated with the positive benefits it can bring, it is increasingly accepted that trade can also undermine food security. One example of this is the "nutrition transition', a term which describes the process by which traditional nutritional foods are replaced by processed items, high in salt, sugar and fat, which are for the most part imported (Hawkes, 2006). The nutrition transition, most notable in the developing world, is linked to rises in non-communicable diseases such as obesity and diabetes. Importantly, while these diseases have been traditionally associated with the wealthy, they are increasingly understood to be found in poorer communities (WHO, 2008), and thus indicative of a lack of access to nutritional food.

It is not only the foods that are traded but also terms which govern trade that are being associated with increasing nutritional vulnerability. Increasing evidence finds neoliberal policies of liberalisation and deregulation fervently applied to developing countries over the last three decades to be undermining developing countries ability to implement policies and practices which would support domestic nutrition. Kelsey (2005) argues that for the Pacific trade and health issues are inextricably inter-twined. Based on this evidence, improving health for Pacific Island people necessarily entails investigations into trade relationships with its partners.

\section{New Zealand trade and Fiji food insecurity}

New Zealand has strong geographical, historical, and cultural ties and is a key trader with the Pacific. However, aspects of this relationship have come under increasing criticism. Question has been raised over New Zealand meat exports to the Pacific, which are often high in fat and of poor quality, and are argued to be contributing to poor health there (Wyber, Wilson, \& Baker, 2009). New Zealand-Pacific trade arrangements have also been criticised for undermining Pacific food security. These exhibit a high level of imbalance, leaving a number of Pacific Island countries food import dependent, a situation, it has been argued, which leaves countries vulnerable (McGee, 1975), threatening their food security. Negotiations are underway at present for a new trade agreement between Pacific Island Forum countries, New Zealand and Australia, which once signed will be irrevocable. Critical evaluation of this 
relationship is needed so that decisions made are done so in the full awareness of the likely impacts of this on the food security and livelihoods of Pacific populations.

\subsection{RESEARCH AIMS AND OBJECTIVES}

This research seeks to examine New Zealand's role in food insecurity in the Pacific through the items it trades and the manner in which it engages in trade. In doing so, the research employs a case study of New Zealand and Fiji. Extraterritorial application of the right to food forms the foundation for analysis of this relationship. In response to this, the research has three aims. Each aim is supported by two objectives. These are listed below.

Aim 1: To describe and analyse food insecurity in Fiji

a) To describe and analyse the manifestation of food insecurity in Fiji

b) To identify factors that have led to and perpetuate food insecurity in Fiji

Aim 2: To describe and analyse the trade relationship with respect to food between New Zealand and Fiji

a) To describe and analyse trends in trade between New Zealand and Fiji with a focus on food

b) To describe and analyse the policy context for trade between New Zealand and Fiji

A new imperative for action by developed states is being brought by the extraterritorial application of human rights. Extraterritorial application of the right to food places obligations on states to monitor and mediate policies and actions which undermine the right to food in other countries. The extent to which the New Zealand government recognises this thus has impacts for the realisation of food security and the right to food in the Pacific and leads to the third aim of this research:

Aim 3: To evaluate the New Zealand government's approach to food security in the Pacific and the right to food based on extraterritorial application of these

a) To identify the New Zealand government's position internationally on the right to food and food security and obligations associated with these

b) To evaluate the extent to which these are incorporated into trade and international development policy with the Pacific 


\subsection{THESIS STRUCTURE}

The remainder of the thesis proceeds as follows:

Chapter two establishes the philosophical underpinnings of the research, as well as the methodology and methods under which the research has been carried out. Ethical considerations are central to research, particularly those that involve human participants, and these are discussed here. This chapter also provides some reflections on the research process. Chapter three provides the theoretical foundations for the research. It establishes the context and foundations for the right to food, including the obligations associated with this right, and to whom they can be extended. In doing so, this provides the basis against which the results of the research are analysed, and conclusions drawn. Chapter four provides the global context in which the present relationship between trade and food insecurity has developed. It covers changes in trade and agriculture over the post World War period. As will be established, it is over this time that fundamental, unprecedented change has occurred which has an integral relationship with global manifestations of food insecurity.

Chapter five responds to aim one of the research by establishing the prevalence of food insecurity in Fiji and the factors in this both historically, and contemporarily. This forms the foundation for subsequent analysis and discussion. Chapter six looks at the trade relationship between New Zealand and Fiji. It covers policy, which influences the relationship, and provides empirical evidence of contemporary trade in foods as well as an historical overview of the relationship. In doing so, this chapter, along with the previous chapter, provides the basis for analysis of the relationship between New Zealand trade and food insecurity in Fiji. With the foundations laid in previous chapters, utilising interviews with key informants chapter seven analyses the relationship between New Zealand trade, in particular food trade, and food insecurity in Fiji, drawing conclusions on this relationship. Responding to the third aim of the research, Chapter eight analyses New Zealand government documents and with support from interview findings assesses the New Zealand position on food security and the right to food. In particular, it focuses on the extent to which New Zealand recognises extraterritorial obligations to protect the right to food. Finally, chapter nine draws the research together, summarising the key findings of the research. Based on this, some theoretical and policy implications are identified, along with areas for further research. 


\section{Chapter 2: Methodology}

\subsection{INTRODUCTION}

This thesis is located in the discipline of Development Studies. It explores areas of health, economics and human rights, reflecting on the interactions between a 'developed' country, New Zealand, and a 'developing' country, Fiji. As a cross disciplinary field (Sumner \& Tribe, 2008, p. 1), Development Studies provides a useful linking framework within which to explore the multiple elements of the research and the relationship between them. As Sumner and Tribe (2008, p. 54) point out, "research in development studies...is shaped and framed by our underlying assumptions about 'reality' and 'knowledge'. Our philosophical beliefs influence our choice of topic, methodology and methods. Although philosophical beliefs guide all research to some degree (Kitchin \& Tate, 2000) it is perhaps even more evident in Development Studies which at its core deals with issues of social justice. The rest of this chapter is dedicated to outlining the process through which the research was carried out, and the ideas underpinning it. The positionality of the researcher begins this discussion. Following this, the epistemological positioning of the researcher is outlined and, stemming from this, the methodology and methods that have been employed in pursuit of the aims of the research as outlined in the previous chapter. In all research, but especially that which involves human participants, there are ethical elements to consider and these are discussed here. The chapter concludes with reflections from the researcher on the research process.

\subsection{POSITIONALITY}

One must think carefully about their position when working in development. There has been much debate over the practice of Westerners carrying out research in 'developing countries'. This has been largely based on concerns over the ethics and impacts of such research where power relations are uneven (Scheyvens \& Storey, 2003). Even where good intentions lie there is potential for exploitation and dispossession by passing over control over representation of themselves to so-called 'experts' (Escobar, 1995). This has provided much food for thought over the potential for Western research to meaningfully support those in developing countries. This research supports the idea that those at grassroots level are best placed to know what is 
needed in terms of their own development, a point in development which is generally acknowledged and accepted, although not always practiced.

At the same time, as Scheyvens and Storey (2003) note, withdrawal from the research process based on the assumption that Western research will necessarily be exploitative fails to acknowledge the power that those in poorer countries do hold, such as to withhold or direct information. Further, there are times when cross-cultural research is valuable. For instance, where the research is centred on the relationship between countries, to ignore the position of those in either country would be erroneous. No nation exists independently of interactions with and influence from other states, and these interactions carry with them implications for everyone concerned.

For the most part, research on poverty takes place in poor countries. This position however leaves out a critical component in 'underdevelopment'. Shaw (1995, p. 96) opines "structural problems between North and South cannot be solved by the South alone". All too often it is the case that those in poorer countries are researched and instructed on what 'they' need to do to overcome poverty. But this is a question for us all.

This research takes inspiration from the work of Mahid Rahnema, a key voice in postdevelopment discourse which has been most critical of the impacts of 'development'. As Rahnema (1997, p. 397) has stated "Before intervening in other people's lives, one should first intervene in one's own”. This can be applied to one's country as well as one's self. Thus, from the outset, a key motivation for this research has been to reflect upon the role of a 'developed' country, that from which the researcher originates, and evaluate the potential for change in its behaviour to realise better outcomes in a place that is struggling as a result of those actions. Further to this, while Rahnema urges mindfulness of positionality and critical examination of personal motivations, he also speaks of a place for friendships between those in centres of power and those who have been subjugated (Rahnema, 1997).

\subsection{EPISTEMOLOGY}

There exist competing views on the achievability of objectivity in research. This debate is played out in the study of epistemology, which building on ontological inquiries around the nature of reality and what is knowable (Sumner \& Tribe, 2008), seeks to define how one can 'know' the nature of 'reality'. One's position on these counts influences the shape and 
outcomes of the research. In making assumptions about the nature of reality and about the aim of knowledge enquiry it lends one towards certain theories and conceptual frameworks which then informs ones selection of methodology and methods (Sumner \& Tribe, 2008). Inevitably, these assumptions filter into findings and conclusions also. It is thus important to outline the researcher's epistemology at the outset. While we cannot escape influence, we can at least acknowledge that it exists, and make it explicit at the outset (Cloke, Philo, \& Sadler, 1991).

\section{Critical realism}

This research employs a critical realist perspective. Positivistic approaches to natural and social science research, which declare the need for neutrality and objectivity in research, have characterised much of the 20th century (Tashakkori \& Teddlie, 2003). There has been a marked turn over the last three decades in which alternative approaches to research have received increasing validity. Presently, within Development Studies a range of epistemological perspectives are evident. These can perhaps best be seen on a spectrum; with positivistic/empiricist approaches at one end, and relativist/hermeneutics/interpretive approaches at the other (Kanbur \& Shaffer, 2005). Within this lies realism which operates from a basis that "there is a knowable Reality independent of humans, but perceptions of that Reality are subjective" (Sumner \& Tribe, 2008, p. 59). Based on this, underlying mechanisms and structures in areas of policy and practice are key sites of research to explain social relations. The task of the realist researcher is then to explain collected observations "within theoretical frameworks which examine the underlying mechanisms which structure people's actions" (May, 1997, p. 12).

Further to this, the research takes a critical approach to research. Habermas (1978) has been attributed with dividing science into three categories: empirical-analytical, historicalhermeneutic and critical. The approaches differ in the opinion on both the "purpose knowledge should serve and how it should be constructed and represented" (Kitchin \& Tate, 2000 , p. 6). A critical approach, distinct from the other two approaches, possesses a moral element. A central objective of critical research is to improve society, and is emancipatory in nature. Such an approach necessarily entails questions of ethics. As Berger (1974, p. vii) notes, "no humanly acceptable discussion of the anguishing problems of the world's poverty can avoid ethical considerations". 


\subsection{METHODOLOGY}

\section{Case study}

A characteristic of critical realist approaches to research is that for change to occur points must be located in the context in which they occur (Bentz \& Shapiro, 1998). The research presented here comes as a case study of interactions between New Zealand and Fiji and outcomes in Fiji. According to Denscombe (2007), case studies allow the researcher to look at an issue in its entirety, exposing relationships and processes and how the different parts affect the whole. In doing so, case studies serve to "to illuminate the particular by looking at the general" (Denscombe, 2007, p. 36). While case studies place the 'spotlight' on one instance, they can provide valuable insights that can have implications for a wider application.

\section{Choice of setting}

The starting point for looking at New Zealand was the researcher's philosophical outlook that of self-review. Given the unique historical and cultural ties with the Pacific, the relationship between the two was a logical progression in which to explore New Zealand's influence and impact on a developing country. Additionally though, the Pacific provides a valuable site for inquiry into the effects of globalisation and trade on local nutrition. Food insecurity has not historically been an issue for the Pacific; to the contrary, the Pacific has a strong history of positive nutrition. Global integration also came later to the Pacific. The relationship between the two may be illuminated by these facts. As for Fiji as the site of research, although not the most food insecure amongst the Pacific islands, there are features which make it a strong location choice for research. For one, Fiji displays attributes of food insecurity, and more so, worsening food insecurity. With a view to the relationship between New Zealand trade and Pacific food insecurity, Fiji has the strongest trading relationship with New Zealand in dollar terms. One of the key challenges in undertaking research in the Pacific, and conversely, what makes the Pacific a place of potential research opportunities, is the lack of primary data available. For this research project, a certain level of data was necessary and more of this was available on Fiji. Additionally, key sites of information for the Pacific are centred in Fiji. Suva, the capital of Fiji, is home to many key organisations - it is the main campus for the University of the South Pacific and the base for the Secretariat of the Pacific Community as well as other regional and international organisations. Thus, Fiji as a site of choice for research is informed by philosophical, theoretical, and pragmatic underpinnings. 


\section{Mixed-method approach}

The research employs a mixed-method approach. This approach has become recognized and attained credibility as an approach in and of itself within the last three decades (Denscombe, 2007). The approach is premised on the tenet that qualitative and quantitative methods can be both compatible and illuminating. This comes in contrast to the more traditional view that research must be one or the other. In addition to this there are two other distinguishing features of the mixed-method approach. First, the concept of triangulation, which posits that by viewing something from different angles a better understanding of the point under investigation can be gained. Triangulation can occur in a number of ways, between methods, within methods, or through employing multiple researchers or theories (Denzin, 1970). There can be a cost to triangulation; undertaking different methods takes time, and as most research projects have a limited time scale, this can place limitations over the amount of data that can be collected in any one method, for example. However, this must be outweighed by the benefits of using such an approach. Where the aim is to present a fuller picture, this method can be justified (Denscombe, 2007). The second additional attribute of a mixed-method approach is that it is pragmatic and problem-driven. Indeed, finding answers to a problem is not unique to this approach, but its position as a driving force behind selection of methods is. This means methods employed in this approach may not always share the same philosophical background and may in other approaches be regarded as incompatible. Thus, employing a mixed-method approach opens up possibility in approaching research, and "can provide alternative perspectives that, when combined, go further towards an all embracing vision of the subject than could be produced using a mono-method approach" (Denscombe, 2007, p. $110)$.

\subsection{RESEARCH METHODS}

The research employs three methods - interviews, statistical data analysis, and document analysis, in achieving the aims of the research. Within these methods, which are both qualitative and quantitative in nature, both primary and secondary data were utilised. Although necessarily presented in an order here, the research process is often not linear, and more often represents a circular progression, re-enforcing and re-designing as it goes (Murray \& Overton, 2003). This has been the experience of this research. 


\section{Semi-structured interviews}

The primary component of this research has been interviews. Interviews are an appropriate method for research "when what they offer is an insight they have as people in a special position to know" (Denscombe, 2007, p. 175). The research attempted to gain a holistic understanding of a complex problem which spanned areas of health, agriculture, trade and human rights. Thus locating individuals who could speak with knowledge and authority was critical. Initial contacts were identified through the review of relevant literature. From this point, however, further contacts were identified through the process of interviews. Interviewees were often well placed to advise and support contact with people to talk to and in this way have been termed "gatekeepers of knowledge" (Murray \& Overton, 2003). It was not always possible to meet with people who were identified as being an ideal candidate with a position to know. Particularly in the case of Fiji, some were simply too busy to take time away from other responsibilities. At the same time, other meetings were purely serendipitous, such as the meeting with one of the community workers who happened to be staying at the same hotel in Suva. The interviews were semi-structured in nature. Less rigidity allows the interviewee to speak more widely within their area of expertise on the issues raised (Denscombe, 2007). A list of issues and questions to be addressed was used (Appendix C). Interviews were then tailored for each interview and scope was allowed for interviewees to direct the interview to some degree, recognising their expertise in the area. Where permission was given, interviews were recorded in order to most accurately represent the information communicated.

In total eighteen formal interviews were carried out over the course of the research; eleven in Fiji; six in New Zealand; and one in Australia via internet. Critical to the research have been the voices of those in Fiji in understanding manifestations of food insecurity and its causes, as well as the impacts of New Zealand trade on Fijian food security and livelihoods. Interviews conducted in New Zealand complemented this and further provided insight supporting the third aim of the research, that of analysing the New Zealand government's approach to food security and the right to food. Although interviews were directed towards particular aims, in reality informants often provided valuable insights that related to more than one of the aims. Over and above this, discussions were had with individuals outside this over the course of the research, which ultimately contributed to the researcher's overall comprehension of the topic, although they are not included directly within the thesis. 
Informants came from a broad spectrum of agencies and expertise. Interviews were carried out with academics, community workers, public servants, workers from national watchdog body Consumer Council of Fiji, CEO of Rewa Co-operative Dairy Company, an employee of the Secretariat of the Pacific Community, who spoke both for the organisation and based on his independent knowledge from working in agriculture, and an ex-agricultural worker in the meat industry, who is also an independent small holder dairy farmer. The areas of knowledge spanned across health, agriculture, ethnobiology, community wellbeing and livelihoods in both rural and urban and informal settlements, economics, business, trade, international development assistance and human rights. Two of the community workers interviewed had close working relationships with 11 villages in one case, and 18 communities living in informal settlements in the Suva area in the other. Another informant also had extensive experience with informal settlements. A guide to informants as they are referred to within the thesis is provided in Appendix A.

The information provided by interviews has credibility based on the fact that there are in a 'position to know'. However, because of the sensitive nature of the information provided in some cases, both the name of the informant and the name of the organisation were requested to remain confidential. As primary importance must be given to ensuring the safety and security of research participants, the researcher asks the reader to have faith in the process and in the researcher that has conducted it.

\section{Data and document analysis}

Prior to conducting field research, an extensive review of a wide range of literature and documents was carried out in order to inform the researchers understanding of the subject. This process served to identify key contacts and the line of questioning. The review of literature and documents continued throughout the process of research. As current issues, developments in both food security and trade policy were happening concurrently with the research and it was imperative to keep abreast of these.

A key component of the research was the review of trade data between New Zealand and Fiji. The use of quantitative methods allows one to gain an idea of patterns and phenomena (Overton \& Dierman, 2003). Trade between New Zealand and Fiji was analysed to ascertain the components and quantity of trade over time, which provided a platform on which to interpret findings from interviews and document analysis. Statistics were obtained from 
official sources, notably the World Trade Organisation, Statistics New Zealand and the Fiji Islands Bureau of Statistics. These sources all use the Harmonised Commodity Description and Coding System (HS), which is an international classification system. Centralising codes and descriptions of items for trade, this system is employed by countries and trade organisations to support and monitor international trade. This research focused primarily on food trade between New Zealand and Fiji. However, separating 'food' from non-food trade within the categories provided by the harmonised system proved to be more complicated than anticipated. Under this system, some categories combine food items with non-food items. The research has attempted to ascertain trade of 'food' to the best of its ability, combining categories that are for the most part, when not all, comprised of food items. Conversely, the research has omitted some categories, which, while they include some food items, consist primarily of non-food items. Beverages are also included in the analysis as milk has key relevance in the research. Although what results is not a perfect representation of food trade, it nonetheless conveys a defensible picture of the state of trade between New Zealand and Fiji in this realm.

Policy and government documents were analysed in order to provide insight into the New Zealand government's approach to food security and the right to food. These included published policy documents, internal briefs, government ministry websites, and government officials' speeches. The time at which the research was carried out meant that a number of key New Zealand government documents were either being updated or not available for comment. This made interviews with key informants ever more essential to providing informed research outcomes.

\section{Personal observations}

In addition to the interviews, data and document review and analysis, personal observations made through five weeks spent in Fiji also contributed to a greater, deeper understanding of some of the issues involved. Time spent perusing the aisles of local supermarkets, markets, and conversing with locals, gave insights which supported textual and anecdotal accounts and instilled a greater appreciation of the complex and sensitive nature of the topic. 


\subsection{ETHICAL CONSENT}

Ethical consent was applied for and granted by the university's Human Ethics Committee. All participants were explained the purpose and parameters of the research, and given an opportunity to ask questions, and to withdraw prior to publication. All the interviewees gave written consent to be a part of the research. Additionally, to conduct research in Fiji, a research visa was necessary and this was obtained.

The question of ethics goes beyond these formal processes. From the moment one decides to embark on a research project, careful questioning of one's motivations for doing so and the potential impacts of said research, is critical. This aspect was considered in section 2.2 of this chapter. This process ought to continue throughout the research process. Care and sensitivity to the needs of the participants, and those who will be impacted by the research cannot be achieved by a piece of paper. Accepting the fallibility that comes with being a human being, all care has been taken in the undertaking of interviews and the inclusion of comments within research to pay respect to those who have generously agreed to be involved. In some cases, this has meant restricting the expanse of the research. While in Fiji I was fortunate enough to visit two separate villages. Initially it was planned that conversation would take place with the communities about their food consumption and production habits. However, the issue of access to food, and particularly difficulty experienced in accessing food is a sensitive subject and great care is needed in approaching such discussions in a way that is most supportive of the individuals. It became quickly clear that in these instances this was not the case. These times, however, became the most cherished experience of the research as a time of shared interest in one another and I am greatly appreciative for this time and to those that that were a part of it.

\subsection{REFLECTIONS ON THE RESEARCH PROCESS}

As with most if not all research, inevitably, the research encountered some challenges. This section reflects on these in the hopes that future research may benefit from the hindsight of earlier research. One of the greatest challenges in conducting research on the Pacific is the paucity of data available. In international publications the Pacific Islands are frequently subsumed under the title 'Asia and the Pacific'. Even where Oceania is dedicated a category of its own, it frequently features only one or two countries from the region. Further, even where countries are listed data is often missing. In order to address such gaps, there is 
potential for greater work to be carried out in this area, with due consent as to who is best placed to carry out such research.

When conducting interviews, especially in a foreign country, inevitably issues may arise. One such issue is the effect of personal identity of the researcher on the interview (Denscombe, 2007). More than simply a person on the other side of the interview, I was researcher, a critique, a foreigner, a student, and a female, all of which can carry particular perceptions and influence responses for the person on other side of the interview. This was felt most in the context of being a New Zealander in Fiji, asking for comment on New Zealand behaviour, and one cannot discount the fact that in some cases, in some measure, interviewees may have been reluctant to be completely frank. However, other than being aware of this, as Denscombe (2007, p. 116) notes "from the perspective of a small scale researcher, there is a limit to what can be done about this".

A common component of research in Development Studies is the research permit. The process of obtaining this is often arduous and lengthy, but it is a process that ought to be carried out. The advice of this researcher is thus to start the process early. If you have a contact in your field location to help you out with this process, all the better.

Finally, for research carried out in Fiji, a common question is how the current political context of non-democratic, military rule by coup affects such research. The researcher wishes to state at the outset that in the context of this research it has had little bearing on the outcomes. As can be seen in the results in chapter six, trade has in fact increased between to the two countries over the period of political instability. As one informant said, 'trade is trade'. This is not to say that trade is not political; indeed it is as is discussed in chapter eight. However, neither the future direction nor content of trade between the two countries has shifted in a manner that would impact on the conclusions of this research as a result of the current Fijian political climate.

\subsection{CONCLUSION}

Research can be a messy process (Murray \& Overton, 2003), one imbued with inherent assumptions, and challenges. This chapter has attempted to make these explicit, stating clearly the epistemology, methodology and position from which it derives. It identified the research as taking a critical realist perspective, employing a case study and mixed method approach. It 
also identified some of the challenges experienced within this research. It is from this basis the remainder of the thesis proceeds. The subsequent chapter lays the theoretical and conceptual foundation for subject of the research, discussing issues of global food insecurity and the right to food. 


\section{Chapter 3: Food Security \& the Right to Food}

"The gap between the promises in human rights standards and the reality faced by millions is still enormously wide, and the rate at which this gap is reduced is disappointingly slow"

(Eide, 2002, p.29)

\subsection{INTRODUCTION}

Food and water are the essentials for human life. They are also a human right (Ziegler, 2003a). However in 2010 around 925 million people did not have enough food to eat (FAO, 2010). On top of this malnutrition affects more than twice that every year (World Food Programme, 2011). Why some continue to lack access to the basic human right of food necessary for a healthy life, despite global plenty, is an underlying theme of this research. This is not a new or original question. Indeed, it has been much and long discussed. Yet despite this, the condition remains. Alston and Tomaševski (1984, p. 9) emphasize the grand neglect in this area:

"the right to food has been more endorsed more often and with greater unanimity and urgency than most other human rights, while at the same time being violated more comprehensively and systematically than probably any other right".

This chapter discusses the progression of understandings of food security, the failure of past and present approaches to ensure food security for much of the world's population, and the potential of the right to food to make ground where previous approaches have failed. In doing so, this chapter lays the foundation for subsequent chapters, for it is against the obligations set by the right to food which analysis of the trade relationship between New Zealand and Fiji and its impact on food security in Fiji is based.

\subsection{EVOLVING UNDERSTANDINGS OF FOOD SECURITY}

"Food security exists when all people, at all times, have physical, social and economic access to sufficient safe and nutritious food that meets their dietary needs and food preferences for an active and healthy life"

(FAO, 2003, p. 29) 
The definition above is provided by the Food and Agriculture Organization of the United Nations (FAO). There have been in excess of 200 published definitions since the term was first established (FAO, 2003). This in part reflects the evolution of understanding of what it means to be food secure. The above definition represents the most current, arguably the most comprehensive definition of food security, and is the most commonly accepted definition internationally by authorities and experts. It is this definition on which discussion of food security in this thesis is based.

The concept of food security emerged in the mid 1970s (FAO, 2003). However as Fogel (2004) points out, chronic malnutrition has been evident for most of history. Discussions of food access attained global importance in international discussions in the 1970s following cereal shortfalls, rises in oil prices and subsequent famines in East Africa, and again reignited in the mid 80s (Warnock, 1987). However, early discussions, lacking a clear understanding of the problem, failed to respond with successful solutions. The term food security has changed considerably since it was first presented at the 1974 World Food Summit. Since then, a deeper understanding of the issues surrounding access to food, and hunger and malnutrition stemming from this, has evolved.

Initial understandings of food security, reflecting general understanding at the time, were primarily concerned with availability of food. To a lesser degree, affordability through stabilising prices for basic food items was considered. This is illustrated in the initial definition, "availability at all times of adequate world food supplies of basic food-stuffs" (United Nations, 1975, p. 6). Increasingly, however, it came to be understood, that while there could be food available, if one could not access it, for example where proximity or financial barriers existed, then this does not constitute food security. This aspect was later included in the definition in 1983 by introducing the need for having both physical and economic access (FAO, 1983). As understanding of the subject grew, subsequent definitions responded accordingly. Thus, the definition of food security has expanded to acknowledge factors such as natural disasters, economic 'collapse' or conflict, as well as structurally entrenched food insecurity due to poverty (FAO, 2003). In 1996 at the World Food Summit the definition was extended to include the terms 'safe' and 'nutritious', recognising qualitative aspects of food. The definition further recognised 'food preferences' acknowledging social and cultural considerations (FAO, 1996). Finally in 2001, influenced by the work of Amartya Sen, social access, which emphasizes the need for access at an individual and household level, was 
incorporated into the definition (FAO, 2002a). Incorporating access into definitions of food security has been a critical element in conceptualising food security. Drèze and Sen $(1989, \mathrm{p}$. 9) explain, "what we can eat depends on what food we are able to acquire". On economic accessibility, Eide (2002, p. 28) clarifies, this "implies that the costs associated with the acquisition of food should be within the reach of all". Access thus goes beyond food to population ratios, incorporating elements of social and economic access, which the poor often lack. It further highlights the structural aspects of food insecurity, leading to questions of control over resources and issues of governance (Kent, 2005) locating the problem as wider than simply individual inabilities.

Based on these aspects of availability, access - both physical and economic, national and individual, as well as quality and preference, recent definitions have evolved to incorporate all of these ideas, as can be seen the FAO definition adopted in this research.

\section{From hunger to all forms of malnutrition}

Despite increasingly expansive definitions of food security, global efforts to fight food insecurity remain focused primarily on undernourishment, typified by fights against starvation and extreme hunger, particularly in parts of Africa and Asia. However, malnutrition, also a manifestation of food insecurity, represents a significant challenge to global food security, arguably a greater problem than hunger (Shetty, 2011). Malnutrition refers generally to 'a lack of some or all nutritional elements necessary for human health' (World Hunger, 2011). More specifically, micronutrient malnourishment, refers to the lack of adequate vitamins and minerals for a healthy body and has been described as 'hidden hunger' (Shetty, 2011). Importantly, malnutrition can occur despite receiving adequate calories (Ziegler, 2006). Understandings of malnutrition are increasingly coming to recognise the state of 'overnutrition' as a further form of malnutrition (World Hunger, 2011). Over-nutrition refers to situations where calories are in excess, that is, an individual may be overweight or obese. However, the lack of essential nutrients for the body to function properly leads to serious health complications. Critically, over-nutrition is a critical factor in non-communicable diseases (NCDs) which increasingly represent a primary cause of morbidity and mortality globally (Chopra, Galbraith, \& Darnton-Hill, 2002).

Despite increasing awareness of the extent and impact of malnutrition across different regions, there remains a dominant focus on hunger and quantity over quality of foods at the 
global level. However, malnutrition, according to Shetty (2011), presents a much bigger problem globally as worldwide nearly two billion suffer from micronutrient deficiencies (most commonly iron, iodine, zinc and vitamin A), many of whom live in developing countries. Iron deficiency alone is responsible for impairing the development of 40-60 percent of children in developing countries (UNICEF, 2004, p. 2). The impacts of malnutrition are also severe. Inadequate nutrition impairs physical and cognitive development and can lead to increased vulnerability to disease. Malnutrition increases the risk of morbidity and mortality, particularly in mothers and infants during childbirth and for children in the early years of life (Shetty, 2011). Children of mothers who are malnourished during pregnancy may not fully develop. The impacts of these conditions can be long-lasting and thus a child who suffers from malnutrition may never fully recover (UNICEF, et al., 2010). Thus, the effects of malnutrition spread across generations and society. Further, in addition to the loss of rights and opportunities for the individual and family, it also carries with it impacts on society as a whole, through loss of productivity and the cost of health care (Ziegler, 2009). Thus, malnutrition represents an issue of community, national, and global concern.

\section{Food insecurity despite global abundance}

Earlier propositions posited that lack of access to sufficient food by some was a result of a global shortage of food. The most notable advocate of this position was possibly Thomas Malthus, writing more than 200 years ago, who argued that the global population would eventually exceed the world's capacity for food production, causing mass starvation (Malthus, 1992) . However, as was noted by Reutlinger (1987, p. 214)

\section{"The often-predicted Malthusian nightmare of population outstripping food} production has not materialized. Instead the world has been faced with the narrower problem of many people not having enough to eat, despite their being enough food for all"

It is generally accepted that globally there is an abundance of food. This point has been made successively (Reutlinger, 1987; Robinson, 2007; Runge, Senauer, Pardey, \& Rosegrant, 2003). Further, FAO predictions for the next two decades are that global production will continue to exceed projected population numbers (FAO, 2002b). Nonetheless, despite a global abundance of food, alarming numbers of people continue to suffer from a lack of access to adequate food, and this is predicted to continue (FAO, 2002b). 


\title{
Food insecurity and poverty intrinsically linked
}

With a realisation that there is ample food in the world, the issue of access to global supplies has become critical in explaining global food insecurity. In this regard, at their root, importantly, both hunger and malnutrition are inherently linked to chronic poverty. While poverty and hunger have long been associated, other forms of malnutrition, most remarkably over-nutrition, have only recently become so. Based on the work of the Commission on Social Determinants of Health (WHO, 2008), UNICEF (2010, p. 7) concluded "It is also now well established, that it is also the less well-off economically and socially who are the ones increasingly at risk of developing obesity and consequent non-communicable diseases". At the same time as being a cause of food insecurity, poverty is understood also to stem from food insecurity. Simatupang and Flemming (2001, p. 17) elaborate on this point:

\begin{abstract}
"While the root cause of food insecurity is poverty, food insecurity is also an important determinant of poverty. In fact, the main constraints to economic development, poverty, unsustainability and food insecurity are interrelated in a vicious cycle that causes chronic food insecurity"
\end{abstract}

Thus addressing the world's food security problems necessitates looking at issues of poverty and causes of it. In particular, global structures that lead to inequality are becoming increasingly engaged in efforts to explain contemporary food insecurity. Given that global resources are sufficient, then the (inequitable) distribution of resources has become a key sight for discussion over the lack of access for some to adequate food (W. Eide, 2005; Robinson, 2007). Changes in recent decades associated with globalisation are also considered inherently linked to malnutrition and hence food insecurity (Hawkes, 2006). Trade and agricultural policies of recent decades, which have benefited developed and developing countries disproportionately are also being discussed increasingly alongside, and in conjunction with, discussions of food insecurity and the right to food (Murphy \& Paasch, 2009; Robinson, 2007). Underlying the above factors are inherent political and economic ideologies. These will be discussed in more detail in the subsequent chapter. Importantly, the nature of food insecurity is not merely an individual failing, but a global, structural one. As Hughes and Lawrence (2005, p. 301) observe "The direct cause of ill health may be lifestyle behaviours but the underlying origins are socio-cultural and political factors influenced by the 
omnipresent forces of globalisation". This necessitates review of the global order and the relationships and interactions which contribute to malnutrition and food insecurity.

Despite recognition of the global dimensions of food insecurity, the level of commitment by global actors to seriously addressing the fundamental causes of global food insecurity has been questioned. This perception is voiced by Eide $(1984$, p. v) who states, "it is not a food shortage that humanity faces but an absolute shortage of will, and words and of political strategies". Although this statement was made 25 years ago, given that for half the world's population the right to food remains unrealised it seems as true today as it was then. To address the fight against global hunger leading scholars across disciplines of ethics, economics, religion and nutrition have called for a new framework based on ethical and legal principles ${ }^{1}$. Central to this is a human rights approach. The right to adequate food, derived from human rights discourse, has been argued as necessary to achieve global food security (Spitz, 2002). This approach provides the foundational framework for this thesis and is discussed below.

\subsection{THE RIGHT TO FOOD AND ASSOCIATED OBLIGATIONS}

\section{Foundations for the right to food}

The foundation for the right to food derives from the Universal Declaration on Human Rights (UDHR) adopted in 1948, and subsequent covenants, treaties and other documents written in support thereof. The right to food was first formally laid out in article 25 of the UDHR where it states, "everyone has the right to a standard of living adequate for the well-being of himself and his family, including food" (United Nations, 1948). The use of 'adequate' here is significant. To have adequate food according to Alston (1984, p. 167) “implies enough food to facilitate a normal, active existence rather than a minimum calorific package which does no more than prevent death by starvation". Subsequent documents where the right to food is outlined include the International Covenant on Economic Social and Cultural Rights (ICESCR) adopted in 1966 and entering into force in 1976. In Article 11 it declares that state parties to the covenant "recognize the right of everyone to an adequate standard of living, for himself and his family, including adequate food" (United Nations, 1976).

\footnotetext{
${ }^{1}$ See for example (Pinstrup-Andersen \& Sandoe, 2007)
} 
Other international instruments further provide basis and support for the right to food, including the Universal Declaration on the Eradication of Hunger and Malnutrition (1974), the International Covenant on Civil and Political Rights (1976), and the Convention for the Rights of the Child (1990), to name some of the more prominent ones. In 1998, the Commission on Human Rights adopted a further resolution on the right to food reaffirming the position and further concluding that the right to food is 'firmly established in international law' (FAO, 1998). More recently, the Declaration adopted at the Rome World Food Summit in 2002 reaffirmed the right of everyone to have access to 'safe and nutritious food', a statement that was supported by the international community (Robinson, 2007). General Comment 12, an extension of the UDHR and its covenants, represents a significant document in supporting the right to food. Importantly it draws attention to the link between poverty and access to food, highlighting the difference between availability and access (Kent, 2005). Significantly too, this document clearly outlines the obligations of states based on this right, that is, the obligation to respect, protect and fulfil. These will be expanded on below. Importantly, the clear basis for the right to food is evident. As Kent (2005, p. 49) elaborates, "there is no need to propose the human right to adequate food; it is already well established in international law. The task now is to ensure the universal recognition and realization of that right"

In carrying out this task it is necessary to identify obligations of parties and individuals stemming from the right to food. These are outlined below.

\section{State obligations associated with the right to food}

The declarations and subsequent covenants, treaties, and comments related to the right to food engender both rights as well as obligations. A covenant, when ratified by a state, is a legally binding document. Those states that sign up legally commit themselves to acting in line with the terms and statements laid out in the document. In respect of the right to food, these are outlined henceforth.

First and foremost is the obligation to be active in making sure the right to food is achieved. It is accepted that realisation of the right will need to happen overtime. This is acknowledged through the 'progressive' aspect included in treaties. However, this does not mean that states need not do anything until they have sufficient resources. On the contrary, it means that 
"states must lay down a roadmap towards the full realization of the right to food immediately, and demonstrate that they are making every possible effort, using all available resources, to better respect, protect and fulfil the right to food" (United Nations, 2010, p. 19). This means that states have an immediate obligation to act and to continue to act making constant efforts to improve the enjoyment of the right to food. Further, no effort should be spared in acting to realise the right; "steps should be deliberate, concrete and targeted as clearly as possible, using all appropriate means and resources" (United Nations, 2010, p. 21).

Amongst all the treaties, obligations for the right to food are most clearly defined in General Comment 12. They have their roots in the work of Henry Shue (1984) "The Interdependence of Duties" in which he discusses levels of obligation. These have been translated into obligations with respect to the right to food and are detailed below as they appear in General Comment 12 on the Right to Food, paragraph 15:

- Respect - "The obligation to respect existing access to adequate food requires States parties not to take any measures that result in preventing such access"

- Protect - "The obligation to protect requires measures by the State to ensure that enterprises or individuals do not deprive individuals of their access to adequate food"

The obligation to fulfil has two identified elements, that of facilitation, and that of provision.

- Fulfil (facilitate) - "The obligation to fulfil(facilitate) means the State must proactively engage in activities intended to strengthen people's access to and utilization of resources and means to ensure their livelihood, including food security"

- Fulfil (provide) - "[W]henever an individual or group is unable for reasons beyond their control, to enjoy the right to adequate food by the means at their disposal, States have the obligation to fulfil (provide) that right directly. This obligation also applies for persons who are victims of natural or other disasters."

The primary obligation on which this research focuses is that of protection by the state, in particular against third parties. Included in this role is the obligation to ensure that foods on the market are safe and healthy. Regulation of food prices and subsidies can also be considered a means of protection (A. Eide, 2002). Critically, there exists the obligation for 
states to ensure that businesses under their jurisdiction are not acting in a manner that deprives others of the right to food.

\section{Business obligations associated with the right to food}

Obligations in respect of the right to food have also been extended to business. The relationship between business and human rights has received increasing attention in recent years from international human rights bodies and international law is gradually expanding to incorporate direct parameters for regulating companies:

"While international treaties do not refer directly to human rights obligations of the private sector, there is an increasing recognition, including by the Human Rights Council and in regional and international soft-law instruments, that corporations themselves have a responsibility to respect human rights, including the right to food'. (United Nations, 2010, p. 25)

Global transformations over the latter half of the twentieth century (see chapter four) find businesses holding increasing power and working increasingly across boundaries. The UN points out that "[m]ost food is produced, processed, distributed and traded across borders by private entities"(United Nations, 2010, p. 25). They also add that "this means that the private sector has an important role in ensuring and improving food security". However, the absence of mechanisms to govern business conducted across state borders has presented a dilemma for the global community. For businesses working transnationally, there is a lack of enforceable regulatory measures to govern them (Visser, Matten, Pohl, \& Tolhurst, 2007). The 'protect respect and remedy' framework, established in 2008 by John Ruggie, Special Representative to the United Nations on Business and Human Rights, has added to understandings of the obligations of businesses in respect of human rights. The framework made a significant step in setting the levels of action required by business in regard to human rights. The document extended the use of the concept of 'due diligence' to include social and environmental risks, placing onus on businesses to investigate for potential rights violations and act accordingly by mitigating risk (Ruggie, 2008).

Through the above, businesses can be seen to have clear and distinguishable duties in respect of the right to food. However, states have a primary and ultimate duty in regards to human rights. 


\section{Extraterritorial obligations associated with the right to food}

The state presiding over a given territory has primary responsibility to ensure the realisation of the right to food for its citizens. This, however, does not preclude other states from having responsibilities (Ziegler, 2006). There are circumstances in which states may be unable to provide for their citizens, such as where they lack the resources, or in times of conflict or natural disaster. In addition, the increasing interconnection between states has brought with it the increased need for rules at an international level that cut across boundaries. In this situation it can be argued that there is a degree of responsibility for the international community to support the realisation of rights and further to ensure that it does not undermine this right. Such responsibilities have been termed 'extraterritorial' obligations.

This issue of extraterritorial rights is taking increasing prominence in discussions on food security. As a recent UN document states, "in a globalized world, structural causes of food insecurity have international dimensions beyond the control of one State" (United Nations, 2010 , p. 22). International trade in foodstuffs is stated explicitly in this regard. Extraterritorial obligations are also discussed by Ziegler (2009, pp. 17-18) who advances:

"National governments are not always able to protect their citizens from the impacts of decisions taken in other countries. In such a globalized, interconnected world, the actions taken by one Government may have negative impacts on the right to food of individuals living in other countries. All countries should therefore ensure that their policies do not contribute to human rights violations in other countries"

From this statement, an important aspect of the extraterritorial dimension is that states should not act in a manner that undermines the realisation and enjoyment of the right to food. Consequently, in the development of policy, care should be taken to ensure that they in no way are constructed and applied in a manner that impacts negatively on the right to food of people in other countries. This point is made below by Eide (2002, p. 44):

"states should also protect the right to food in other countries. This requires that they should monitor the impact of their external aid and trade, as well as the impact of transnational corporations under their jurisdiction, on the enjoyment of the right to food in other countries and take corrective measures where a negative impact can be shown" 
There are strong foundations for extraterritorial obligations in international treaties. UDHR article 28 states "Everyone is entitled to a social and international order in which the rights and freedoms set forth in this Declaration can be fully realized". Article $11(1 \& 2)$ of the ICESCR further provides for extraterritorial application of the right to food:

"The States Parties to the present Covenant recognize the right of everyone to an adequate standard of living for himself and his family, including adequate food,... States Parties will take appropriate steps to ensure the realization of this right, recognizing to this effect the essential importance of international co-operation"

"The States Parties to the present Covenant, recognizing the fundamental right of everyone to be free from hunger, shall take, individually and through international cooperation, the measures, including specific programmes, which are needed"

However, according to Fons Coomans, at the Centre of Human Rights, Maastricht University, extraterritorial obligations are yet to be fully developed in international law. Reviewing the evidence he concluded that "international obligations to respect are part of existing human rights law (de lege lata), while obligations to protect and to fulfil are still part of the law 'under construction' (de lege ferenda)" (Coomans, 2005, p. 50). However, with the backing of international academics and human rights institutions, and with clear foundations in existing human rights law, it is likely that extraterritorial obligations will only strengthen with time.

\section{Summary}

From the above, clear obligations can be seen to exist for states and businesses. Businesses have been identified by the United Nations and experts on business and human rights as having a role in respecting and ensuring the right to food. This entails investigation and mitigation of potential violation of this right by business through their activities. However, states have the ultimate obligation to protect, respect and fulfil the right to food, ensuring neither they nor parties within their jurisdiction undermine this right. In the case of states, these obligations carry the weight of international treaties and international law. There is thus an imperative for the state to satisfy these obligations. These exist towards all individuals, both within and outside their borders. 


\subsection{REALISING THE RIGHT TO FOOD AND FOOD SECURITY}

Having established the precedent for obligations to respect and protect the right to food, both territorially and extraterritorially, to what extent are these obligations being enacted? Based on the fact that hunger overall is on the rise in developing countries (FAO, 2006), Ziegler (2009, p. 3) concludes "the overall trend is one of regression, rather than the progressive realization of the right to food". Add to this the two billion worldwide that are afflicted by malnutrition and the global failure to realise the right to food for half the world's population is even more glaring.

A number of challenges are argued to exist in effectively operationalising the right to food. While the broad normative content of the right is clear, what this means in practice has been criticised as being too vague (Alston, 1984). Difficulty also arises in clearly determining what constitutes violation in this context. As Eide (1984) explains, some rights, or more specifically, violation of those rights, are more easily recognisable, and where situations are complex, such as in the right to food, identifying causation can be problematic. Attempts have been made to address this. The Voluntary Guidelines to Support the Progressive Realization of the Right to Adequate Food in the Context of National Food Security, also known as the Right to Food Guidelines, is one such measure. Adopted in November 2004, the guidelines represent the first time the international community reached agreement on the content and meaning of the right to adequate food (Rae, Thomas, \& Vidar, 2007). However, it remains that the initiative is somewhat limited as it is not legally binding. Hence a further barrier to realisation of the right to food is the lack of avenue for enforcement. At present, there is little scope for actors to be held accountable in regards to violations of the right to food. Without corresponding obligations and means for enforcement rights may be of little value (Marinoff, 2007).

Perhaps more critically, lack of action on realising the right to food is said to represent the relative low priority of food security (Pinstrup-Andersen \& Sandoe, 2007). Historically, it is argued, greater priority has been placed on civil and political rights over economic social and cultural rights (Breining-Kaufmann \& Foster, 2006). This, it is said, is indicative of a Western bias in the attention to human rights in general. In addition, it has been argued that there has been a tendency to focus on negative rights such as the right to freedom, as opposed to 
positive rights which would require action, and further that this can be regarded as relating such rights to charity rather than a responsibility to act (Balakrishnan \& Narayan, 1996).

Further, it has been suggested that due priority is not being given to human rights in the development of state and international policy. International agreements such as in trade and rights, it is argued, are typically viewed in isolation of each other, which exemplifies the lack of coherence between business and human rights (Ruggie, 2009). Here, "economic or business focused departments and agencies that directly shape business practices - including trade ...conduct work in isolation from and largely uniformed by their governments human rights agencies and obligations" (Ruggie, 2009, p.2).

The primacy of human rights in this case is well established (Paasch, Garbers, \& Hirsch, 2007). This was the conclusion of the UN World Conference on Human Rights in Vienna in 1993: "Human rights and fundamental freedoms are the birthright of all human beings; their protection and promotion is the first responsibility of Governments" (United Nations, 1993, p. 4). Trade liberalisation policies were exemplified in the Concluding Observations of the Committee on Economic Social and Cultural Rights on the report presented by Canada on the implementation of the ICESCR in the 2006 as a case in point, whereby protection of human rights takes precedence over other trade and investment agreements (Paasch, et al., 2007). It is thus clear that the right to food must be taken in to consideration when developing national policy. Where there is conflict between policy or alternative institutional agreements, the precedence of human rights clearly prevails.

In spite of the overall lack of attrition, there are a few states taking on board the obligations associated with the right to food. Twenty-three countries within their constitutions explicitly acknowledge the right to food as an individual human right. Nineteen countries have either already adopted, or are in the process of drafting framework law, that would legislate the right (Knuth \& Vidar, 2011). However, at present, these remain an exception to the rule, and for the most part countries have not adopted explicit legislation or policies recognising these responsibilities. While countries have ratified treaties, and thus agreed at least in principal to up hold it, action on realising the right to food has remained weak (Rae, et al., 2007). 


\subsection{ADOPTION OF THE RIGHT TO FOOD IN THIS RESEARCH}

In light of the challenges presented above why pursue the human rights approach? As Robinson (2007, p. vii) states "by embracing a human-rights perspective, we are able to draw on tools of legal accountability which can help push governments and other actors to take appropriate actions to fight hunger and poverty". Eide, (2002, p. 32) points out that a key function of the right to food is that it "seeks to determine the locus of responsibility in each specific context”. He explains:

"The main function of a rights-based approach to food security is to address the issues of responsibility and accountability. Wherever there are rights there should also be corresponding responsibilities, and institutions should exist to monitor the implementation of responsibility" (A. Eide, 2002, p. 30).

Further, as Robinson (2007, p. ix) states, by framing the discussion in terms of rights "taking action is an obligation, not an act of charity".

Importantly, food security, itself, does not carry with it legal obligations nor entitlements for individuals. Food security has been described as a "precondition for the full enjoyment of the right to food" (United Nations, 2010, p. 4). The right to food has been determined a "crucial strategic element of the food security debate" (Spitz, 2002, 73). Food security would result from the realisation of all individuals' right to food (Eide, 2007, 102). Thus, the right to food can be viewed as a means by which to progress the food security agenda. The right to food and food security can be seen as complimentary and are increasingly being discussed in conjunction (Kent, 2005) and it is in this context that they are used throughout the remainder of the thesis.

\subsection{CONCLUSION}

"The vision of a world where nobody needs to go hungry and where natural resources are managed sustainably can be achieved by 2020. But achieving it will require policy action of a nature and magnitude not currently pursued by most governments. Governments must decide that creating such a world is of paramount importance and give it the highest priority. Decision makers in the public and private sector must join forces with civil society around the common goal of facilitating sustainable food security for all and together take the necessary steps. Agreeing that access to 
sufficient food to live a healthy and productive life is a basic human right for all, rings hollow if those in power do not make every effort to assist individuals and communities in getting access." (Pinstrup-Andersen \& Pandya-Lorch, 2001, p. 270)

The above was written a decade ago, and little progress has been made in realising this vision. It remains however, a vision worth striving for. Eide (2007) has voiced the need for more attention to be given to the responsibility of states to support individuals in fulfilling their right to food. This chapter has laid out the obligations of states to respect and protect the right to food, highlighting that these have an extraterritorial element. However, as Kent (2005) argues, even where clear obligations exist, in order for progress to be made in this regard, actors must be aware of the obligations and further how actors' actions are impacting on the right to food. On this basis, this research seeks to advance greater awareness of the right to food in one area, trade, and in one bilateral relationship, by identifying the ways in which New Zealand trade with Fiji interacts with food security and the right to food in Fiji. As global processes influence national actions, the subsequent chapter provides a context within which to place this relationship by outlining critical global structural changes that have occurred over the last 60 years, and which have had implications for food security and the right to food. 


\title{
Chapter 4: Globalisation and Food Security
}

\author{
"Food and globalisation are inseparable"
}

(Nutzenadel \& Trentmann, 2008, p. 1)

\subsection{INTRODUCTION}

Nutzenadel and Trentmann (2008, p.1) argue "In no other area have the interactions between global exchange and local practices been as discernable as in changing food cultures". This research seeks to explain the relationship between food insecurity in Fiji and New Zealand trade with Fiji. In doing so it is necessary to provide the global context in which the relationship has developed. As Hawkes (2006) highlights, global economic and agricultural policies affect what the world eats. Responding to this, the chapter covers global developments in the economy and agriculture following World War II. During this period the global economy and global agricultural practices have undergone fundamental changes which have significant implications for food security.

Discussion is framed under the title of globalisation. A contested term, the chapter begins by providing the foundations for the use of globalisation in the context of this research.

Following this, it moves on to review changes in the economy and agricultural practices over the post World War phase of globalisation, as well as highlighting implications of these for state sovereignty. As globalisation has not been felt evenly (Castells, 2010), a critical feature of this discussion is how these changes have been experienced across the globe, with a particular focus on developing countries. Review of the underpinning forces driving the most recent phase of globalisation, namely neoliberal ideology, follows. The chapter concludes by reflecting on these discussions and the implications they hold for the remainder of the thesis in analysing the relationship between New Zealand trade and food insecurity in Fiji.

\subsection{GLOBALISATION DEBATES}

Whether or not the world has globalised, is globalising, or is no more 'global' than in the past is a matter of debate (Murray, 2006). The term itself is highly disputed. According to Dicken (2007) 'globalisation' is one of the most 'used', 'misused' and 'confused' words in existence. 
As such, there remains much disagreement about what globalisation is. While acknowledging debates surrounding 'globalisation', this research supports the view that there have been recognisable changes in the depth and breadth of global relationships experienced in the latter half of last century, the likes of which have not been seen before (Castells, 1996; Dicken, 2007; Held, McGrew, Goldblatt, \& Perraton, 1999). During this time it is argued that there has been increased intercommunication and interactions at a global scale (D. Shaw, 2005) and greater and more extensive transference between cultures (Amin \& Thrift, 1994). Tremendous developments in technology resulting in great advances in communications and transport were critical in the evolution of these developments. The post World War period has also been one in which power relations have shifted, from a dynamic between nation-states to one in which transnational corporations and globalised political institutions have come to assert greater control, challenging the role of the state and state sovereignty (Murray, 2006). While many of the developments of this period of globalisation have earlier origins, it is argued that the speed, extent, and impact of change has not been seen before (Dicken, 2007). A definition which encompasses the fundamental ideas commonly associated with arguments for the existence of globalisation is that provided by Held et al. (1999, p. 16) and it is based on this that discussion proceeds.

[Globalisation is] a process (or set of processes) which embodies a transformation in the spatial organisation of social relations and transactions - assessed in terms of their extensity, intensity, velocity and impact - generating transcontinental or interregional flows and networks of activity, interaction and the exercise of power"

Critically, as McGrew and Lewis (1992) point out, the nature of globalisation is that the events, while occurring in different and sometimes distant parts of the globe, have significant consequences for individuals and communities all over the world. Further, the impacts of globalisation are felt unevenly (Held, et al., 1999). Castells (2010, p. xviii) reiterates this point, noting that the global system which emerged in the latter half of last century "included some people and territories while excluding others, so inducing a geography of social, economic, and technological inequality".

Developments that have occurred throughout this period of globalisation, in particular, shifts in global trade and agriculture, have had significant implications for food security, especially 
in developing countries. These are discussed below, along with their relationship to food insecurity in developing countries.

\subsection{GLOBALISATION IN TRADE AND THE ECONOMY}

The post World War global economy has been one of increase and integration, at a level previously not seen. The second half of the twentieth century saw an unprecedented rise in global aggregate economic growth, with world gross domestic product (GDP) increasing sixfold (Maddison, 2001, p. 125). Importantly, this period saw economic activity spread extensively across national boundaries and into a wider range of activities than previously as global economic networks became more diverse and complex (Dicken, 2007). Global trade in goods occurred significantly above global GDP (Maddison, 2001) and of production over the same period (Dicken, 2007). There has also been greater flows of capital between countries through foreign direct investment (FDI) displaying a further level of interconnectedness (Dicken, 2007). Thus, McMichael (1996, p. 27) states, "Global economic integration is an empirical fact". Dicken (2007, p. 36) describes the overall trend for the global economy of the second half of the twentieth century, as clearly one of "more and more production ... being traded across international boundaries". The trend appears to be one which has strengthened over time; the last decade of the twentieth century showing greater levels of global economic integration than the decades leading up to it (Dicken, 2007).

However, while over the last six decades there has been an aggregate increase in wealth globally, the same period has seen a rise in inequality between countries and within countries, as wealth has been concentrated amongst a powerful few. As Dicken (2007) points out, over this period only a few developing countries have seen substantial improvements in economic growth. While developing countries make up around 80 percent of the world's population, they account for less that 20 percent of the global GDP (Soubbotina \& Sheram, 2000) ${ }^{2}$.

\section{Influence of international institutions}

A further feature of the post World War economy is that international trade has come to increasingly be governed overwhelmingly through international institutional frameworks (Dicken, 2007). Most notable are the International Monetary Fund (IMF), the World Bank,

\footnotetext{
${ }^{2}$ It is important to note that the same period has seen a rise in inequality within many developed countries also
} 
and the World Trade Organization (WTO) ${ }^{3}$. These institutions emerged following World War II in an attempt to maintain global peace and security (Jackson, 2006). A key objective in this pursuit was to increase global economic wealth, thus providing a basis for global economic prosperity. Reduction of poverty emerged later as a further goal of the international economic institutions (Jackson, 2006). Contemporarily, these institutions create common goals and laws for the international communities, influencing the design of economic and social policy in the great majority of countries. As evidence of the command of the international trade institutions, at the end of last century approximately 90 percent of all trade was done so under the WTO framework (Connell, 2007).

\section{0s Neoliberal turn}

Increased economic interconnectedness experienced in recent decades has been supported by neoliberal policies, readily adopted by the world's leading economic institutions.

Neoliberalism presently represents the dominant ideology informing economic and political decisions by governments globally (Murray, 2009a). At its core, based on neoclassical theories of economics, neoliberalism promotes market-led, open economies, with a primary role for the private sector, and a limited role for the state (Murray, 2009a). Prior to the neoliberal turn, regulation of the economy by the state was characteristic of government policy (P. McMichael, 1994) as was protection of domestic markets (Glipo, 2006).

Economic deregulation and liberalisation are key policies of neoliberalism. Based on the premise of the 'trickle-down effect', neoliberalism promotes free markets and free trade as the path to greater global wealth and the elimination of poverty (Harvey, 2005). The deregulation of markets and international trade has been suggested as in fact the core objective of globalisation by some (A. McMichael \& Beaglehole, 2000). A key assumption of trade liberalisation is that of comparative advantage developed by David Ricardo in the early 1800s. In short, this concept promotes the idea that all nations will benefit when each nation directs efforts and resources towards producing the goods in which they have a relative advantage, obtaining all other necessities via trade. Since the 1980s trade liberalisation has formed a key component of developing country policy reform (Glipo, 2006).

\footnotetext{
${ }^{3}$ The General Agreement on Trade and Tariffs was the predecessor to the WTO as was the IMBRF to the World Bank
} 
Despite assertions over the benefits of opening up to trade, the result of adopting these policies for many developing countries has been overwhelming detrimental. Many have since experienced stagnating or declining growth rates (Glipo, 2006). Over the same period a number of them have seen a decline in agricultural export shares, as well as growing agricultural imports, revealing a rise in trade deficits, and a decline in income terms of trade (Sarris, 2009). Associated with this, developing countries have become increasingly dependent on imports (Ilbery, 2005) and a number have become net food import dependent (Goodman \& Watts, 1997).

Critics have argued that the present trade system disproportionally affects developing countries (Ziegler, 2009). One reason for this is that trade liberalisation policies fail to take into account the economic and structural realities of poorer countries. On this point Winters (2000, p. 38) states, "The poor cannot always take advantage of the opportunities that liberalization creates because they lack either the skills or capital." At the same time, developing countries, Ziegler (2009) claims, are under greater pressure to liberalise than developed countries. However, in a study of the relationship between trade and development Rodrik (2001) concluded that not only is economic growth not guaranteed by pursuing trade liberalisation, but in fact for many countries that have achieved economic growth, they have done so under protection, liberalising only after they were on the path of growth.

Additionally, many countries that presently advocate liberalisation continue to maintain protections over their own industries. Moreover, A United Nations report found that agricultural products remain most protected of all products by trade agreements adopted by OECD countries, adding "This may have had the advantage of benefiting farmers in the richer countries, but it has harmed those in developing countries" (UNESCAP, 2009, p. 48). The result for many developing countries, it is argued, is that trade liberalization has worsened structural weaknesses of developing country economies and "tied them deeper into unjust trade relations" (Glipo, 2006, p. 44).

\section{Decline of the state - rise of transnational corporations}

While neoliberalism's foundations derive from classical economics, the reach of neoliberalism into all arenas has been extensive, underpinning social, political and economic decisions at national and international levels (Harvey, 2005). As mentioned, one area states have traditionally exerted control is in the regulation of the economy. However, under the 
neoliberal philosophy there has been a push for removal of the state from the economy, which is viewed as leading to inefficiency and market failure. As Harvey $(2005$, p. 66) notes, under neoliberalism, "State sovereignty over commodity and capital movements is willingly surrendered to the global market". Consequently, in recent decades, the market has become established as the arena through which economic activity is 'managed' (Murray, 2006) and transnational corporations (TNCs) the 'primary shapers' of the global economy (Dicken, 2007). In this process, Daniels (2005, p. 298) argues, the "power of individual nations to regulate their own economic development or to exercise a strong influence on the outcome ...has been diluted". With the retraction of the state, businesses increasingly exert greater power and control. The last six decades has seen a dramatic and unparalleled rise in the power of transnational corporations and the economic power held by corporations now equals that of states (Fritsch, 2008). Of the top 150 economies, corporations make up almost two thirds (Visser, et al., 2007). Additionally, corporations now carry out functions once reserved for states. For example, corporations provide more in development finance than official aid programmes. In this way corporations can be seen to be entering in to a role not unlike that of states (Soederberg, 2007).

\subsection{GLOBALISATION IN AGRICULTURE AND FOOD}

Agriculture is critical to food security in developing countries. As the Food and Agriculture Organization of the United Nations (2003, p. xii) notes

\section{"Agriculture is one of the central contributors to food security in most developing} countries, both via its direct contribution to the availability of food, and indirectly as a key engine of economic development and hence improved access to food"

However, developments in agriculture and global trade over the past half century, and in particular the last three decades, have resulted in a subsequent undermining of the base for livelihoods for many in the developing world, thus undermining their food security. The following section briefly examines these shifts, in particular, the industrialisation of agriculture, dietary change, and the role of global supply chains and transnational corporations in food supply. For as Hughes and Lawrence (2005) argue, the process of globalisation has left some communities dispossessed of control over food supply, food culture and governance. 


\section{Industrialisation of agriculture of food}

A fundamental shift occurred in agricultural production post World War II away from subsistence production to productivist, industrialised agriculture (McCullough, Pingali, \& Stamoulis, 2008). This shift saw increasing specialisation, greater dependence on inputs, and greater marketing of outputs on commercialised farms (Pingali, 1997). Further, industrial and biotechnological developments have allowed foods to be kept fresher for longer and, supported by developments in transport, allow products to be exported greater distances (Ilbery, 2005). Processed and high value products now form an increasing value share in agricultural production and trade, accompanied by a decline of bulk commodities (Regmi \& Dyck, 2001). In the shift towards the commercialisation of agriculture, agricultural policies focused on exports have neglected important food staples in many developing countries leading to a decline in production for local consumption (Ilbery, 2005). Industrialisation and intensification of food production has also left a heavy mark on the environment, threatening biodiversity and livelihoods (Murray, 2008).

\section{Dietary shift}

Technological developments in food processing, increases in volume and reach of trade, urbanisation and increases in income levels have seen marked dietary change occur, particularly in developing countries (Hawkes, 2006; McCullough, et al., 2008). As Kennedy et al. $(2004$, p. 1) determine

"globalization is having a major impact on food systems around the world...affect[ing] availability and access to food through changes to food production, procurement and distribution...in turn bringing about a gradual shift in food culture, with consequent changes in dietary consumption patterns and nutritional status that vary with the socio-economic strata"

At a global scale, diets are more diverse, contain higher amounts of fresh produce, animal products and processed foods. Increased consumption of meat and dairy products in developing countries is also a key feature of the last three to four decades (McCullough, et al., 2008). The shift in diet, towards an increase in high in fat and sugary foods, particularly noticeable in the developing world, has been termed the 'nutrition transition' (Hawkes, 2006). Both the restructuring of agri-food systems and trade liberalisation are argued to be critical 
factors in facilitating this transition (Blouin, Chopra, \& Van Der Hoeven, 2009; Hawkes, 2006). Critically, this dietary shift has been found to be a key factor in increased rates of obesity and non-communicable diseases in parts of the developing world (Hawkes, 2006). These conditions are particularly serious amongst the poor (WHO, 2005).

\section{Global supply chains and TNC domination}

Global interconnection in the food industry, termed the 'agro-food complex' (Whatmore, 2002), has been established. This is manifested in global supply chains characterised by producers to processors to traders to distributors. Supported by developments in technology, increasing liberalisation of trade in recent decades has seen a more integrated market in food production and distribution. This network has enabled the development of monopolies both domestically and transnationally to take control over agricultural production and trade (Glipo, 2006). As Ziegler (2003b, p. 12) concludes, "transnational corporations increasingly control our food system". Robinson (2007, p. xii) explains: "every facet and segment of the global food system is increasingly dominated by huge transnational corporations which monopolize the food chain". The result of recent decades of global transformation in trade and agriculture, it is argued, has threatened the livelihoods of small farm producers who struggle to compete with large scale agricultural producers (Murray, 2008). Despite developments in agriculture, small plot production remains characteristic of developing country agriculture and input is typically limited, with modern technology largely restricted to use on big farms (Glipo, 2006). As Glipo (2006, p. 33) states "small scale farmers are clearly not in a position to compete with big players in the international market, particularly highly subsidized big farmers and transnational corporations in the developed countries." This has led, ultimately, to small rural producers increasing exclusion from the market and global food networks.

\subsection{GLOBALISATION AND FOOD SECURITY}

"If the present trend of liberalisation and globalisation continues unabated... [we] may see an increase in food insecurity".

(Spitz, 2002, p. 74)

As lower income nations have become more integrated into the global food and trade system many countries, particularly developing countries, are experiencing greater vulnerability. The 
following section highlights three areas, food dependency, trade liberalisation and a market driven economic system, which have particular implications for food security.

\section{Food dependency and loss of control over food supply}

As early as the 1950s food dependency was recognised in the Pacific by McKee (1957). Food dependency refers to the situation whereby countries are not in full control of their food supplies in turn placing their food security under the control of foreign interests. In the 1970s McGee coined this situation 'dietary colonialism' (McGee, 1975). McGee attributed food dependence in the Pacific to "the manner in which Western contact and control has integrated these Pacific Island economies into the international economy” (McGee, 1975, p. 2). McGee further identified a number of risks associated with food dependence including negative trade balances, limitations on growth of indigenous food production for sale, and a relationship through importation in which the suppliers will always be better off. Links can be drawn between McKee's work and dependency theory, which took form in Latin America in the 1970s, driven by the works of authors such as Andre Gunder Frank ${ }^{4}$ and Theotonio Dos Santos ${ }^{5}$. However, food dependency has been deemed by to be a particularly serious kind of dependency. First, because it makes a country vulnerable to both a reduction in food supplies as well as their purchasing power (Thaman, 1990). Further, and perhaps most critically, as a group of experts at a seminar of food distribution systems in the late 70s stated, "food supports life; it is the raw material of existence" (Bellam, 1980, p. 24).

The risks of being food dependent were in some manners realised in the most recent food crisis, which highlighted the vulnerability of lower income nations highly engaged in international trade on food. For many the reliance on imported foods meant a sharp increase in the costs of foods and hardship for many families in developing food importing countries (FSP Working Group, 2009). Although food prices have fallen since their peak in 2008, a report by the World Food Programme and FAO found that the cost of food remains high (Lancet, 2009). UNICEF (2010) add that it is the poor of food importing countries who suffer the most in these conditions.

\footnotetext{
${ }^{4}$ For example see Frank (1967) Capitalism and Underdevelopment in Latin America

${ }^{5}$ For example see Dos Santos (1970) The Structure of Dependence
} 
Critically, too, in the Pacific links have been drawn between consumption of imported food and poor health. A study in Micronesia found that in areas dependent on imported foods, four times as many people were malnourished, as compared with areas where traditional food was the main diet (Rody, 1978). In addition research from Vanuatu found people more than twice as likely to be obese and almost two and a half times more likely to be diabetic when consuming fat from imported foods as opposed to fat from traditional sources (Hughes, 2003).

\section{Trade liberalisation - undermining local production and state autonomy}

Based on the fact that a large percentage of low income countries are net food importing countries Panagariya (2002, p. 3) calls for a "realistic analysis of liberalization" which would "address the question how food importing countries and the poor living there will be impacted by agricultural liberalization". As Sarris (2009) has noted, discussions of agricultural trade often neglect food security. Increasing policies of trade liberalisation have in many cases undermined local production in developing countries. FAO $(2003$, p. 38) in a report on trade reforms and food security stated "the claim that [removal of agricultural protection and export subsidies] will bring net gains to the least developed countries as a whole is at best questionable and at worst outright wrong". The report further concluded:

"the potential gains from trade liberalization are not guaranteed and will not necessarily be reflected in improved food security status of all groups within society. In particular, there are likely to be significant differences between the impacts on small scale and commercial farmers, rural non-farm producers and urban consumers both within and across countries" (FAO, 2003, pp. 16-17)

Developing states autonomy to assert themselves has become increasingly diminished in recent decades. Liberalisation, Glipo (2006, p. 5) argues, has undermined developing countries capacity to pursue their food and agriculture policies in line with their own development needs and objectives. Proposed solutions, such as bans of unhealthy food and subsidies for healthy locally produced food 'run afoul' of GATT and WTO regulations, thus making solutions problematic (Evans, Sinclair, Fusimalohi, \& Liava'a, 2001). As Chopra et al. (2002, p. 953) point out "the ability of countries to formulate comprehensive interventions of this kind is increasingly limited by the norms and trade laws associated with globalization". 
Critics argue that this loss of policy space will only worsen with increased adoption of free trade policies and agreements (PANG, 2009a).

\section{Market driven economic system - failing to account adequately for social goods}

There is considerable debate as to whether an economic system driven by the market, lacking in regulation and a concern for social goods, can cater for the needs of the majority of the populous. The present method of distribution based on the market has come under criticism as being a key factor contributing to food insecurity. Mary Robinson, Executive Director of the Ethical Globalization Initiative in 2007, elaborates on this:

"Where they [food supplies] are distributed through market mechanisms that are not accessible to those without resources, questions should be asked about agricultural development policies which invest so little in small farmers and local food systems, and which would be more likely to actually feed people who cannot access food through normal market systems" (Robinson, 2007, p. ix)

There are arguably some areas in which the market cannot, and should not, be left to govern. The Commission on Social Determinants of Health, for example, determine that there are some goods and services such as access to clean water, and healthcare, which are basic human and societal needs and that such services should not be determined by market access, but be universally accessible by all (WHO, 2008). It further highlights that the arena in which to do so is the public sector, not the market. In its failure to acknowledge these realities, neoliberal protagonists prioritise certain values and certain interests and needs, over others. On this point, Dierckxsens (2000, p. 16) determines that "directing the economy in the function of the Common Good necessarily entails economic regulation where private interests are mediated by the interests of all citizens, but in the case of contradiction are subordinate to them."

\subsection{CONCLUSION}

In our collective enthusiasm for creating a new world trading system, we run the risk of forgetting one vital factor. Trade development is all about people.

The Honourable Mr. Isimeli Bose (1996)

Nutzenadel and Trentmann $(2008$, p. 3) refer to globalisation as a "complex process of inclusion and exclusion" as while globalisation has yielded benefits for some, others have 
become increasingly disadvantaged as a result. Former United Nations Secretary General Kofi Annan in his Nobel Laureate acceptance speech in 2001 stated "Today's real borders are not between nations, but between the powerful and the powerless, the free and the fettered, the privileged and the humiliated" (Annan, 2001). However, globalisation is neither a 'natural' nor a 'self-sustained' process (Nutzenadel \& Trentmann, 2008). Rather it is the "result of collective human actions, agendas, desires and perceptions” (Murray, 2006, p. 89).

Neoliberal policies of the past twenty to thirty years in particular have been implicated in the divisions that have been created within and between societies, and those with and without. Harvey (2005) points out that after more than two decades of neoliberal policies bringing lower barriers to trade and a high degree of market determination, poverty remains in large numbers. What neoliberalism has achieved, he argues, is to increase the wealth of some at the expense of the many, through redistribution of wealth and income (Harvey, 2005, 159).

Amin (2004) argues that the inequalities that have been seen thus far in neoliberal globalisation are not inevitable. While globalisation has been occurring for some time, according to some as long ago as $1500 \mathrm{AD}$, the neoliberal influence has only been evident over the last 30 years (Murray, 2006). Further, neoliberalism is simply an ideology, fuelled by particular economic and political interests and based upon particular ethical assumptions (Sandoe, Jensen, \& Pinstrup-Andersen, 2007). Firth (2000, p. 112) states explicitly "We should remember that economics, while it claims authority on the basis of technical expertise, is in fact a branch of political philosophy favoring one political outcome over another". Thus, it is possible to envisage globalisation that is not inherently tied to neoliberalism (Dierckxsens, 2000).

This chapter has described economic and agricultural change as it has occurred in the post World War period. This period saw unprecedented changes in levels of global wealth, and intensity and extensity of global trade. Further, the chapter described a fundamental shift, as control over economic affairs came to be increasingly commanded by business entities and international institutions, with states taking a subordinate role. Importantly, neoliberal ideas of market determinism and openness in trade have formed the premise for the most recent developments of increasingly liberal trade and the deregulation of economic activities, as well as limited state involvement. In the process of these changes, many developing countries have found themselves more marginalised in the global agricultural and economic arena. As 
was stated in a 2004 report by Ziegler on the right to food (p. 2), "international trade in food and agriculture is not necessarily benefiting the vast majority of the poor and marginalized people, but rather creating even greater marginalization and inequality". As a result, access to nutritional food is increasingly out of reach for a great many.

It is generally accepted that some degree of international trade is unavoidable (UNDP, 2006) and is indeed in many ways desirable in the pursuit of food security. However, "neither trade nor growth can ever be ends in themselves; instead they are simply means towards the larger goals of expanded human development and combating poverty and deprivation" (UNDP, 2006, p.2). Critically, how trade is carried out and how it is governed is crucial in determining whether it will prove to be largely beneficial for a country or largely detrimental. It must therefore be evaluated as to whether the manner of trade is achieving those aims, or further entrenching them. The present path of global interactions in trade, framed by neoliberal ideology, must not be taken as a given but be evaluated as to its relevance, inclusiveness and success. This is a central aim of this research.

The subsequent chapter moves from a global focus, to look closer at food security in one developing country, Fiji. A particular focus of the research is the extent to which increased global integration through trade with New Zealand in food has played a role in this. The discussion from this chapter prefaces and informs the subsequent discussion. 


\title{
Chapter 5: Food Insecurity in Fiji
}

\author{
"Intrusion from outsiders has resulted in disease and death and the beginning of an \\ epidemiological transition"
}

(Hughes, 2003, p. 43)

\subsection{INTRODUCTION}

This chapter responds to the first aim of the research by establishing the context for contemporary food insecurity in Fiji. As food insecurity plays out differently in different settings, to understand the relationship between Fijian food insecurity and New Zealand trade it is first necessary to have a clear understanding of the former. In doing so it provides the foundation for subsequent aims. The Pacific has been, for the most part, neglected in international discussions on food security, yet they are highly vulnerable. The chapter begins by providing background information on Fiji, locating it geographically, economically and politically. The chapter then proceeds to provide a picture of food insecurity in Fiji. The islands existed in a state of good health and nutrition, supported by subsistence affluence for thousands of years until the time of western contact (Hughes, 2003). The result of more than a century of outside influence has seen a massive shift in food production and consumption amongst Pacific Island countries, including Fiji. The chapter explores this shift from a wellnourished to malnourished people, identifying factors that have both led to and maintain the current position of food insecurity. The chapter draws on information from literature and databases, as well as interviews carried out in the research process, to provide a comprehensive understanding of food insecurity within the country and factors in this. This chapter finds that the Fijian situation provides some key insights into issues associated with access to nutritional food, highlighting qualitative aspects of food, and economic access to foods that support healthy living. It further finds trade to be a key factor in food insecurity in Fiji, both historically and contemporarily.

\subsection{THE FIJIAN CONTEXT}

The 332 islands of Fiji, totalling 18,274 kilometres of land (CIA, 2011) belong to a sub regional category of islands known as Melanesia located in the South Pacific. The islands are primarily of volcanic origins and are rich in natural resources, with fertile land for growth. 
Around one third of the islands that make up Fiji are thought to be occupied, with the majority located on the three main islands, Viti Levu, Vanua Levu and Taveuni. At the last census in 2007 the population was 837,000; 465,739 of which were indigenous Fijian, 313,000 were of Indo-Fijian ethnicity, and 47,724 were of other decent (Fiji Islands Bureau of Statistics, 2010, p. xi). Whilst traditionally rural dwellers, now just over half live in urban areas (Fiji Islands Bureau of Statistics, 2010). Rapid urbanisation has led to establishment of growing numbers of informal settlements on the outskirts of main centres in Fiji.

Fiji has a dual economy in which market and subsistence both play important roles, combining a commercialised agricultural system with a subsistence sector. While a few areas remain largely self-sufficient, most if not all are integrated into the cash economy. Agriculture plays a critical role in Fiji, providing close to 50 percent of total employment, almost one fifth of Gross Domestic Product (GDP) and approximately 43 percent of foreign exchange, and as such represents the foundation of the country's economy (Watters, 2008). Tourism also represents a significant and increasing contributor to the economy.

Over the last two decades Fiji has experienced both economic and political struggle. With negative growth for the past decade, the Fijian economy has been described as 'weak', and 'volatile' (Ministry of National Planning Fiji, 2010). Contributing to this, Fiji's leading industries, sugar and garment-making have both experienced declines in recent years with changes in trade policy (Morgan, 2010). The last quarter century has been turbulent politically, with four coups occurring since 1987. The absence of democratic rule has been responded to with sanctions from neighbouring countries, New Zealand and Australia. Based on trade figures ${ }^{6}$ trade appears largely unaffected by these.

\subsection{EVIDENCE OF FOOD INSECURITY}

"Communities in the Pacific used to have a church and a school, now they have a church and a school and a renal dialysis unit, and that's happened quite suddenly” KI(Matheson)

Research into traditional lifestyles in the Pacific Islands present common findings in regards to nutrition. They find that across the islands, communities had an abundance of food and were well nourished (Fisk, 1972; Parkinson, 1973; Thaman, 1984) and were described as living in 'subsistence affluence' (Fisk, 1972). Descriptions of the people of the Pacific pre-

\footnotetext{
${ }^{6}$ See chapter six
} 
colonial contact converge on a picture of 'tall, muscular and well-proportioned people' (Houghton, 1996, p. 31). Such was the strength of the traditional diet that malnutrition was virtually unknown (Thaman, 1982). In 2010, however, UNICEF (2010, p. 5) reported:

“All aspects of malnutrition - undernutrition, overnutrition and/or inappropriate diets - are increasingly occurring together in the same communities, and are present in all the Pacific Island Nations and Territories to a greater or lesser extent"

This section provides a picture of food insecurity in Fiji. Present international measures of food security tend to focus on undernourishment, which measures only total calorie intake ${ }^{7}$. However, food security means that food is available, that individuals are able to access it, physically, economically and socially, and that it is adequate for a healthy lifestyle, as per the FAO (2003) definition. Based on this definition, in which access to nutritional food is a clear requirement for food security, this section attempts to provide a more complete picture by taking into account malnutrition, and over-nutrition, which are also manifestations of food insecurity. The measurements utilised primarily give national level data. However national measures do not show variation or distribution and individual and household food security does not necessarily follow from national food security (Sharma, 2007). Thus, interviews are employed to provide a more complete picture.

Food insecurity is primarily represented in Fiji and the Pacific by the high incidence of obesity and non-communicable diseases (NCDs). NCDs can be directly related to food insecurity as an unhealthy diet has been identified as one of the main risk factors for NCDs (Snowden \& Swinburn, 2008). Equally, a clear relationship has been established between social and economic poverty and presentation of NCDs (WHO, 2008). It is estimated by WHO that 75 percent of Pacific Islanders dyeing prematurely do so due to NCDs (SPC, 2009b), making NCDs the primary cause of premature death for people in the Pacific Islands (Snowden \& Swinburn, 2008). Health statistics from 2007 revealed that in Fiji NCDs such as diabetes, heart disease, high blood pressure and respiratory diseases were the principle cause of death (Tuiketei, et al., 2010). A 2002 study carried out by the Fiji Ministry of Health found while indigenous Fijians are overrepresented in obesity and hypertension statistics, with obesity almost double the rate of Indo-Fijians, Indo-Fijians are overrepresented in rates of

\footnotetext{
${ }^{7}$ see chapter three for discussion on this point
} 
diabetes (MOH, 2002). Thus, while it manifests differently, both ethnic groups display characteristics associated with lack of access to nutritional food.

Obesity is considered one of the greatest risk factors in non-communicable diseases such as diabetes, hypertension, and cardiovascular disease (Coyne, 2000). Displaying the highest prevalence of obesity and type two diabetes in the world, the region is facing a problem which has been described as being of epidemic proportions (Hughes, 2003). The Fiji 2004 National Nutrition Survey estimated just over 32 percent of Fijians were overweight, and almost 24 percent were obese. While this is less than the Pacific average, the rate of increase is of major concern. In the ten years since the previous report obesity increased by 23 percent (National Food and Nutrition Centre, 2007). Further, recent estimates from the Fiji Ministry of Health reflect the trend, and estimate that over 60 percent of Fijians are overweight or obese (Niumataiwalu, 2009).

Food insecurity is also represented in the prevalence of micronutrient deficiencies. Vitamin and mineral deficiencies stem in part both from heavy consumption of poor quality food as well as low consumption of the nutrient rich foods (FSP Working Group, 2010) both of which access to has a socio-economic element. There is still limited data available in this area but from what is available, indications are that they present cause for concern. Anaemia is prevalent in more than one fifth of women and children in the majority of Pacific Island countries. In Fiji, anaemia has been described as endemic, although efforts have been made to address this via adding iodine to salt (Parry, 2010). Other vitamins such as folate, zinc, thiamine and some B vitamins, are also believed to be insufficient in some areas of the Pacific, and the full of extent of the problem yet to be seen (UNICEF, 2010).

Other measures which can be used in creating a picture of food security are weight at birth and healthy life expectancy. Low birth weight can be an indicator of poor health and nutrition of the mother during pregnancy (UNICEF, 2010). Under-nutrition in infants can cause irreversible damage, impairing cognitive development. Data for the period 2000-2008 shows low birth weight in 10 percent of newborns in Fiji (UNICEF, 2010). Additionally, life expectancy gives some indication of the general standard of health of a given population, of which good nutrition can be said to be a factor. The (WHO) indicator of healthy life expectancy at birth (HALE) for Fiji is 63 years (WHO, 2010, p. 50). Additionally, just 16 
percent of the population is over 55 and this is attributed to premature death of which noncommunicable diseases is the primary cause (Parry, 2010).

Finally, although not typically associated with the Pacific, there is evidence that hunger exists in Fiji. While it is increasingly being recognised by specialists that hunger exists in the Pacific $^{8}$, by most it is generally thought not to be a problem due in part to a (misheld) belief that everyone has access to land or water to grow or catch food. The Fiji National Nutrition Survey 2004 remarked "No one conceded that they could not feed their families. A small number of households reported having insufficient food on occasions" (National Food and Nutrition Centre, 2007, p. 154). The reality is that the topic of hunger is a sensitive one, and may be underreported. One participant recounted her experience upon finding families going without food in the villages she worked with, stating "they were embarrassed, shocked themselves, I think it was there but nobody talked about it openly...in many ways they were relieved the issue came up" $\mathrm{KI}($ Roberts). Thus, it is likely that in many measures of hunger, there may be a level of underreporting. However, through discussion with participants who work with both rural and urban communities, it is clear that hunger is an issue for people in Fiji, and that it may be more prevalent than is often recognised. One participant who worked with people living in informal settlements commented "I can clearly say that for the families that don't have an income they are barely surviving on a daily basis and their nutritional needs are not being met" KI(Koto). From another participant working with people in informal settlements her experience is that people are skipping meals or consuming minimal meals because they cannot afford otherwise, as is evident in these quotes: "often there will be a missing of a meal if they can't afford it... if people don't have anything they'll just have cassava and tea" $\mathrm{KI}($ Moore). The indication from interviews is that the situation exists for more than a small number of households and that rather than being occasional, it is for some a regular condition.

This section has described extreme levels of obesity and disease related to poor nutrition as well as evidence of hunger for some as a regular condition, thus illustrating food insecurity in Fiji. This comes in such stark contrast to the past; even in times of natural disaster, Fiji, like other islands in the Pacific, was able to provide nutritionally for its population. How has this situation thus evolved? The following section looks at the evolution of malnutrition in Fiji.

\footnotetext{
${ }^{8}$ For example see Abbott and Pollard 2004, UNICEF 2010
} 


\subsection{EVOLUTION OF FOOD INSECURITY}

Subsequent sections describe key changes that have been instrumental in the shift from a well nourished population to one displaying extreme levels of malnourishment. Changes are separated into historical factors, and contemporary social and individual factors. The reality is, however, that the delineation of factors is not straightforward and these often overlap. Nor is the list exhaustive as factors in food security are multiple and complex. It does, however, provide key factors as they pertain to the research. It finds that there is a clear lack of access to nutritional food for a significant portion of the population, and that trade has played both a role in the origins and maintenance of this. Before going on, however, it is helpful to describe Fiji in times of food security and abundance and what contributed to this.

\section{Factors in earlier food security}

The good health and nutrition of Pacific populations is largely attributed to the content of the diet and its effective distribution, and this is true of Fiji also. The traditional diet in Fiji was highly diversified, based largely on root crops and wild plants, and in lesser amounts, marine life. Bananas, coconut, plaintain, breadfruit, yams and dalo (taro) were common staples. Importantly the traditional diet was highly nutritious, providing the necessary vitamins, minerals and nutrients for a healthy diet, and low in salt, sugar and saturated fats (Thaman, 1990, 2005). Preparation and cooking methods also contributed to positive nutrition. Foods were smoked, cooked in umu (underground) and often eaten raw. As Thaman (1990) notes, while there was diversity among the Pacific Islands in the food grown and consumed, due to diverse ecological systems, the ability to feed the population was consistent across the region. Traditional knowledge and networks were key to the positive nutrition and wellbeing of the Pacific population. Pacific Island societies were based on subsistence living, growing for the needs of local consumption (Thaman, 1984). Strong kinship and community networks existed through which food could be distributed. As Schultz (2004, p. 203), states "The communal and mutual care philosophy of Fijian society meant that no one went hungry". Systems were also in place to provide for the population in unexpected times of need, such as drought and other natural disasters (Thaman, 1984). Knowledge of what to eat, and how it could be accessed, processed, prepared and stored for use in hard times, was widely known. Food production worked in harmony with the environment (Thaman, 1984); come the $21^{\text {st }}$ century the situation is vastly different. 


\section{Dietary change influencing food insecurity}

\section{Decline in consumption of traditional foods, rise in fat and energy consumption}

The most obvious factor in recent increases in malnutrition and related disease is changes in dietary composition. The nutrition transition, referring to a shift to consumption of foods high in fat and sugar, away from traditional more nutritious sources, has been experienced in Fiji as it has elsewhere in the Pacific (Schultz 2004). Various food-consumption and dietary surveys taken in Fiji since 1950 collectively document a dramatic change in food consumption and nutrient intake. Overall energy intake has increased significantly - 1952 to 1982 alone saw a rise of 50 percent (Hughes, 2003). Over time there has also been a change in the make-up of energy contributions to the diet. Cereals ${ }^{9}$ have increasingly come to replace common staples such as root vegetables, and are considered to be typically of less nutrient value than traditional staples. Additionally, fats, in particular fat from meat and offal, forms an increasing part of the diet. At the same time, calories from traditional sources such as coconuts and root crops have declined (Hughes, 2003, p. 14, 35). Recent surveys show a continuing trend. The 2004 Fiji National Nutrition Survey ${ }^{10}$, comparing data from ten years earlier, found an increase in consumption of animal fat, sugar and cereals, and at the same time a general decrease in consumption of fruits, vegetables, and traditional starchy vegetables. It further found fat derived from sheep meat alone contributed 39 percent of fat to the total fat intake for meat per capita per day in 2007 (National Food and Nutrition Centre, 2007, p. 3). In addition, a 2002 report by the Ministry of Health Fiji looking at noncommunicable diseases, found 66 percent of participants in a survey conducted reported eating less than one serving of fruit per day and 26 percent ate less than one serving of vegetables per day (MOH, 2002).

\section{Food purchased rather than communally grown, high consumption of imported food}

While both local and imported products contribute to Fiji's food supply, food is increasingly sourced from vendors rather than from local community production and networks (Baxter 1980) and more and more of what people are eating is highly processed, packaged and imported (Schultz, 2004). Consumer Council representatives made the point in interviews that more of what people eat is being sourced from supermarkets. While some products sold at

\footnotetext{
${ }^{9}$ For example wheat, flour and rice

${ }^{10}$ This was the most recent available at the time of writing
} 
supermarkets are produced domestically, a large proportion is imported. There is also increasing sale of products processed in Fiji from imported raw ingredients (Schultz, 2004). A clear trend has been established of increasing reliance on imported food (Vatucawaqa, 2009). In 1961 energy from imports was estimated at 37 percent. In 2007 that figure had risen to approximately 60 percent (Coyne, 2000, 23, 7). KI(Larkan) stated simply:

"if you go to our shops just at a glance you will know what we are eating, the more shelf space provided to something is something that we are consuming more...you see a lot of canned food you see canned fish, canned mutton, canned beef, that's what we are eating" (see Plate 1)

\section{Plate 1: A typical supermarket aisle in Suva, Fiji}

Photograph taken by Laura Barrett

Reliance on purchased, processed and imported is particularly evident for urban populations. While some may continue to receive food through family networks, a large proportion, if not all, must be purchased. Rural Fijians are believed to have retained more of the traditional diet than urban Fijians (Coyne, 2000). Interviews, however, indicate that processed and imported foods are increasingly making up a large proportion of the rural diet also. KI(Yabaki) states: 
"a lot of processed items, they are in the villages, they are part of our daily items". Further interviews illustrated how traditionally sourced foods are becoming occasional meals.

$\mathrm{KI}($ Yabaki) stated:

"fish for the village that I have been to, it is tinned fish, for us the main meal is on Sundays, you have time to prepare and go out and get fish, that is the best meal of the week, otherwise the rest of the week is a lot of processed food".

Talking about her childhood, growing up rurally and relating it to the area now, KI(Roberts) states:

"when I was growing up we had alternatives but we still had a lot of root crops. We find now there is none, they eat the rice, they eat the flour, produce pancakes, the roti, they eat it because there is nothing else, so it becomes a staple diet".

Interviews suggest that even in areas where food continues to be produced, this is often sold and what is consumed is primarily products from the supermarket. As KI stated

"most of the women who come from the village or who come from the rural area come and sell at the market what they normally do after...they'll go to the supermarket where they get foodstuff that is already there to take back to the village"

Interviews suggest that in some areas, the proportion imported foodstuffs make up of local diets is likely higher than standard estimates. Estimates for the proportion of processed or imported food by two participants for the rural communities they work with were consistent, at around 70 percent.

\subsection{HISTORICAL CAUSAL FACTORS IN FOOD INSECURITY}

While the effects of dietary and nutritional change have been witnessed primarily within the last fifty years, the roots of change undoubtedly lie earlier in history, namely colonial contact and changes stemming from this. These are described below.

\section{Colonisation - the genesis of food insecurity}

As established above, prior to colonisation, there was plentiful supply of foods and exceptional nutrition. Within the region there was a limited degree of exchange, however there was little interaction with those beyond this realm (Thow \& Snowden, 2010). In the 
1850s the Pacific Islands began integrating into the global economy as "the buccaneers of global capitalism arrived on their shores" (Firth, 2000, p. 181). Industrialisation abroad drew the need for suppliers of raw materials and in the 1900s the Pacific Islands were drawn into the global economy as primary export colonies (Denoon, 1997). Colonial settlement brought with it key changes to the foundation of society. These can be linked to changes in habits and subsequent nutritional decline, as is discussed below.

\section{Commercial production and export promotion - changing the foundations of Fijian society}

A critical change occurring with colonial settlement was the introduction of commercial production (cash crops). Cash crops are attributed with decreasing the availability of traditional foods crops and hence an increased need for imported foods (Coyne, 2000). These took prime agricultural land, reducing space for subsistence growing which were relegated to less fertile land (Thaman, 1990). They also took bodies away from subsistence production (McGee, 1975). Commercially focused production further led to a decrease in biodiversity which is critical to food security in the Pacific (Thaman, 2005). Additionally, the introduction of commercial production led to fundamental changes in the economic foundations of society and traditional concepts around food (Pollock, 1992). The new mode of production brought with it the concept of monetisation, whereby land, labour and produce acquire market values (Watters, 2008) and through which "products became the foundation of island monetary economies" (Baxter, 1980, p. 1). Cash cropping, commercialisation, and monetisation, Thaman (1988b) argues, have contributed to making imported food accessible and at the same time contributed to deterioration of traditional food systems.

Comments from interviews illustrate the impact of this change: In contrast to the past, food produced in communities is often sold. $\mathrm{KI}($ Yabaki) elucidates on this point:

"most of the rural community plant food to sell at the market and whatever is left over is for them to consume, but in fact in theory the situation should be the other way round, you feed yourself and whatever is left, is excess, goes for selling”

This has also resulted in a shift in production to the kinds of products being grown to those that are the most marketable, rather than those that would support the family diet. KI(Roberts) statement illustrates how time and economic pressures influence food production: "women have no time to do all the little things...everyone is so busy trying to make money that the 
garden has been forgotten...everything is geared towards economic gain". This process has ultimately led to declines in health.

\section{Rural to urban migration - a barrier to sourcing traditional food}

Urbanisation is a product of colonial settlement; prior to this, populations in the Pacific lived in villages and scattered hamlets with small-scale populations. With colonial settlement urban centres developed as places to support colonial administration and trade (Connell \& Lea, 2002). With trade came logistical areas established to administer trade, drawing bodies away from villages to work on plantations and in areas to support the import/export process (McGee, 1975). These developments created a market for imported foods. Along with ease of preparation of many imported items, according to Parkinson (1973) traditional foods cost up to 10 times more in urban centres than rural areas. With more living in urban areas and more consuming imported foods traditional foods saw a decline in consumption and production.

\section{Introduction of imported food}

Consumption of imported food is intrinsically linked to declines in health in Fiji. As

$\mathrm{KI}($ Halavatau) stated "we rely on imported food and because of that we are eating low quality food and the impact of that is poor health". Prior to colonisation food imports were negligible (Thow and snowden, 2010). Imported foods came with early settlers who displayed a clear preference for foods from home. For a long time such foods were limited to settlers and a small few Fijians (Baxter, 1980). Over time imports have become increasingly available with more than half of available energy supply now derived from imports (Schultz, 2004).

Multiple factors have contributed to changes in food consumption described above, influencing both the need to purchase and purchasing habits. The following sections describe contemporary factors, both at an individual and societal level, which have lead to the changes described above, namely decline in consumption of traditional food, increase in purchasing food and increase in consumption of imported foods

\subsection{CONTEMPORARY CAUSAL FACTORS IN FOOD INSECURITY - SOCIAL}

\section{Poverty exists and is increasing}

Poverty is a critical factor in access to food and malnutrition (Simatupang \& Flemming, 2001) and thus the prevalence of poverty and hardship in Fiji has strong implications for food 
security. In the Pacific, 'poverty' can prove difficult to assess due to high levels of subsistence living. Estimates of poverty over the last decade in Fiji reflect this and vary considerably; Barr and Naidu (2002) estimated that 50 percent of the population struggles with degrees of poverty. Narsey (2006) based on the Household Income and Expenditure Survey 2002/2003 estimated that 34 percent were living below the national poverty line. Asian Development Bank reports for the same period were between 33 percent and 50 percent (ADB, 2006). More recently, Narayan (2009) put poverty levels somewhere in the middle at 40 percent.

Translating these figures into real terms, 12.5 percent of the population live in squatter settlements (Ministry of National Planning Fiji, 2010). Participatory assessments of hardship (PAH) carried out found that one out of five households in Fiji is "unable to meet the costs of food and other basic needs and services that are essential for a minimum standard of living" (Abbott \& Pollard, 2004, p. 1). In 2007, from a population of 594,150 over 15, approximately half were economically active. Even for those who have an income, wage rates are low. In 2004, the mean hourly wage was F\$2.71 an hour (Fiji Islands Bureau of Statistics, 2010, pp. $14,92)$. Thus, even in households with a wage, it is often not sufficient leaving households to making choices between food or community obligations, house bills or school fees (Abbott \& Pollard, 2004). The link between poverty and food security is evident in these last two statements.

Indications are thus that hardship in exists for a significant number of people in Fiji and further, as Abbot and Pollard (2004) suggest, that it is more widespread than has been attributed to it in the past. Concerningly, the trend appears to be one of increasing poverty in Fiji. Estimates of those living below the poverty line in 1990 were 19.5 percent (Ministry of National Planning Fiji, 2010). Recent years have seen a rise in unemployment contributing to poverty levels and food insecurity. Between 1996 and 2007 unemployment figures rose from 3.7 to 8.6 percent, and some believe the actual figure to be much greater (Fiji Islands Bureau of Statistics, 2009b, p. 2). The number of people living in squatter settlements more than doubled between 1999 and 2007. The number of people seeking assistance also increased. Between 2004 and 2009 there was an increase of 19.5 percent (Ministry of National Planning Fiji, 2010). Recent global crises have worsened the situation for many in Pacific islands. Real food prices were typically 19 percent higher in 2010 than two years prior making access to 
food for many even more difficult ${ }^{11}$ (FSP Working Group, 2010, p. 8). Rising poverty in the Pacific Islands has been directly related to rising food prices (ADB, 2008).

\section{Urban living - limiting space and time for home production}

The link between urbanisation and changes in food habits in the Pacific has strong foundations ${ }^{12}$. In particular, reliance on imported foods has come with shifts to urban living (Coyne, 2000). In many instances individuals have greater access to income. With typically less time and space to plant, urban dwellers often require access to purchased food. This latter point was supported in interviews in particular for those in informal settlements, as pointed out by $\mathrm{KI}(\mathrm{Koto})$ : "in urban areas there's little option for them to plant".

\section{Plate 2: Cassava planted alongside the side of a public footpath}

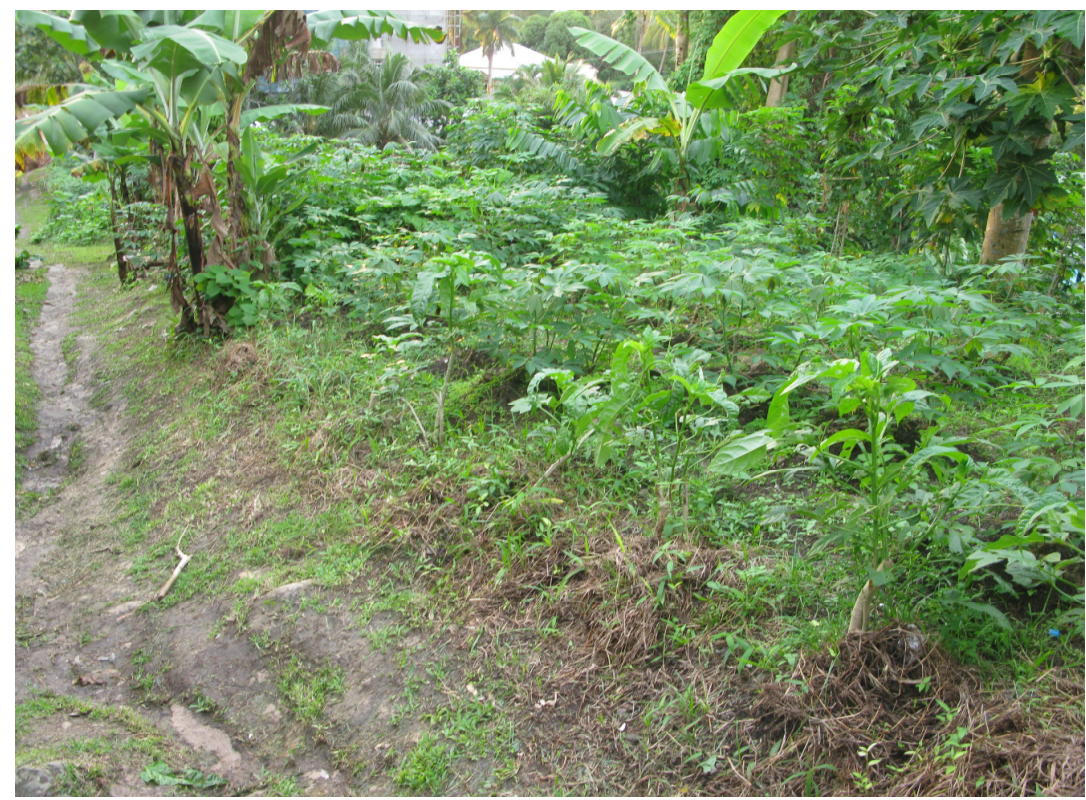

Photograph taken by Laura Barrett

Huge efforts are made to plant traditional foods, displaying both a need and a desire for traditional crops. Participants spoke of people going great distances to plant in vacant space, on the sides of roads, and in valleys (see Plate 2). This in itself is a time consuming activity and does not ensure access; it was reported in interviews others sometimes take what is planted.

\footnotetext{
${ }^{11}$ This figure takes inflation into account.

${ }^{12}$ See Coyne (2000)
} 


\section{Availability of non-traditional less nutritious sources}

What is consumed is closely tied with what food is available and it is clear food supply has changed dramatically over the last three decades. Food Balance Sheets prepared by the National Food and Nutrition Centre in Fiji present a picture of food supply and availability, displaying quantities and types of food available for human consumption. Although measurements do not account for subsistence production, the data remains valuable in providing a picture of what is available, especially for those who are reliant on purchasing food. In 2007 cereals represented the largest contribution to calories available at 34 percent of the total calories available. Cereals were followed by animal protein and oils and fats, both at 16 percent, followed by sugar at 14 percent. Together oils, fats and sugar represent 30 percent of available calories. Root crops comprised just 11 percent of total available calories ${ }^{13}$. Pulses, nuts and other seeds, and fruit and vegetables combined accounted for 7 percent of the total available calories, at 2, 3 and 2 percent respectively (Vatucawaqa, 2009). Further, the same report found an increase in energy availability since 1985 with more of that energy now coming from fat.

\section{Marketing - over-representation of imported foods in the media}

Advertising too has been implicated in shifts in consumption away from traditional foods. Imported foods and foods with imported ingredients are over-represented in advertisements (Thaman, 1988a). Additionally, the majority of the foods advertised displayed characteristics of those linked with poor nutrition, which is high in sugar, salt and saturated fat, or highly refined and low in nutrients and minerals. On the relationship between New Zealand trade and food insecurity in Fiji KI(Thaman) commented "because of advertising you may have got a shift from locally produced foods, nutritious foods to imported foods and non nutritious foods...so it may be the commercialisation".

\section{Decline in local production}

There is clear evidence of a decline in local food production in Fiji as imported foods have taken up an increasing role in diets. Figure 1 shows production over time, displaying a clear trend of overall decline in production since $1990^{14}$. One example of this is traditional root

\footnotetext{
${ }^{13}$ It is important to remember however that this does not account for subsistence production

${ }^{14}$ These figures do not show subsistence production
} 
crops. Coyne (2000, p. 17) finds a steep decline in availability of root crops in Fiji, and further, that Fiji has among the lowest availability of starchy root vegetables in a study of several Pacific Islands. Importantly, as is shown in Figure 1 the decline in per capita production is greater that overall production. As SPC (2009a) observe, “Agricultural production is not keeping pace with population growth rates". This, they add, represents a threat to food security.

Figure 1: Food production index Fiji 1990 - 2009

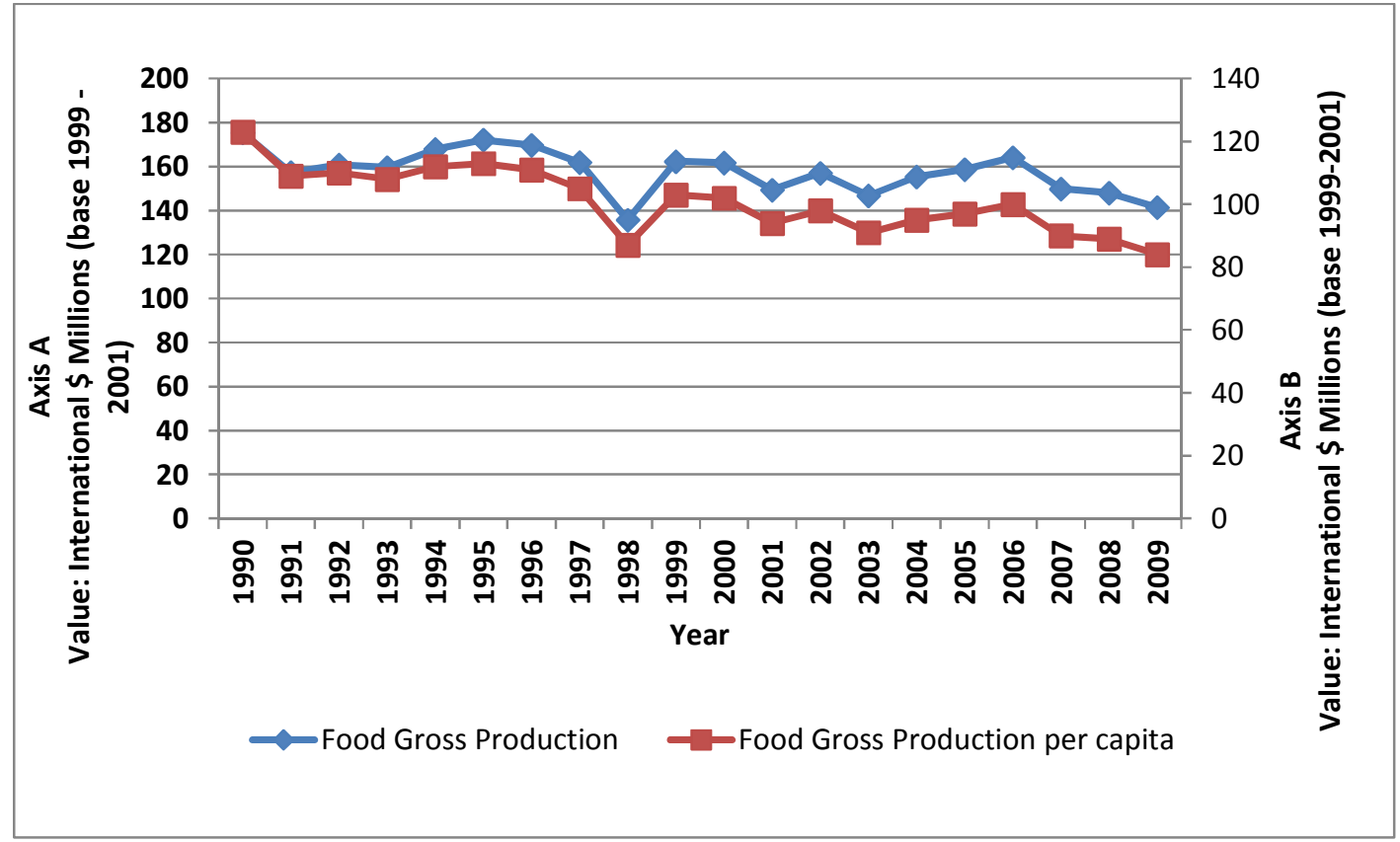

Source: FAO

\section{Economic and agricultural policy influencing local production and availability}

Government policies have affected domestic agricultural production and food availability. Coinciding with a period of export promotion by the Fijian government (Thow, et al., 2011), the 'Family Crops Regulation' requiring indigenous Fijians to grow sufficient root crops for their needs, was uplifted in 1962, and a decline in local production of starchy crops followed (Coyne, 2000). Trade liberalisation policies of the last two decades, along with export promotion policies, have, according to Thow and Snowden (2010), resulted in large-scale reductions in traditional agriculture and subsequent dietary change. With trade liberalisation 
policies, previously classified luxury goods on which high import tariffs were placed, came into the country in greater numbers (Thow, et al., 2011). The authors also point out that government policy can support local production by way of import substitution policies, investment in agriculture and protection of domestic markets, which have seen rises in production root crops.

\section{Loss of knowledge}

In the process of change, combined with a lack of value placed on traditional systems, valuable knowledge has been lost concerning food names, what can be eaten and how to prepare them (Thaman, 2005) thus reinforcing the consumption and production habits ${ }^{15}$.

\subsection{CONTEMPORARY CAUSAL FACTORS IN FOOD INSECURITY - INDIVIDUAL}

At this point, it is pertinent to look at food availability in Fiji. This is a central component of food security, that sufficient food is available. Fiji has in excess of the required number of calories per person per day. In 2007 Fiji had an excess of 53 percent of overall energy available per capita based on FAO recommendations (Vatucawaqa, 2009, p. 7). Hence, this is not the source of food insecurity for Fiji, nor the majority of Pacific Island countries as pointed out by Dr Halavatau: "the food available in the country on average is more than the minimum requirement of 2100 calories per day per person, of course most of the countries in the Pacific have more than that".

In addition to availability, both access and nutrition are key aspects. Food must be physically, economically and socially accessible, as well as of a nature that supports an 'active and healthy lifestyle' (FAO, 2003). These aspects of food security however often get overlooked. As KI(5) observes "people tend to simplify the concept to one of just food availability but availability, access and utilisation are all equally critical food security plays out".

It is evident from the above that access to food is clearly an issue for people in Fiji. This point was made also by $\mathrm{KI}($ Halavatau).

\footnotetext{
${ }^{15}$ There has been a renewed appreciation in recent times of Pacific knowledge of traditional food sources and systems which has seen them being taught in schools and universities.
} 
"it's only when we talk about excess that we are now coming in to what is the real problem ... within that country...there are pockets where people don't have enough food, ... pockets where people can 't access food, one they don't have land to grow their food, two ...they don't have land and they don't have income to purchase their own food, so when you start looking at access, then it is not availability any more, it's how do you access food"

\section{Taste, ease of preparation, status all factors but cost ultimately dominant factor}

Taste and individual choice undoubtedly are factors in consumption and purchasing habits in Fiji (ACIAR, 2002). The comparative ease of preparation of imported foods has also been influential in the shift away from traditional foods which typically take time and effort to prepare. As KI(Moore) stated "we have a wide variety of fruit and vegetables in the market but it requires time and effort so people are inclined to go for things liked tinned fish and the less nutritional food...instant food". In addition, there is a certain amount of status which since their arrival have been attributed to western foods (Pollock, 1992). However, cost ultimately plays a large and determining role (ACIAR, 2002). Thow and Snowden, (2010, p.158) conclude, "economic factors are comparatively more important than taste and preference in shaping the rising consumption of food imports in the Pacific region". Importantly, where access is limited, such as buy cost, and nutritional food is out of reach for a significant proportion of the population, then this does not constitute food security.

For many people in Fiji income is limited and comparative to income, nutritional food is too expensive and thus inaccessible. This point was made by a number of participants: KI(Moore) "a lot of it is to do with income [buying unhealthy food], they can't access what is available";

$\mathrm{KI}$ (Randy) "the good quality meats and good quality fish are beyond the means of most of the common people here". At the same time, a relationship between imported foods and cost was made. KI(Kumar) from the Consumer Council of Fiji stated: "the society in Fiji they look at imports as a cheaper option and therefore they rely on imports". The point was reiterated by KI(Namoce): "people have gone for the cheaper imported products, local products tend to be more expensive". Further, interviews indicate that there may often be an awareness that the food is not good for them. KI(Yabaki) stated "[they] will go for the cheapest food even though it is not nutritionally good for the family". However, because of limited income they buy the products anyhow. This point was made again by $\mathrm{KI}($ Koto): 
"they'd like nutritional food if they could afford it but in most instances nutritional food is very expensive so they'll just go for whatever their money can buy so tinned stuff, rice, canned fish, canned beef, and even when they go to the butcher it's mutton"

It is clear from interviews that a large portion of Fijians lack access to nutritional food. As $\mathrm{KI}$ (Moore) remarked "a lot of the time you're talking about food merely to fill stomachs rather than be good nutrition...". This is in clear contrast to earlier accounts of the Pacific where access to nutritional food was widespread.

\subsection{CONCLUSION}

This chapter sought to establish the context for food insecurity in Fiji by describing manifestations of food insecurity in Fiji, and identifying the driving factors behind this. It has established that Fiji has in excess of the daily calorie requirements; hence, food security in Fiji is a matter of access, and critically access to nutritional food. As chapter three established, if people cannot access nutritional food in sufficient quantities then this does not constitute food security. Findings presented here show that in the case of nutritional food, for a significant proportion of people it is not accessible. The result of this is heavy consumption of poor nutritional food, leading to obesity and non-communicable diseases. Thus, as $\mathrm{KI}($ Halavatu) points out, "If the food is not healthy and the body can't turn the food into healthy nutrients then you will have what we are having in the Pacific right now which is 70 percent of the people [who are] dying in the Pacific, they are dying from non-communicable diseases, so that is the real issue."

The situation above comes in stark contrast to earlier accounts of Fiji where malnutrition was unheard of and access to nutritional food was widespread. Factors in the shift from positive nutrition to poor nutrition have been explored in this chapter. While they are clearly multifaceted, stemming from a complex interplay of historical, and contemporary social and individual factors, there can be little doubt that impacts stemming from global integration, and specifically trade, have been instrumental in this change. In particular, the role of imported foods in food insecurity in Fiji is clear.

Evans et al. (2001) argue given the involvement of economics in the problem, the solution to poor health in the Pacific must therefore also involve economics. Based on this, as a key trader with Fiji, the foods that that are exported from New Zealand to Fiji require exploration 
into the role they are having on access to nutritional food for people in Fiji. As domestic production and food systems are also affected by the overarching trade system, the relationship between Fiji and New Zealand in this regard must be analysed also. These two aspects of trade will be explored in the two subsequent chapters. 


\section{Chapter 6: Trade between New Zealand \& Fiji}

\subsection{INTRODUCTION}

A central aim of this research is to identify the role of New Zealand trade in food insecurity in Fiji. The previous chapter identified that trade, specifically imported food, is a contributing factor to lack of access to nutritional food and subsequent poor health in Fiji. New Zealand has a longstanding trade relationship with Fiji. To what extent then is New Zealand contributing to food insecurity in Fiji through trade? The subsequent chapter evaluates this question. This chapter seeks to lay the foundations for this discussion by defining the contemporary trade relationship between Fiji and New Zealand.

The chapter begins by briefly outlining some key geographic features which limit Fiji's capacity for global economic engagement. Following this, an empirical overview of the relationship, focusing on food trade between New Zealand and Fiji, and how this fits within broader trade relationships, is provided. The chapter then outlines the policy framework for engagement between the countries. Finally, as a new agreement to govern the trade relationship is currently under negotiation, the direction of these negotiations is discussed along with potential implications for future trade and food security.

\subsection{BASIS FOR TRADE - LEVEL PLAYING FIELD?}

Like other Pacific Island states, Fiji faces a great many challenges when it comes to trade and economic security. As a Small Island Developing State (SIDS) Fiji faces challenges with size, remoteness, vulnerability and lack of economies of scale (Sharma, 2007). Fiji's population, with less than a million people, is small. It is also geographically isolated, increasing transport costs and adding to the cost of production. Like many other islands in the Pacific, Fiji has a limited resource base, and limited economies of scale. In order to obtain economies of scale Fiji focuses on a small range of primarily agricultural products, leaving it highly vulnerable to fluctuations in global prices (Thow et al., 2011). Adding to this, the Pacific Islands are some of the most highly vulnerable to natural disasters globally (World Bank, 2006). New Zealand, on the other hand, is a developed nation with a well-developed economy, strong productive base, and a foothold in the global market in dairy, meat and fresh produce. Hence, at the outset, there is an unequal starting point for engagement in trade. 


\subsection{EMPIRICAL REVIEW OF TRADE}

\section{Global overview of Fiji Trade}

Over the past six decades Fiji has become increasingly engaged in international trade. Figure 2 shows trade in goods between Fiji and world partners between 1950 and 2009. Over this period, not accounting for inflation, the level of imports and exports increased considerably. In 1950 exports were US\$20 million, and imports US\$18 million. Since then, the trend for international trade for Fiji in both imports and exports has been one of marked increase. By 2009 exports had risen to US\$650 million and imports US\$1470 million. Total value of trade thus increased approximately 55 fold in nominal terms. Importantly though, increase in imports has been much greater than exports. While during initial stages of increasing global integration through trade imports remained close in value to exports, over time the gap between the value of exports and imports has grown considerably. At its peak in 2008, Fiji had a negative trade balance of \$US1343 million.

Figure 2: Fiji total goods trade (global) 1950 - 2009

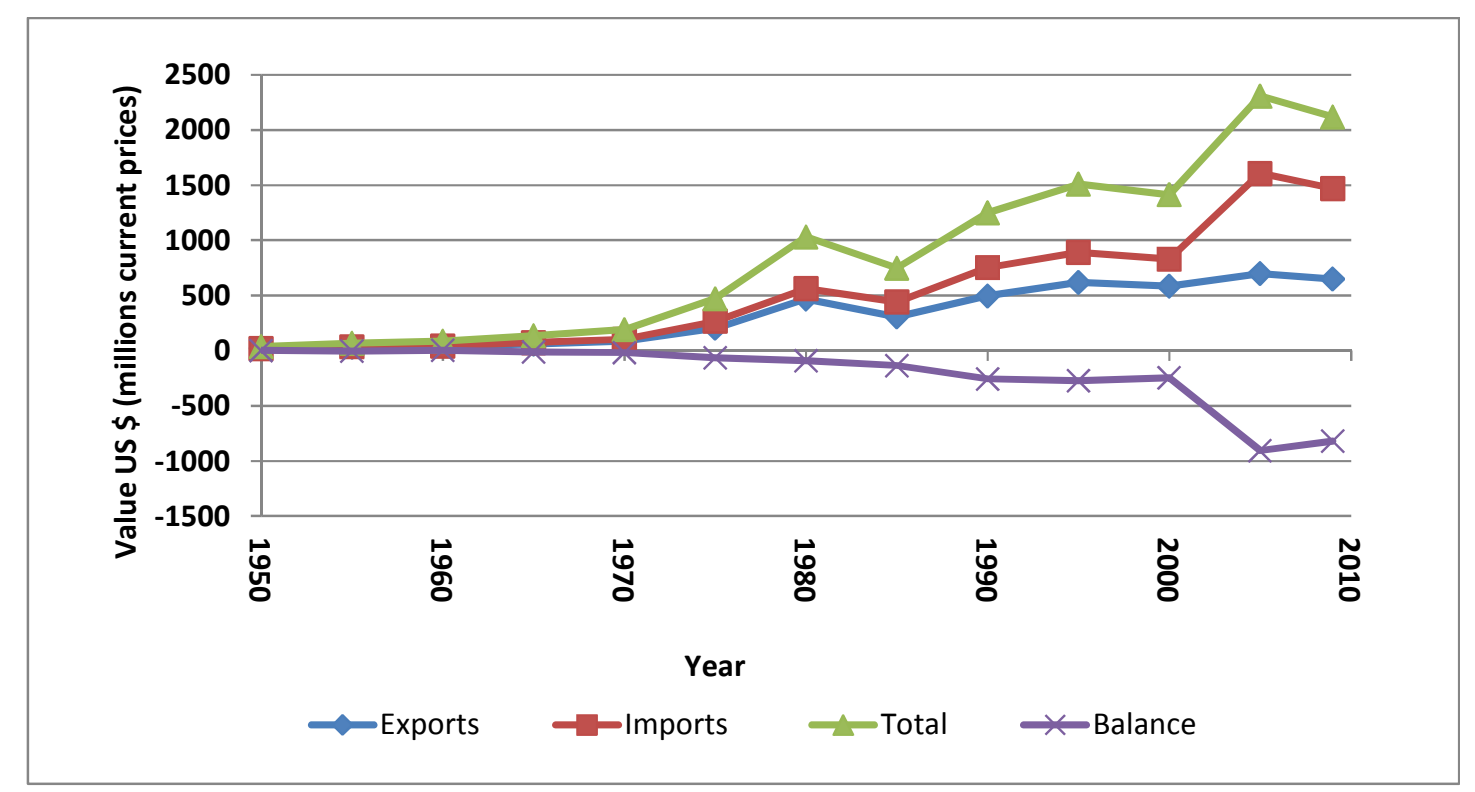

Source: WTO 
Interestingly, slight gains have been made recently in reducing the trade imbalance, as shown in Figure 3. However, this may largely be a result of an increase in poverty and decline in incomes. The fact remains that the trade imbalance remains significant. For 2009 it was negative US\$820 million. Worth noting is that Fiji re-exports some of the products it imports, however the majority are retained. In 2008 retained imports (imports minus re-exports) equated to 88.2 percent of total imports (Fiji Islands Bureau of Statistics, 2010).

\section{Figure 3: Fiji total goods trade (global) 2000-2009}

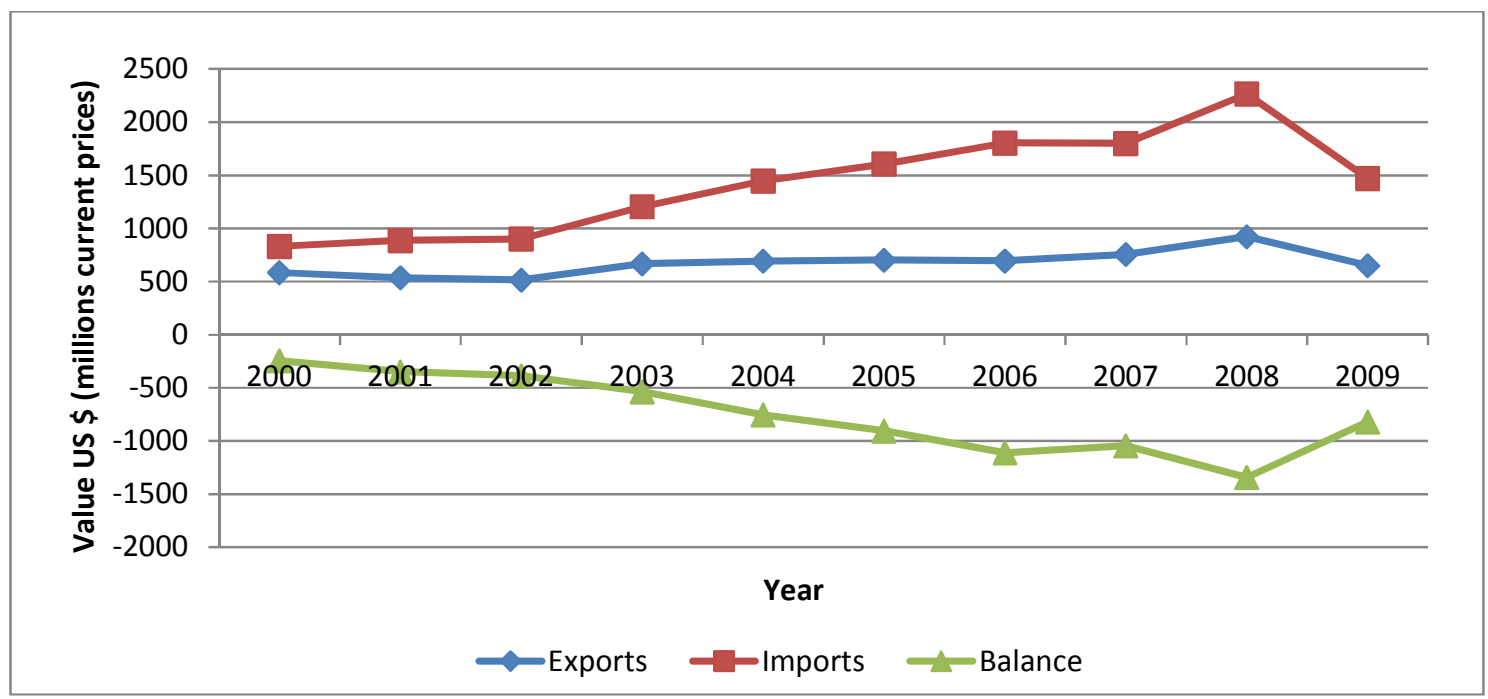

Source: WTO

Fiji's large trade imbalance can in part be explained by reliance on a number of materials which cannot be sourced domestically, for example mineral oils. Figure 4 provides a breakdown of imports for the period 2003 to 2008. It shows that mineral fuels account for the largest proportion of imports, at around one third in 2008, followed by machinery and transport equipment. Between 2003 and 2007 food represented the fourth largest import, behind manufactured goods, but in 2008 overtook manufactured goods taking third place. In that year, food equalled 14.4 percent of all imports. Thus, food represents a consistently significant share of imports and one displaying a trend of increase. 
Figure 4: Fiji imports 2003 - 2008

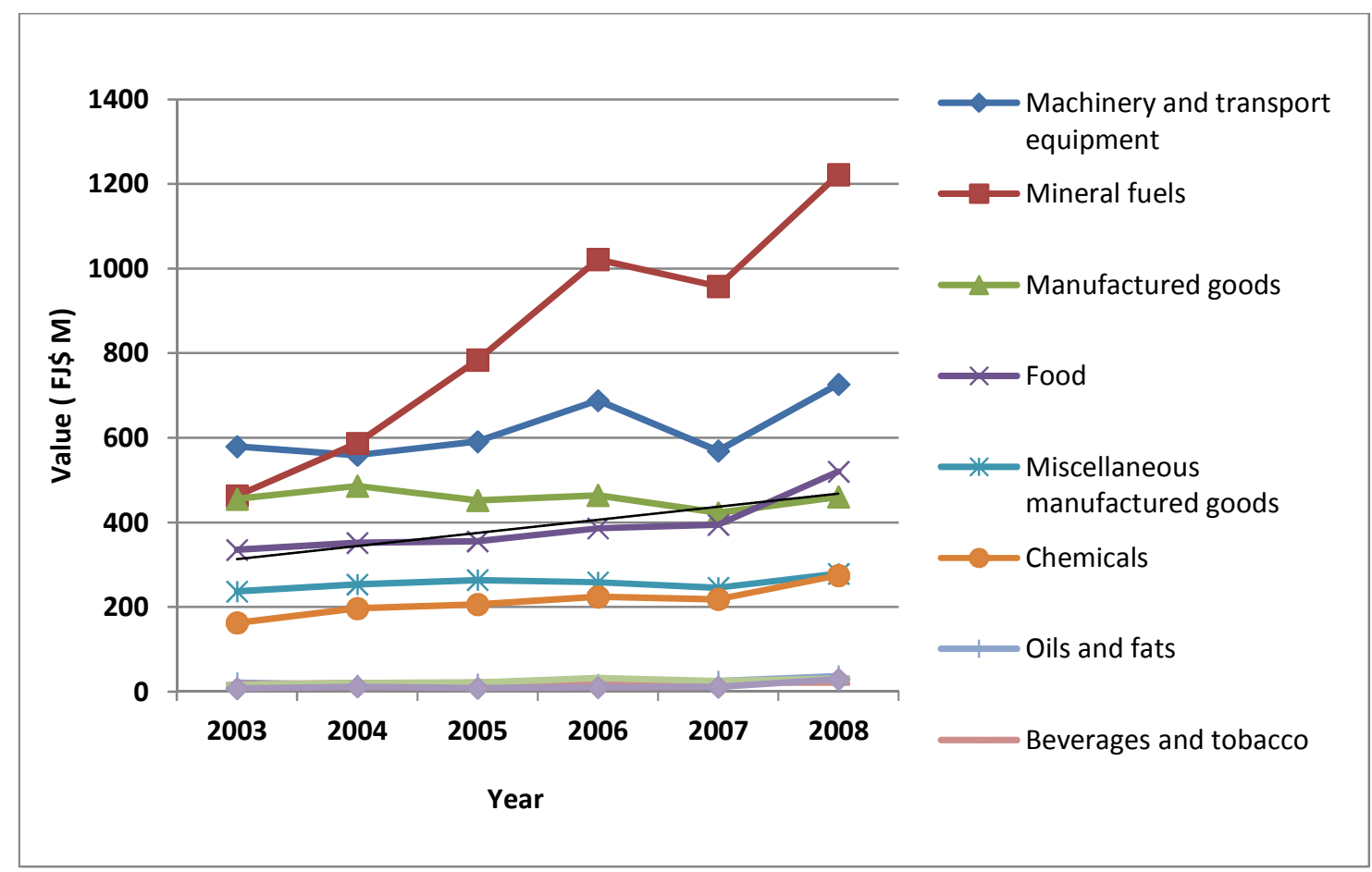

Source: Fiji Islands Bureau of Statistics

\section{Fiji Trade with New Zealand}

Fiji's trade relationship with New Zealand is an important one, for both partners. Among Pacific Island countries, New Zealand trades the greatest amount with Fiji. Fiji is one of only two Pacific Islands to rank amongst New Zealand's top fifty bilateral trading partners. In 2010 Fiji was ranked $30^{\text {th }}$. For that year, of NZ $\$ 830$ million exported to Pacific Island Forum countries $^{16}$, Fiji accounted for just over 36 percent of exports (Statistics New Zealand, 2010). The other Pacific Island country to rank on the list is Papua New Guinea. Total trade between New Zealand and Fiji is more than double that in dollar terms than New Zealand's next most significant trading partner from the Pacific Islands, which has a population more than six times that of Fiji. Comparatively, New Zealand ranks third on Fiji's list of bilateral trading partners based on level of imports and total trade, behind Australia and Singapore. In 2008 imports from New Zealand represented a little over 13 percent, or more than one eighth of Fiji's total imports. New Zealand is also a major destination for exports from Fiji. New

\footnotetext{
${ }^{16}$ Excluding Australia
} 
Zealand is the fourth most significant export destination, and accounted for 7.5 percent of exports in 2008, behind the United Kingdom, Australia, and the United States (Fiji Islands Bureau of Statistics, 2010). However, despite the relative importance on both sides, the relationship is not a balanced one. Imports from New Zealand to Fiji are far in excess of exports from Fiji to New Zealand, resulting in a large trade imbalance, as shown in Figure 5. In 2010 the balance of trade in goods with New Zealand for Fiji was negative NZ\$190 million.

Figure 5: Goods trade between New Zealand \& Fiji 1988-2010

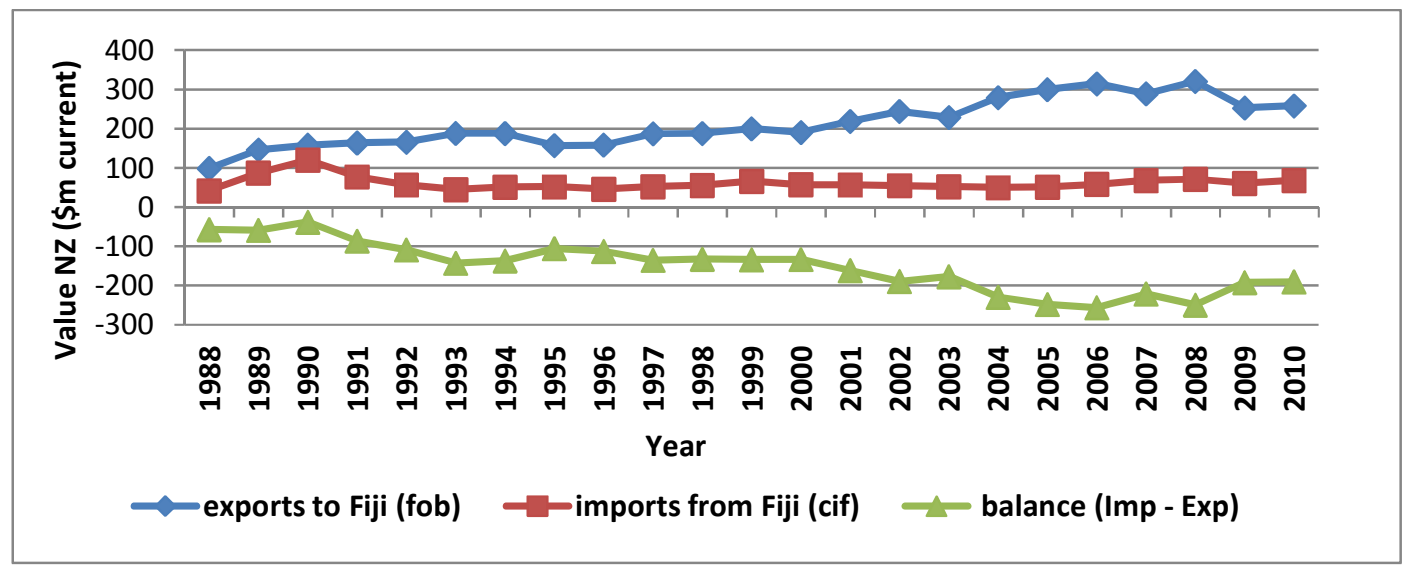

Source: Statistics New Zealand

\section{Fiji exports to New Zealand}

For 2010 New Zealand imported around NZ\$68 million in goods from Fiji. As shown in Figure 5 this value is far less than New Zealand exports to Fiji which for the same period which were close to NZ\$260 million. Figure 6 below shows the top fourteen imports by category, all of which represented over NZ\$1 million in value, imported from Fiji between 2008 and 2010. Vegetable roots and tubers represented the greatest proportion of that, followed by 'bread, pastry cakes etc' and 'confidential items'. Fresh fish is also among the top commodities traded. 
Figure 6: New Zealand top 14 imports by category from Fiji

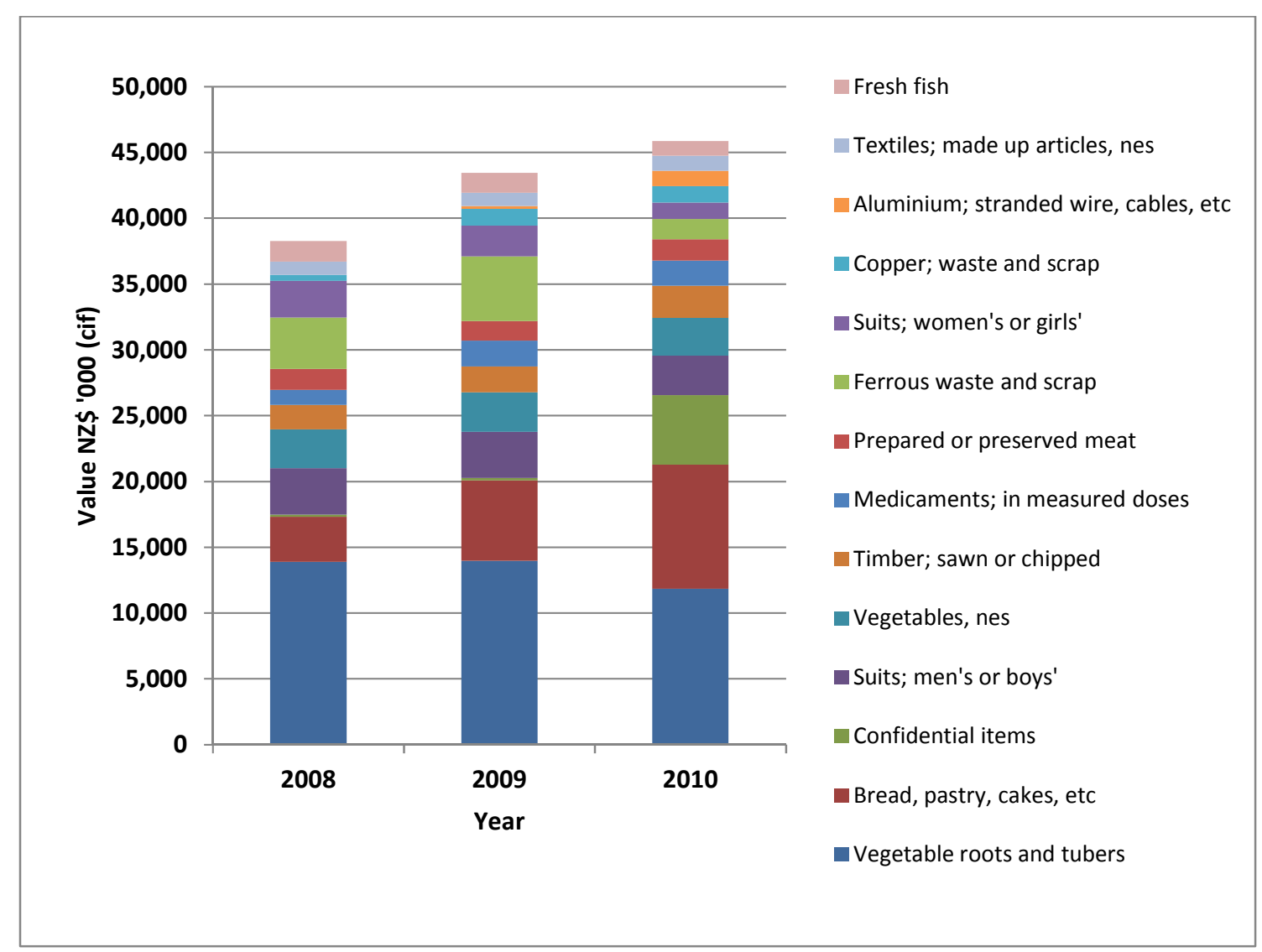

Source: Statistics New Zealand

\section{New Zealand exports to Fiji}

New Zealand exports an extensive range of goods to Fiji. Of goods exported, food represents a significant proportion. Figure 7 displays total exports, and exports in food ${ }^{17}$ from New Zealand to Fiji, as well as food as a proportion of total trade ${ }^{18}$. The figures show that both food exports, and food as a proportion of exports have increased in value over time. Between 2003 and 2008 food imports from New Zealand represented on average one quarter of all food imports.

\footnotetext{
${ }^{17}$ Calculation derived based on harmonised system categories - refer to chapter 2 for further explanation

${ }^{18}$ Calculated using exchanges rates from Pacific Exchange Rate Service (http://fx.sauder.ubc.ca/data.html) and data provided within this chapter
} 


\section{Figure 7: Food exports as a proportion of total exports - New Zealand to Fiji}

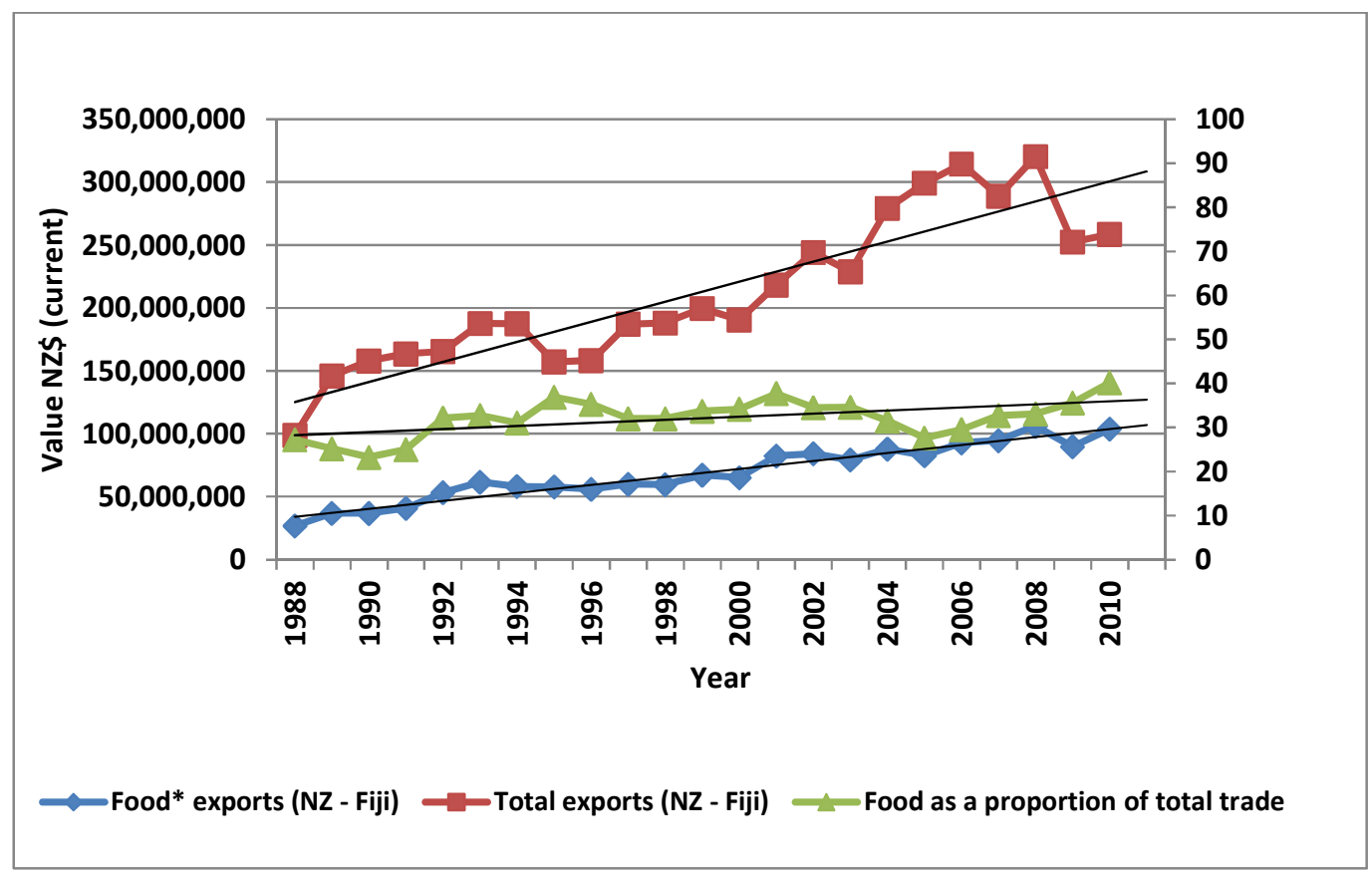

Source: Statistics New Zealand

Having established that New Zealand food exports represent both a significant proportion of total New Zealand trade, and total food exports to Fiji, it is necessary to look closer at items that are being exported. Table 1 shows New Zealand food exports to Fiji by category for 2010. The chart is derived from data categorised by the Harmonised System (Appendix D) and provides the best possible representation of food exports given the limitations of the data $^{19}$. It shows clearly the dominance of meat, dairy and vegetables in exports to Fiji from New Zealand. In 2010 dairy produce represented 35 percent of food exports, meat and edible meat offal was 22 percent and vegetables, roots and tubers represented 18 percent. Combined, meat and dairy equated to over half of food exports from New Zealand to Fiji. Figure 8 shows the trend over time in exportation of these categories. It shows an increase in value over time in nominal terms.

\footnotetext{
${ }^{19}$ For explanation see chapter 2
} 
Table 1: Food exports by category - New Zealand to Fiji 2010

\begin{tabular}{|lrr|}
\hline \multicolumn{1}{|c}{ Item } & $\begin{array}{c}\text { Value } \\
\text { (NZ \$'000) }\end{array}$ & Percentage \\
\hline Dairy produce & 36388.4 & $35.0 \%$ \\
\hline Meat and edible meat offal & 22403.5 & $21.6 \%$ \\
\hline Vegetables and certain roots and tubers & 18754.4 & $18.1 \%$ \\
\hline Beverages, spirits and vinegar & 4415.8 & $4.3 \%$ \\
\hline Miscellaneous edible preparations & 3979.7 & $3.8 \%$ \\
\hline Fruit and nuts, edible & 3026.4 & $2.9 \%$ \\
\hline Preparations of vegetables, fruit, nuts & 2743.2 & $2.6 \%$ \\
\hline Animal or vegetable fats and oils & 2479.0 & $2.4 \%$ \\
\hline Cereals & 2414.0 & $2.3 \%$ \\
\hline Preparations of cereals, flour, starch or milk & 1813.1 & $1.7 \%$ \\
\hline Fish and crustaceans & 1469.5 & $1.4 \%$ \\
\hline Malt, starches, inulin, wheat gluten & 1147.2 & $1.1 \%$ \\
\hline Sugars and sugar confectionery & 931.2 & $0.9 \%$ \\
\hline Salt & 701.3 & $0.7 \%$ \\
\hline Meat, fish or crustaceans; preparations thereof & 656.1 & $0.6 \%$ \\
\hline Cocoa and cocoa preparations & 388.1 & $0.4 \%$ \\
\hline Coffee, tea, mate and spices & 132.6 & $0.1 \%$ \\
\hline Seeds and grains & 21.8 & $0.0 \%$ \\
\hline TOTAL & $\mathbf{1 0 3 8 6 5 . 5}$ & $\mathbf{1 0 0 \%}$ \\
\hline
\end{tabular}

Source: Statistics New Zealand

Figure 8: Top three food exports by category - New Zealand to Fiji

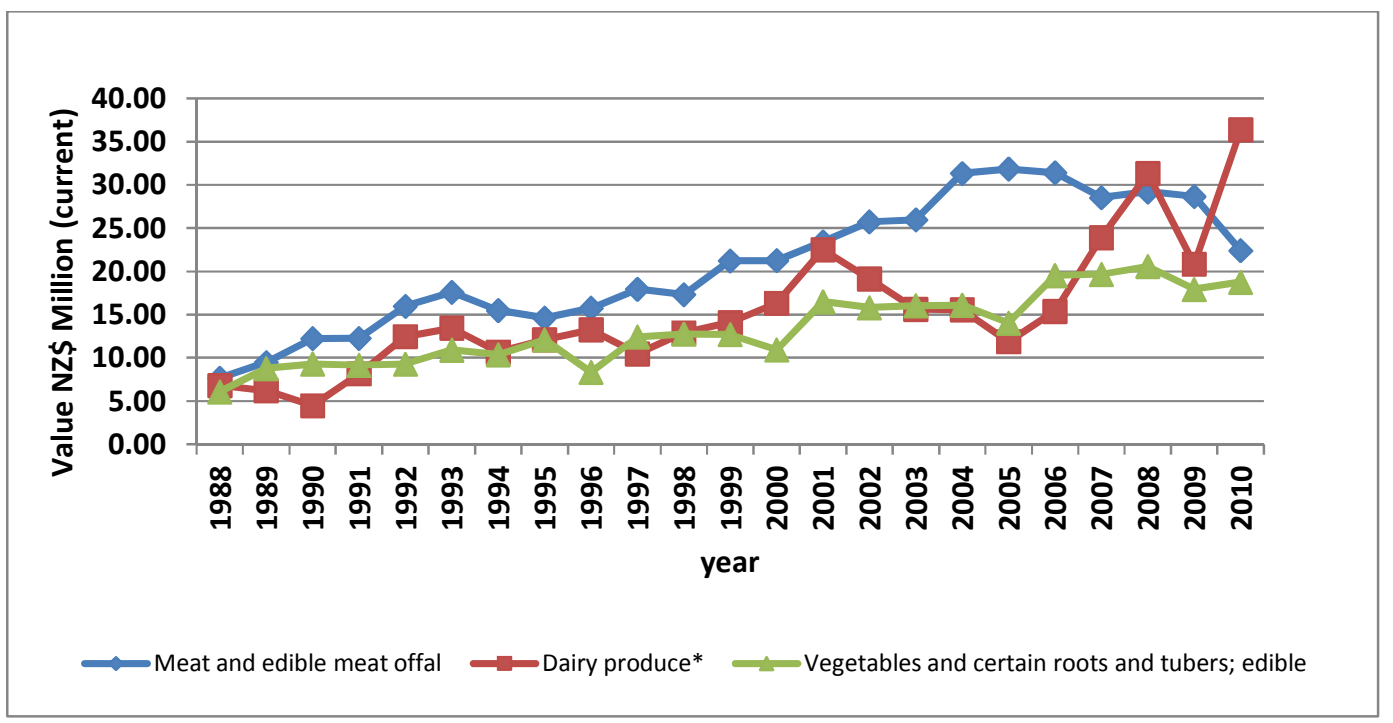

Source: Statistics New Zealand 
Of food commodities exported from New Zealand to Fiji, six make up over half of the value of exports. Primary commodities exported in 2007 and 2010 are shown below in Table 2. The six primary commodities exported by New Zealand since 2007 are sheep meat, potatoes, milk powder, butter, onions and fresh milk (Statistics New Zealand, 2010). In 2010, the combined total of these was NZ\$ 57,560,000, representing just over 55 percent of total food trade. A comprehensive list of food products exported by New Zealand to Fiji from 2008 to 2010 can be found in Appendix E. The list is too large to be included here but some points are worth noting. An extensive range of foods are exported in varying quantities. In addition to the primary exports discussed above, New Zealand exported around NZ\$1.5 million of fish and seafood in 2010, and a variety of fruits, a large proportion of which were apples.

Table 2: Top food exports by commodity - New Zealand to Fiji 2007 and 2010

\begin{tabular}{|c|c|c|c|c|}
\hline & \multicolumn{2}{|c|}{2007} & \multicolumn{2}{|c|}{2010} \\
\hline Rank & $\begin{array}{c}\text { Value } \\
\left(\mathrm{NZ} \$ \$^{\prime} 000\right)\end{array}$ & $\%$ of food exports & $\begin{array}{c}\text { Value } \\
(\mathrm{NZ} \$ 000)\end{array}$ & $\%$ of food exports \\
\hline 1 & Sheep meat $(20,490)$ & 21.6 & Sheep meat $(15,355)$ & 14.8 \\
\hline 2 & Potatoes $(10,223)$ & 10.8 & Milk powder $(11,646)$ & 11.2 \\
\hline 3 & Milk powder $(7,659)$ & 8.1 & Butter $(11,250)$ & 10.8 \\
\hline 4 & Butter $(8,342)$ & 8.8 & Potatoes $(9,422)$ & 9.1 \\
\hline 5 & Onions $(5,206)$ & 5.5 & Onions $(5,679)$ & 5.5 \\
\hline 6 & Fresh milk $(3,908)$ & 4.1 & Fresh milk $(4,208)$ & 4.1 \\
\hline & Food Total $(94,665.5)$ & & Food Total $(103,865.5)$ & \\
\hline
\end{tabular}

Source: Statistics New Zealand

\section{Summary}

In sum, the data presented here shows an increase over time in the level of exports from New Zealand to Fiji. At the same time the level of imports from Fiji has remained relatively stagnant, resulting in a growing gap between imports and exports and a worsening trade balance for Fiji. Food represents a considerable and increasing proportion of exports from New Zealand to Fiji. Within this, meat products, dairy and vegetables constitute the majority of exports. 


\subsection{POLICY CONTEXT}

This section looks at trade policy that has informed the trade relationship between New Zealand and Fiji since independence in 1970. Coming out of this relationship and into sovereign rule Fiji's economy was relatively open (Browne \& Scott, 1989). A few years later, in 1973, Fiji implemented a number of restrictive and protectionist trade measures in an attempt to reduce imports and a heavy trade imbalance (Thow et al., 2011). In line with global shifts in economic policy away from protection and government intervention to neoliberal policies of privatisation and market rule (see chapter 4), in 1987 Fiji began implementing trade liberalization policies, leading to reduction of tariffs and other trade restrictive measures (Thow et al., 2011). Trade agreements developed since the eighties between Pacific Island Forum Countries, Australia and New Zealand have attempted to set regional frameworks and rules for trade. These have seen the erosion of preferential access and concerted pressure to move towards free trade (Morgan, 2010). The remainder of this section outlines the agreements that have governed the trade relationship between New Zealand and Fiji since Fiji independence.

\section{SPARTECA}

The South Pacific Regional Trade and Economic Cooperation Agreement (SPARTECA) was the first regional trade agreement post independence to be formally negotiated between New Zealand and Pacific Island Countries, and hence Fiji. The agreement came into force in 1981. Importantly, this agreement recognised the different capabilities of the nations involved and allowed for preferential access of goods for the fourteen developing country members of the Pacific Islands Forum ${ }^{20}$, then the South Pacific Forum, into New Zealand and Australia (Kelsey, 2004b). This agreement is non-reciprocal, meaning duty free access is granted to New Zealand and Australia for developing Pacific Island states without them having to offer the same in kind. This agreement has played a major role in supporting exports from Fiji, and other Pacific islands such as Samoa and Papua New Guinea to New Zealand and Australia. Under this agreement over the past seven years, Fiji has exported goods valued between F\$12 and F\$17 million annually (Fiji Islands Bureau of Statistics, 2009a).

\footnotetext{
${ }^{20}$ Fiji, Kiribati, Nauru, Cook Islands, Federated States of Micronesia, Tonga, Solomon Islands, Vanuatu, Papua New Guinea, Palau, Niue, Samoa, Tonga, Republic of Marshall Islands
} 


\section{PICTA and PACER}

In 1999 members of the Pacific Islands Forum ${ }^{21}$ agreed to future negotiations for a regional free trade and economic integration agreement amongst all member countries. The agreements that formed the basis of this transition are the Pacific Islands Countries Trade Agreement (PICTA) and Pacific Agreement on Closer Economic Relations (PACER). PICTA came into force in 2003 and governs trade between Pacific Island Forum states, with the exclusion of New Zealand and Australia. The agreement requires members in time to allow goods from other member states access without restriction, meaning no tariffs or quotas. The agreement set a limited time frame for realisation of the goals, 2010 for developing country islands, and 2012, for least developed country islands (Kelsey, 2004b). This has since been extended to 2021 (MFAT, 2010a). While this agreement does not apply to trade with New Zealand or Australia, it provides the foundation for eventual free trade between PICTA members and New Zealand and Australia. Hence an underlying objective of PICTA is to set in motion gradual movement towards free trade across the region:

"The liberalisation of trade amongst FICs [Forum Island Countries] under PICTA can be seen as a stepping stone and a necessary precursor to trade liberalisation between FICs and New Zealand and Australia through PACER Plus" (MFAT, 2010a, Pacific Island Countries Trade Agreement (PICTA) para. 2).

The PACER agreement provides for eventual inclusion of New Zealand and Australia in a trade relationship with other Pacific Island Forum countries, including Fiji. This came into effect in 2002. While there are few immediate obligations, this agreement establishes the foundations for eventual trade liberalisation and economic integration and a 'single regional market' between Forum member states (Kelsey, 2004b). A further key objective of PACER according to MFAT is "to help create favourable conditions for private sector led growth throughout the region and stimulate economic development" to be achieved by "fostering increased economic opportunities and competitiveness through more effective regional trade arrangements" (MFAT, 2010a, PACER Plus para. 1, 2). A crucial element of PACER is that if PICTA members make any commitments or enter negotiations with other countries, they must also offer the same to New Zealand so as not to disadvantage New Zealand and thus 'safeguarding' New Zealand's interests in Pacific Island markets. While PICTA establishes

\footnotetext{
${ }^{21}$ The fourteen developing country members (previous footnote) plus Australia and New Zealand
} 
the preconditions for free trade amongst the Pacific Island countries, PACER makes sure that New Zealand and Australia are included (Kelsey, 2004b).

\section{WTO, Cotonou - EPA, Melanesian Spearhead Group}

New Zealand and Fiji are both members of the World Trade Organization (WTO) and thus are also governed by its rules. A key principle of the WTO agreement is the Most Favoured Nation principle which promotes trade 'without discrimination'. The WTO provides provision for exception to this, such as in the case of providing special access for developing countries under 'Special and Differential Treatment' (WTO, 2010). Fiji has also been party to the Cotonou agreement. The Cotonou agreement, formerly Lomé Convention, represented a partnership between African, Caribbean and Pacific countries (ACP) and the European Union (EU), and provided preferential access for ACP countries to the EU market. This agreement expired in 2008 and a new agreement is under negotiation. Fiji is one of two Pacific countries to enter into an interim Economic Partnership Agreement (EPA) with the European Union protecting Fiji's access to European markets (Morgan, 2010). This agreement is an example of the kind of future negotiations and commitments to which New Zealand does not want to be disadvantaged by and it is this agreement in part which set PACER Plus negotiations in process (Australian High Commission Fiji, 2007). Fiji is also part of a sub-regional agreement with three other islands in Melanesia under the Melanesian Spearhead Group. Some argue this represents an alternative regional arrangement to those in which New Zealand and Australia have a hand (Walsh, 2010).

\subsection{FUTURE TRADE-IMPLICATIONS OF PACER PLUS}

PACER Plus is under negotiation at present and will supersede all previous agreements. It builds on PACER and PICTA which established the ground work for a free trade agreement. The outcomes of PACER Plus negotiations will determine the future trade relationship between New Zealand and the Pacific Islands. PACER Plus is very much a work in progress. At present there is scarce concrete information on what the final PACER Plus agreement will look like. The New Zealand government promotes the agreement as both a trade and development agreement that will bring significant benefits to the region. It states the agreement will enable Pacific Island countries: 
"to capitalise on their potential for trade ... equip Pacific Island countries better to withstand external shocks, to raise standards of living, to increase jobs and export capacity in the region and to address the significant goods trade imbalance that currently exists between the Pacific and New Zealand" (MFAT, 2010a, PACER Plus para. 6)

Others are sceptical of the benefits promised to come from this agreement. On the one hand MFAT (2010) has labelled PACER Plus as a free trade agreement and stated that this agreement "is part of the commitment to a wider process of economic integration and trade liberalisation" (MFAT, 2010, PACER Plus para. 4). At the same time it has also stated "PACER Plus will not be a traditional trade negotiation in which commercial interests alone define New Zealand's approach" (MFAT, 2010, PACER Plus para. 6). To what extent this will be realised is unclear. New Zealand is a member of the WTO. As such it has been suggested that they are likely to argue that PACER Plus be fully compatible with the rules of the WTO which require "rapid and deep trade liberalization" and liberalisation of "substantially all trade' 22 (PANG, 2009a). A WTO-compatible agreement, it has been argued by some, is both inappropriate and dangerous to the region (Penjueli \& Morgan, 2010).

A range of commentators such as Oxfam New Zealand, Pacific Network on Globalisation (PANG), and academic Jane Kelsey have expressed concerns regarding the proposed agreement and the move towards greater trade liberalisation and free trade (Kelsey, 2009b; Oxfam New Zealand, 2009; PANG, 2009a). It is argued that the benefits of such a deal would likely be received by Australia and New Zealand, and a small few in Pacific Island countries, while the majority of people in Pacific Island countries would suffer. Critics argue that the agreement will lead to greater exports to Pacific Islands as tariffs and barriers are lowered, but because of limitations in the Pacific Islands they will not see the same improvement in exports from their side (Penjueli \& Morgan, 2010). This is to say nothing of the already great imbalance in trade. Alongside this, unemployment is predicted to result as businesses and industries close down in the face of outside competition (Institute for International Trade, 2008). Important revenue from import taxes, which play a significant role in supporting Pacific Island governments, will likely be lost (Penjueli \& Morgan, 2010). Further the burden of recouping these would likely be placed onto consumers (Oxfam New Zealand, 2009). In addition, there is concern that the Pacific Islands will lose policy space to provide support and

${ }^{22}$ derives from Article XXIV in GATT on trade of goods (PANG, 2009) 
protection of local industries. Agricultural support plays an important role in developing industry, particularly small and infant industries, in the Pacific Islands. When this support is taken away, it is almost certain that industries and the livelihoods supported by these industries will suffer (PANG, 2009a).

Important in the development of this agreement, is not only the outcome, but also the process by which it is undertaken. There is deep concern over the pressure on leaders to bow to pressure from Australia and New Zealand (PANG, 2008). The Pacific Island countries are heavily dependent on aid, in fact some of the heaviest in the world, per capita (Morgan, 2010). Pressure from aid donors and international institutions has been a key factor in Pacific Island economic integration and past trade negotiations (Firth, 2000; Kelsey, 2004b). There is also evidence of New Zealand and Australia using direct pressure tactics in the past to influence negotiations (Kelsey, 2004a, 2009b). There is concern room is not being made for critical segments of the Pacific community to be consulted under pressure from the New Zealand and Australian governments to move negotiations ahead (PANG, 2009b). Nor, it is argued, is their sufficient understanding of the full implications of the agreement across the region, and that this requires time and resources (Kelsey, 2009b). Fiji has been excluded from negotiations due its current political position. However, as the legality of decisions reached without the involvement of Fiji would be challengeable (Kelsey, 2009a) and given Fiji's significant role in trade in the region, the agreement will inevitably involve re-inclusion of Fiji.

Critically, this agreement will be binding and long term and will leave little room for change. Thus, it is important to investigate the potential impacts of such a decision before it occurs to allow time for informed decisions. For a supportive and equitable relationship to be established it must take into account the unique realities of individual member countries and the impacts any agreement will have on local livelihoods.

\subsection{CONCLUSION}

This chapter has provided an overview of trade between New Zealand and Fiji, describing the political and empirical context for engagement. In sum, it has found the relationship to be a significant one for both parties but also one which displays significant imbalance, and which appears to benefit New Zealand disproportionately. Stemming from the findings of the 
previous chapter, a further aim of this chapter has been to establish a picture of food trade between the two countries, primarily food exports from New Zealand to Fiji. Broadly, the findings show that both the value of food and the proportion of food to total exports have increased over time. Additionally, while New Zealand exports a diverse and extensive range of products to Fiji, meat, dairy and vegetables make up the bulk of this, and further within this, a handful of products, including sheep meat, milk, butter, and potatoes, make up more than half of food exports.

A further aim of this chapter was to outline the policy context which shapes trade between New Zealand and Fiji. In sum, it found for the New Zealand government this to be overall one of more and more open trade, with the ultimate aim of a single regional market. New Zealand alongside Australia and Pacific Forum Island countries, of which Fiji is one, are in the process of negotiating a new trade agreement that will supersede prior agreements and govern trade indefinitely. While the New Zealand government has stated that this will not be a 'typical free trade agreement', it nonetheless is questionable over its ability to redress current imbalances in trade, which are in favour of New Zealand. Moreover, the agreement may lead to fundamental, irrevocable hardship for Pacific nations, and this will undoubtedly impact on food security. The subsequent chapter draws from this chapter, and the preceding one to evaluate the relationship between New Zealand food trade, and trade more generally, and food insecurity in Fiji. 


\section{Chapter 7: New Zealand Trade and Food Insecurity in Fiji - The Links}

"there is not a dimension of this which trade isn't playing a role, whether positive or negative, it's totally enmeshed in any discussion, in any aspect. When you talk about food safety, NCD aspects of food, food availability, food access, food marketing, all of them have a trade dimensions" KI(Matheson)

\subsection{INTRODUCTION}

It is well accepted that trade plays a central role in food security, be it positive or negative. In 2010 the Food Secure Pacific Working Group, made up of leading international authorities on health and agriculture, stated that trade, while supporting food security in the Pacific countries, also poses a threat to food security in the region (FSP Working Group, 2010). As a key trading partner with the Pacific Islands, this raises question over the role of New Zealand trade in food insecurity in the Pacific, and whether it is supportive or a threat to food security in the region. This chapter examines this question, focusing on New Zealand's trade relationship with Fiji. Drawing from previous chapters, it identifies some links between New Zealand food trade with Fiji and food insecurity there. These are grouped into two categories, direct and indirect factors, direct being immediate factors that arise from the consumption and presence of New Zealand imports, and indirect being factors that develop over time as a result of New Zealand trade. This research acknowledges that there are multiple factors which contribute to food insecurity in any given context. However, this research posits that New Zealand, while not necessarily the main driver of food insecurity in Fiji, through trade has an important role to play nonetheless, and aims to draw attention to this.

The findings of this chapter are assessed against the FAO (2003, p. 29) definition of food security as discussed in chapter three and provided again below:

"Food security exists when all people, at all times, have physical, social and economic access to sufficient, safe and nutritious food which meets their dietary needs and food preferences for an active and healthy life" 
Foundations for this chapter also lie in the right to food, which highlights access and nutrition as key components in realising this fundamental right. The right to food is increasingly being viewed as having obligations for states to those not only within their territory, but those in countries which are affected by state actions or actions by parties under the control of the $\operatorname{state}^{23}$.

As discussed in chapter five, food insecurity in Fiji can be seen most poignantly through poor statistics in obesity and non-communicable diseases, which are indicative of over-nutrition. In this case, one has excess calories but inadequate nutrients. Food insecurity in Fiji is also evident through micro-nutrient and vitamin deficiencies, as well as under-nutrition or hunger. There are multiple factors in the development of poor health in Fiji, as are outlined in chapter five. However, there is a clear relationship between declining health in Fiji and the rise in consumption of processed and packaged foods, many of which are imported.

Chapter six provided evidence of New Zealand's trade relationship with Fiji. It established that New Zealand has a well-established trade relationship with Fiji; however, considerable imbalance exists, with a high negative trade balance for Fiji. It also showed that New Zealand exports a significant amount to Fiji - just under NZ\$260 million in 2010, a large and growing proportion of which is food. Additionally, a few primary products make up the bulk of exports. Based on this, as well as interviews with key informants presented in this chapter, New Zealand can be seen to interact with access to nutritional food in Fiji at a number of levels.

New Zealand trade affects local access to nutritional foods directly through the products it exports and imports with Fiji. In addition, New Zealand trade affects local production, which in turn affects availability of and access to nutritional food. Further, the framework in which New Zealand engages in trade with the Pacific has implications for food production in Fiji, and also on local livelihoods, both of which limit access to nutritional food. These points are discussed throughout this chapter, as well as potential impacts on food security with upcoming changes to the standing trade agreement between the countries. A final point of discussion is the degree to which New Zealand has a responsibility to act to address the role it plays in food insecurity in Fiji.

\footnotetext{
${ }^{23}$ See chapter three for discussion
} 


\subsection{DIRECT IMPACTS OF NEW ZEALAND TRADE ON FOOD SECURITY IN FIJI}

\section{Increasing availability of calories}

A common assumption is that exporting food to a country where food insecurity exists will improve food security by making more food available (Mechlem, 2006). Supply of a wider range of goods at lower cost is a common argument for trade as countries are no longer bound by the limitations of their own country but can see the entire globe as their supermarket. New Zealand exported over NZ\$100 million worth of food products to Fiji in 2010 and is thus increasing the amount of food available on the Fijian market. Many of the foods that New Zealand exports to Fiji are not produced in Fiji, or not in amounts sufficient to meet demand, as is evident in the following quote: $\mathrm{KI}(1)^{24}$
"those products Fiji imports from New Zealand are the products that are not supplied in this country by domestic producers, for example, dairy products, we have a dairy industry in Fiji but it only supplies about 50 percent of Fiji's needs, the other 50 per cent has to be imported. If you look at meat lamb, Fiji cannot meet its market, the meat industry is very small, and therefore it has to import lamb from New Zealand"

Thus the view of a number of participants in Fiji was that New Zealand imports are 'filling a gap' in Fijian production. The following statement by KI(Yabaki) is representative of this.

"We import milk from New Zealand and butter to make up for the shortfall we have in the needs for dairy products. In that way New Zealand is very helpful. When you look at the bigger picture New Zealand is an advantage because it helps us make up the shortfall in our foods needs for our people."

By providing the market with options not locally available, New Zealand can thus be viewed as supporting food security. This position is again reflected by $\mathrm{KI}(1)$ :

"There are some products that are not available in Fiji and they have no choice, for example if you look at apples we don't produce them here ... in Fiji we have these tropical fruits which are very seasonal, and if we continue to get apples which are always available in the market throughout the year that contributes to nutritional level."

\footnotetext{
${ }^{24}$ Informants identity confidential - see chapter two for explanation
} 
The implication of the statements above is that Fiji cannot supply its dietary needs. However, as established in chapter five, Fiji has in excess of calorific needs for its population (Vatucawaqa, 2009) and thus this statement requires review. A key question is whether the foods New Zealand is exporting are supporting the nutritional element of food security.

\section{Undermining local nutrition}

In keeping with the definition of food security, to be supportive of this the food must be supportive of an 'active and healthy life'. A list of consumables exported from New Zealand to Fiji between 2008 and 2010 is supplied in Appendix E. Among these products, some provide more nutritional value than others. Two ways can be identified in which the quality of exports can undermine nutrition. The first and most obvious is where the products are nutritionally deficient, and consumption of those products leads to poor health outcomes. A further, less obvious way in which exports can undermine nutrition is where the product itself is not necessarily of poor quality, or nutritionally deficient, but where it draws consumption away from healthier, previously consumed items. Both of these situations are evident with New Zealand exports to Fiji.

\section{Case one - nutritionally deficient items}

New Zealand exports a large amount of meat to Fiji. Meat and edible meat offal accounted for 22 percent of New Zealand food exports to Fiji in 2010. Sheep meat alone is New Zealand's largest food export to Fiji, at a value of over NZ\$15 million in 2010. High grade cuts of meat in the right amounts, and cooked in low fat ways, can be supportive of health by providing iron and protein. However, low quality meat, in particular sheep meat, has been associated with poor health outcomes in the Pacific (Wyber, et al., 2009). While Fiji has banned the import of mutton flaps, the cut of the sheep meat most heavily criticised for its negative health implications, it is evident that meat that is low grade and high in fat continues to be exported by New Zealand to Fiji. The practice of sending cuts of meat to the Pacific that would not be exported to some other places has led to those portions of meat being labelled the 'Pacific cut' and as one participant confirmed "the Pacific cut as they call it, that's still being brought in" KI(Roberts). The Consumer Council of Fiji, pursuing concerns over the quality of meat coming from New Zealand, carried out a project looking at the price and fat content of lamb chops and found it supported claims that the quality of the meat was low. KI(Larkan) further 
attested to the types of meat being brought into Fiji from New Zealand. He stated "you [New Zealand] are exporting all your raw material to us and these are usually the low value cuts, the tongue roots, heart offal, and it is very high in fat content". In response to this the Consumer Council has been calling for quality standards to be put in place to control the quality of meat that is brought in from New Zealand.

While some products go direct to the shelf, other parts are used in the production of items such as tinned corned beef and mutton, which are a commonly consumed item in Fiji and which, when consumed on a regular basis, have serious health consequences. Increasingly, Fiji is processing and packaging more meat, but many of the ingredients are coming from New Zealand. These products, for which New Zealand is supplying the ingredients as attested to by ex-agricultural worker KI(Larkan), are one of the lead causes in poor nutrition. As $\mathrm{KI}$ (Thaman) points out "the classic thing that is considered to be the worst food for anybody in the world is tinned corned beef and tinned mutton ...they range from nutritionally low quality to nutritionally disastrous quality”. In addition, while New Zealand may have stopped exporting mutton flaps, this does not mean mutton flaps coming from New Zealand are not for sale. Sheep carcasses are exported from New Zealand which can then be cut and sold in Fiji (Appendix F). So, while New Zealand may have decreased the export of nutritionally deficient products, it still has a hand in their placement on the market, and receiving revenue for it.

Although discussion of New Zealand undermining health in the Pacific has typically focused on meat, other products which are exported are questionable in regards to its support of nutrition. Butter is an example of this. Butter is among the top six food commodities exported by New Zealand to Fiji; in 2010 it represented NZ\$11,250,000, and 10.8 percent of food exports $^{25}$. Consumed in small quantities, along with a balanced diet, it need not be disease inducing. However, there are few if any arguments for this item as contributing to positive nutrition. In addition, it is typically high in salt and fat. Another example which could fall into this category is milk. In 2010 fresh and powdered milk combined represented NZ\$15,854,000 and 15 percent of New Zealand food exports to Fiji. While a source of protein, and calcium, milk can also contain a significant amount of fat. Dairy and meat are further associated with the nutrition transition which has seen rising rates of obesity and non-communicable diseases (NCDs) in parts of the developing world (Cassels, 2006). Over-consumption of fat is a key

\footnotetext{
${ }^{25}$ See table 2
} 
contributor to obesity and NCDs, an increasing problem in Fiji, and one of the greatest manifestations of food insecurity in Fiji. Additionally, Fiji does not have a problem sourcing protein and calcium locally. As discussed in chapter five, traditional foods provide essential vitamins and minerals and have done for millennia, further doing so without negative impacts on health (Thaman, 1990, 2005). Milk and sheep meat are two products that were given by informants as examples of New Zealand 'filling a gap' above. However, there is little evidence that these products are supporting a nutritional gap and thus supporting food security, but are likely contributing negatively to nutrition.

\section{Case 2 - items which detract from more nutritional alternatives}

Few could argue against the notion that by providing vegetables this is supportive of nutrition in Fiji. An exception to this is where the presence of those vegetables is drawing away from consumption of healthier, previously consumed options. New Zealand exports a wide range of vegetables to Fiji, although these consist primarily of potatoes, onions, carrots and garlic (Appendix E). Potatoes and onions are among the top six food commodities and top twenty commodities overall exported to Fiji (Statistics New Zealand, 2010). According to KI(Kumar) from the Consumer Council of Fiji there has been a shift away from the traditional staple dalo towards potato. If one compares potatoes against the traditional staple dalo, it is less nutritional, as stated by KI(Moore) "potatoes might not be as healthy as dalo, dalo has got more fibres". Therefore, the move to consumption of potatoes away from dalo, it can be argued, is detracting from the health of Fijians. Other such examples include cereals, which are a key component of diets in Fiji, overtaking root crops as the primary staple, although New Zealand is not the lead exporter on this count. While New Zealand may be exporting items of quality, and of nutritional value, that does not necessarily mean that it is supporting food security, as the presence of those items can arguably be undermining health.

\section{Best and most nutritious foods out of reach of most}

A key element of food security is access: physical, social and economic. A common argument for trade is increased availability to a wider variety of products. A key argument in support of trade liberalisation is the provision of these goods at a lower cost to consumers. This point was made in the case of New Zealand exports to Fiji by KI(1): 
"If New Zealand has the economies of scale, produces at lower cost per unit and it comes into the Fijian market the consumers will obviously benefit because they pay a lower price and consumers can access high quality good products at a cheaper price".

However, the reality for most Fijians is that exports from New Zealand that would contribute to positive nutrition are out of reach. This is the case with many vegetables: As KI(Thaman) states "New Zealand, most of the vegetables they send us are probably too expensive for the low income to buy". With poverty levels estimated between 30 and 50 percent (ADB, 2006), and wages low, 'the low income' represents a considerable proportion of the population. The same point is made of other items which New Zealand exports, those with the highest nutritional value or conversely, the least detrimental elements, such as fat. This point was represented by $\mathrm{KI}($ Yabaki):

"New Zealand may ship some of their best meat cuts but it is only for the very rich people who can afford those things, but for the rest of us who are poor, we have no choice but to buy the cheap meat".

The statements given here reflect a key element of food security, that of access. If the majority of Fijians are not consuming them, who then are they going to, or put in another way, who are they being exported for? From interviews it was evident that exports from New Zealand go to two different groups. The high quality food typically goes the tourism industry and the more affluent minority, while the products of lower nutritional value, and which regular consumption of leads to poor health, are purchased and consumed by the majority of the population in Fiji. KI(Larkan) expresses this point:

"you [New Zealand] are the suppliers of our mutton but it goes for two consumptions it goes to general consumption and the tourist industry so people in the industry like the tourists they import the A+ but for the general populous we are a price market, if the price is cheap and you sell stones and call it prime lamb people buy it"

While there may be an argument for New Zealand to export these items, it is not in the context of food security. It is important that the situation whereby the best foods New Zealand sends, those that would support nutrition and health and go to a small few, not obscure the fact that the greater proportion of exports which go to the majority of the local population 
remain questionable in their quality, and rather than supporting, only contribute to deterioration of health and food security.

\section{New Zealand low quality exports - Better than the alternative?}

A point raised in the research process in defence of New Zealand exports which have dubious nutritional value was that they are providing access to food to individuals who may otherwise go hungry. It was conceded that food may not be of the highest nutritional value, but none the less provides calories and protein at low cost. Potentially, as a short term solution this may have value if simply preventing hunger or starvation was the goal. Interviews do point to people purchasing imported items as a more affordable option (see chapter five). However, Fiji does not have a calorific problem, or a protein problem. Further, if, as established above, the foods being consumed are not good for health, then that is in fact detracting from food security by encouraging people to eat poorer foods. If the end goal is food security, which includes good health as part of its definition, then supplying cheap foods which do not promote this, seems to go against this objective.

The point that New Zealand is not the only exporter of foods of questionable quality to Fiji was also raised during the course of research. It was suggested that were New Zealand not to export these products, the demand would simply be filled in other ways, and that in some instances, these foods might be of more dubious quality. In the current trade climate this is indeed a very real likelihood. Based on this, it has been argued that it is better for New Zealand to continue to supply these products. The perception that New Zealand was a preferred choice in providing food was held by many participants also. The following quotes reflect this view: "I guess New Zealand food is certainly better than Indonesian on one side" $\mathrm{KI}($ Moore); "because if not New Zealand, China would bring worse food than what New Zealand is bringing, at least from New Zealand we know what goes in the bags is carefully watched" KI(Roberts). However, what this says is simply that New Zealand is the least worst option, not that it is supporting food security. By following this path, New Zealand is establishing itself as simply another country which provides availability of processed foods and high fat foods, with which links to obesity and non-communicable diseases is well established. 


\subsection{INDIRECT IMPACTS OF NEW ZEALAND TRADE ON FOOD SECURITY IN FIJI}

Strong domestic production has been critical to the success of the Pacific in supporting availability of and access to nutritional food resulting in well-nourished populations. Despite experiencing a decline in recent decades due to a more urbanized population, a cash based economy, and changes in food sourcing which relies increasingly on supermarkets and imports (see chapter five), local production remains essential to Fiji in providing access to nutritional food for its population. It is the 'core' of the food system (FSP Working Group, 2010). Both the food itself and the income generated from production by smallholders and local production is critical to supporting livelihoods and food security in Fiji. As KI(Morgan) stated "many people lack cash-incomes to afford imports, and rely on localised food production for livelihoods, nutrition, and what small cash they do earn". Thus, where trade affects local production, it also has implications for food security.

\section{New Zealand exports changing local consumption}

Evidence from the research suggests New Zealand exports to Fiji have influenced consumption habits in Fiji and drawn away from local supply. KI(Thaman) commenting on links between New Zealand trade and Fijian food insecurity stated this: "maybe the responsibility is more in the breakdown of the traditional, not just in the ability to produce it, but that people are not motivated to buy the local food". Fijians are consuming more processed foods and foods with salt, fat and sugar, which is in contrast to the traditional diet: "things in the nutritious local diet were not highly refined foods so were vitamin rich" $\mathrm{KI}($ Thaman). Meat is one example of a product which did not feature highly in the traditional diet which was supportive of nutrition in Fiji. KI(Thaman) explains: "the traditional diet was mainly root crops, not a lot of fatty meats, ... so there's been a real change in the modern diet”. Meat is also a product which New Zealand exports considerable amounts of to Fiji; more than NZ\$22 million in 2010.

Dairy is another example of New Zealand exports changing local consumption in Fiji. As $\mathrm{KI}($ Thaman) notes "in the long run [dairy products] are not something that they are used to... Pacific Islanders have historically suffered from lactose intolerance". The introduction of milk powder also saw a decline in breast-feeding in the Pacific, which is directly linked to nutrition in infants (Thaman, 1984). The suitability of some of the products that increasingly 
make up the diet of many Pacific Islanders thus ought to be questioned. The introduction of dairy, meat - and in particular meat high in fat, and processed foods has shifted consumption habits and by creating demand has created a gap which may be better suited to the economic needs of New Zealand than the health needs of Fiji.

\section{Imports displacing local production}

Through the process of changing consumption habits production of local crops have been displaced. KI(Kumar) stated:

"because more imports are coming in and these imports are more convenient and can be stored longer, so it has an implication on local production and on people's choice, potatoes are cheap, easily available, have longer storage as compared to dalo so more and more people are not going into dalo"

While New Zealand exports to Fiji are often supported by the argument that the foods in question cannot always be produced in Fiji, and consequently are arguably filling a gap in the market, the reality is that foods need not be the same to displace local production, as is evident by this last quote. As the introduced items may also comparatively provide less nutrient value than the traditional staple, as with dalo, the impact of imported foods on the market is twofold. It can lead to both a decline in consumption of nutritional foods as well as decline in availability of nutritional foods. Some Pacific informants were of the view that Fiji could supply a lot more of the nutritious traditional staples but because of the change in consumption away from these products, in part driven by the competition from imports, production was inhibited. KI(Thaman) stated:

"I think it [Fiji] certainly does have enough to produce good nutritional food for its people but given the increasing level of poverty and available incomes for a lot of urban people they may not be able to afford the high quality root crops and locally grown rice... some of these vegetables, for example carrots, ... these are nutritious crops that we can't really grow... so the answer is no, I don't think we can produce enough good nutritional food for low income families and some of the things that people have developed a taste for that are nutritional" 


\section{Fiji unable to compete with imports}

Production takes many forms in Fiji, but only in a few cases are the producers in a position to compete in an international market. The majority of producers are small holders. An example of this is the dairy industry which $\mathrm{KI}($ Seniloli) Rewa Dairy CEO describes .

"85 percent of farmers are small holders...they are still milking in cans some of them... altogether farm numbers are around 250, altogether about 28 are bulk suppliers, they are similar to New Zealand where they have their own milk machine and vats but the others are all very, we call them small dairy holders, where they hand milk the cows and it goes in to cans and then we have utes going around picking up the cans and they bring it to a central location"

The reality of agriculture in Fiji is that it is for the most part disadvantaged in terms of modern technologies of efficiency. Investment in agriculture has been limited. Fiji is also limited by its remoteness and lack of economies of scale. New Zealand, on the other hand, over time has developed a strong, globally competitive agricultural industry, which utilises advanced technology and a comparatively larger economy of scale. The New Zealand agricultural industry has developed through preferential markets, support from the state and high inputs of cash into development (Gow, 2007). All of this makes it very difficult for local industries in Fiji to compete with imports. Imports may be cheaper and of a higher standard due to improved technological development in New Zealand. While this may benefit consumers, the same does not necessarily ring true for producers.

Traditional crops or introduced, the reality for most agricultural industries in Fiji is that they cannot compete with New Zealand industries. Interviews found both dairy and meat have struggled in the face of exports from New Zealand. In the case of meat, KI(Larkan) states "when you are sending this mutton then it impacts on our pricing structure ....we have to keep close to your price otherwise we can't sell ours". According to KI(Namoce) the local milk industry has "died because of imports".

Initial pains such as this are typically defended simply as a 'period of adjustment'. However, as Connell (2007, p. 10) states "it is improbable that island states will ever be able to compete effectively with larger states in free market conditions". Ex-agricultural worker and smallholder farmer KI(Larkan) supports this view for Fiji. In regards to trade with New Zealand, he 
states: "your efficiency is too mammoth to compete". The necessary conditions of a level playing field and a comparative advantage that could compete on an international scale are not clear in Fiji. KI(5) elaborates:

"there just isn't the same commercial development of agriculture to be able to take advantage of opportunities, there isn't the scale that makes for comparative advantage, so often the Pacific just isn't in the space to be able to capitalise on those opportunities and certainly not in ways that are there for the majority of people...you do get individual farmers that can ...but the majority ...there haven't been many success stories in the Pacific"

Producers in Fiji are struggling to establish themselves in the presence of New Zealand competition. At the same time, Fiji faces great challenges in exporting their goods to New Zealand. KI(1) describes barriers to Fiji exports:

"I think the level of trading between New Zealand and Fiji and other Pacific countries is unequal and one of the reasons is New Zealand tries to impose protectionist measures largely against agricultural producers from Fiji and Pacific Island countries. They have stringent controls at the border in terms of meeting foods, quarantine, fumigation...they'll set high standards and that tends to reduce imports from other countries.. Fiji cannot afford it, it's a small country, it doesn't have the capacity...so once you set very high standards you basically wipe out some of those importers"

While there are good reasons for New Zealand to maintain protection measures against biosecurity hazards, it nonetheless presents a challenge to Fiji producers. At the same time, New Zealand is well able to export to Fiji, and this reality means that local producers find it much more difficult to compete and survive. A question of motive was also raised by the informant, who stated "[one way to] minimise its imports by imposing all sort of legislation...there are a lot of countries that are using excuses to stop imports" KI(1).

Decline in supply of local production to the market and increased reliance on imported products has lead Fiji into a state of food dependency. The threat associated with food dependence was described by McKee in 1975, and were seen in the last food crisis, with sharp rises in food costs. New Zealand's relationship in dairy with Fiji illustrates the vulnerability 
associated with dependence. In the most recent food crisis, obtaining dairy, which Fiji has become reliant on with the decline of the local industry, was an issue for Fiji. As KI(Seniloli) stated "We are a small buyer in the market so availability became an issue". This point affirms the importance of local production in times of global volatility in food prices. As $\mathrm{KI}($ Morgan) states "local food production is especially important in the context of fluctuating international prices for food staples".

\section{The contribution of Fijian exports and export-led development to food insecurity}

Up to this point, the discussion has centred around the importation of products into Fiji from New Zealand and the impact that has on food security in the country. However, importing products is not the only way in which trade can affect access to nutritional food. Exportation of products, without ensuring sufficient availability of equally nutritional, equally accessible products also diminishes food security. The introduction of commercial production and the effect that has had on Fijian food consumption and production was discussed in Chapter five. It established that the mode of production has been a contributing factor in a decline in food security. Presently, the export system that has developed continues to contribute to food insecurity in Fiji, through unsustainable practices and reducing local access to key nutritional products. On a daily basis, exportation of local resources is decreasing local food supply, taking away the best of local produce, and at the same time replacing it through imports with poorer quality foods. As KI(Halavatau) states:

"The issue of trade is really important because when you are generating foreign currency earnings from your own traditional food like what is going on in Taveuni, you are growing your taro and exporting your taro, in that sense what they are doing is sending the best taro to New Zealand for people, Pacific Islanders to eat and the poor taro is the one they are eating, and if they don't have leftover taro they start eating imported food, so in that way that is how trade also affects the contribution of domestic production in food security"

Globally export orientated production has impacted on the quality and sustainability of the environment (Murray, 2008) and this is also evident in the Pacific. Previously fertile land, and employment of sustainable practices where minimum input was required and quality of the natural resources was maintained, has experienced deterioration under systems which favour short term yield over long term sustainability. This has led, according to KI(Halavatau), to a 
'downward spiral of productivity'. Fallow periods, where plots are alternated to protect soil quality, are an example of this. Under pressure to earn money crops are often planted repeatedly in the same area leading to a decline in the quality of the soil, and subsequently less productive crops and less nutritious output. Inputs can be added to compensate, these are however not without their own set of consequences for future sustainability of the environment and long-term health effects. The importance of local natural resources to the economy and the people cannot be underestimated, a point which Thaman $(2009$, p. 888) comments on:

"for islands, their biodiversity and ethnobiodiversity constitute the most important natural and cultural capital, which must be managed as the living bank account and foundation for sustainability. Such diversity has been the foundation for "subsistence affluence" and self-reliance for millennia, a foundation that is now seriously threatened"

Exportation of domestic goods, thereby bringing in foreign currency, is a measure employed by countries to finance import costs and raise domestic revenue. However, it must be weighed against its impacts on local livelihoods, and health. Where it is in fact decreasing access to nutritional food, and in the process impacting on the health of the local population, decreasing local productivity and increasing the health burden on government and communities, then this relationship requires review. This point was made by $\mathrm{KI}($ Halavatau):

"trade ...has helped to generate income for the country but on the other side it does affect food security, relying on domestic production for export, so in a way you are sending your food to New Zealand and you're bringing from the other side flour and rice for the people, countries need to have a more balanced look at how they balance their trade"

\section{Trade environment contributing to food insecurity in Fiji}

The question over the objectives of trade was raised in the 2006 UNDP report 'Trade on Human Terms'. It stated that trade should not be a means in itself, but a means to an end, that of human development. Given that food security remains at threat, and the trade balance is not 
in favour of Fiji, one is forced to question what end, or perhaps whose end is trade meeting in this case?

The genesis of commercial production for domestic and international supply has its roots in the early period of colonisation. However, New Zealand continues to promote export-led development through its development assistance programme and in the PACER Plus negotiations underway. The imbalance in trade which makes exports necessary is also contributed to in part by New Zealand. Where there is a link between promotion of exports in an unsustainable manner, leading to a decline in present and future domestic access to the country's resources for the local population, and New Zealand is promoting this, then it would seem that in this way, too, whether knowingly or not, New Zealand is contributing to an environment in which food security is undermined.

Increasing exports from Fiji is one solution to an imbalance in trade and increasing domestic revenue, ultimately ensuring better security for its people, but there are other options. Reducing reliance on imports is one such example. Local production and supply is a key factor in being able to achieve this. As KI(1) states "it's a basic market issue, if you are able to supply your own market and the more you supply the less you will import because you can meet domestic demand". The consequence of not being able to supply its population with domestically produced food has led to a decline in health and decline in livelihoods through a decline in local production. The existence of imported foods on the market in Fiji, of which New Zealand exports represents a quarter, has at least to some extent, contributed to that result.

Trade must be balanced against the impacts it has on local needs and this requires a framework that is aware of and accounts for all the impacts of trade, and does not rely on economic rhetoric alone. As $\mathrm{KI}($ Halavatau) states:

\section{"definitely trade is having an impact so it's a matter of how to strategise so that you make money from your own domestic production but you are not threatening your own food security”.}

This is the challenge facing Fiji, and many of the Pacific Islands. In recognition of the vulnerable position in which it sits, Fiji has been making attempts to increase production and consumption of local and traditional foods (see Plate 3). KI(1) explains: 
"with the food crisis and global crisis...the [Fijian] government took the initiative to produce more food and therefore it's moving into import substitution of food products. There's a lot of emphasis on domestic production of food and allowing domestic producers to supply the domestic market as well as the hotels and tourism sector...if there are more and more domestically produced food products ... the domestic supply will increase and therefore Fiji will have to reduce its imports from New Zealand...it won't happen overnight but over time it will, domestic production will increase"

\section{Plate 3: Advertisement for Fiji's 'Go Local' movement encouraging production and consumption of local produce}

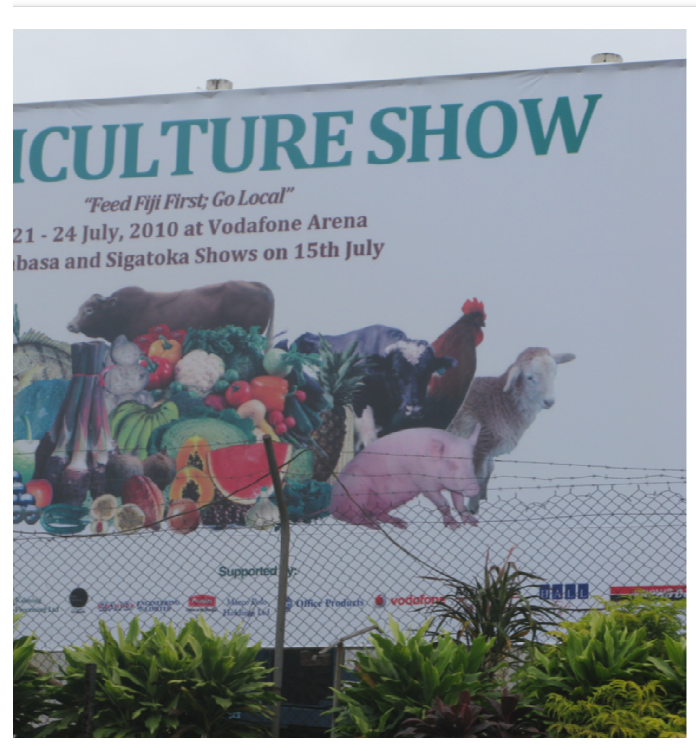

Photograph by Laura Barrett

A question that remains is whether this will be supported by the New Zealand government. Under extraterritorial application of the right to adequate food the New Zealand government has an obligation to ensure that its policies do not interfere with the right to food in other countries $^{26}$. One barrier to this is the trade framework within which New Zealand works. As one measure to boost local production Fiji has employed import substitution. However, this runs counter to free trade principles as stipulated by the WTO and supported by the New

\footnotetext{
${ }^{26}$ See chapter 3 for discussion
} 
Zealand government. Fiji, in the past, has also placed restrictions on imports by banning mutton flaps from New Zealand due to the associated health risks, a move that was met with opposition from New Zealand (Fiji Government, 2001). It remains that other meat of low quality continues to come in. So a further aspect that must be considered is the way in which the New Zealand government approaches trade, and the framework it employs to do so, as this will have a role in determining to what extent New Zealand is supportive of food security in Fiji, or contributing to poor health outcomes. This point will be explored more in the subsequent chapter, but based on interviews there are some key points worth noting at this point.

\section{Food insecurity likely to be exacerbated under PACER Plus}

As was discussed in Chapter six, the trade environment between Fiji and New Zealand is set to change with the PACER Plus negotiations underway. What the agreement will entail is still unclear. However, there are strong concerns over potential impacts on food security if a free trade agreement were to be established. What are these concerns based on?

One concern is the loss of employment and income resulting from manufacturing closures, predicted to occur with PACER Plus, which could equal three quarters of Pacific manufacturing and thousands of job losses (Institute for International Trade, 2008, p. 85), consequently impacting people's access to food. As discussed above, the Pacific Islands lack comparative advantage and economies of scale and there is potential for the agreement to further adversely affect local industries. KI(1) stated:

"The issue is very clear, the larger countries, the larger suppliers, the efficient suppliers they are going to benefit .... all the Pacific Islands countries are developing countries, they are less advanced so the advantage will always be to the advanced economies because they have the competitive advantage".

Further on this point KI(Seniloli), CEO of Rewa Dairy stated:"“free trade will really, can kill the industry here....with the economy of scale, it's in favour of New Zealand...it has already happened here in terms of rice". 
A further area of concern is the removal of restrictions to trade and the impact this will have on Fijian producers. KI(1) explains:

“now there's restrictions... free trade means free, there's no barriers to trade, you cannot impose quotas, taxes... when free trade comes in the government will not be able to intervene as the government is intervening now to support local industries" ... so then New Zealand producers will come in in large numbers and they will supply the entire market and the domestic dairy industry will face a lot of problems..."

A further issue with the removal of tariffs on imports is where revenue lost in the process will come from. Due to limited income tax, Fiji, like many other Pacific countries, is dependent on revenue from trade taxes. In 2007 trade taxes formed 26 percent of total government revenue (Feeney, 2010). A common way to recoup this is through value added tax (VAT) on goods (PANG, 2009). The case is often made that food will become cheaper for consumers as imports come in. However, this will not necessarily occur given the need for governments to seek to recoup the loss of revenue from imports, negating any benefits of tariff reductions negligible for consumers and affecting affordable access to nutritional food. KI(Morgan) explains:

"it is not at all clear that lowered tariffs will lead to reduced prices for food for consumers in the Pacific...PICs need to collect government revenue from somewhere. Shifting the tax burden from tariffs to value added taxes (VAT), or raising taxes, is unlikely to lead to net reductions in prices, it'll just shift the tax burden to Pacific peoples...[and]...in PICs often competition is poor and an oligarchy of importers control prices. Hence tariff reductions may be captured by a few and not passed on to consumers"

The outcome of this will see producers and exporters in other countries reap the benefits while there is little if any gain for local consumers. Is it thus neither evident that removal of tariffs is in the interests of the Fijian people, or what they want, as KI(Moore) stated:

"we need tax our government needs tax in order to pay for our health and housing and schooling and we actually want that ... our government needs to be able to get tax off food and imports so it doesn't work for a developing country to have tax cuts" 
According to the Pacific Network on Globalisation (2009), a free-trade agreement if created is likely to create even greater reliance on food imports. Given the links described here between imported foods, health, and local livelihoods, the coming negotiations must be treated with extreme caution. It is unclear at this stage whether parties to PACER Plus will be able to maintain government support to industries but if not, there will undoubtedly be impacts on the local agricultural industry. The New Zealand government has indicated that PACER Plus will not be a typical trade agreement, but it is not clear what this means at present. Given that New Zealand must comply with WTO rules it is likely to be closer to a free trade policy than not. The agreement under negotiation has potential to support food insecurity and this will depend largely on New Zealand's ability to account for the imbalance in trade, and the impacts New Zealand trade has on domestic industries, production, and health outcomes.

\subsection{A LEGAL AND MORAL OBLIGATION FOR NEW ZEALAND TO ADDRESS ITS ROLE IN FOOD INSECURITY IN FIJI}

The preceding sections have drawn links between aspects associated with food insecurity in Fiji and trade with New Zealand. This research does not suggest that New Zealand is the cause of food insecurity in Fiji. There are multiple factors at play. Further as one informant pointed out: "it's not that New Zealand is directly responsible because it seems to be an urban highly refined diet that seems to the main causative factor of nutrition in the Pacific" $\mathrm{KI}($ Thaman). Arguably, eating foods high in fat, salt or sugar, in small quantities, and as part of an otherwise nutritional diet need not be detrimental to health. Thus, there is an aspect of individual responsibility to be upheld. Participants from Fiji reiterated this element of individual responsibility. KI(Larkan) stated:

“you'll only send us what we want you won't send us B grade if we ask for A, because we are asking for this cheap quality that's what you are sending us that's what we are able to afford ...if it's not good for our diet that's our fault because we have ordered it....nobody is forcing us to buy it"

In addition, where products are deemed to be a having an unacceptable impact on society, certainly the government of the nation in question must take primary responsibility to put in prohibitive or preventive measures. This point was supported by KI(Kumar): 
"In terms of responsibility I am sure the responsibility lies with the government of the day here in Fiji because the government needs to make sure that they stipulate the quality standards and also the border control"

Indeed, within human rights law there are clear obligations for a state in respect of its citizens. However, this does not preclude a role for the New Zealand government. As Ziegler (2006, p. 8) states "The primary responsibility always rests with national Governments. However, all other Governments have a responsibility to refrain from taking action that cause food insecurity".

There are both moral and legal arguments for New Zealand to address its role in food insecurity in Fiji. Firstly, placing the full onus on local solutions ignore some key realities. One is that the Fijian government has limited resources and capacities and is not able at present to monitor quality and provide border control. As KI(Kumar) from the Consumer Council of Fiji stated "there is no border control, because there is no quality standards, anything and everything comes in". Secondly, consumers' choice in Fiji is constrained by availability and income. KI(HLarkan) makes this point: "we only ask for it because that's what our consumers can pay ... Fijian consumers we don't have high disposable income so you are just matching our demand". Thus, there are elements that are out of control of the Fijian population. There are also elements in which New Zealand does have choice and with this a degree of individual responsibility. KI(Yabaki) stated:

"with trade it really depends on what New Zealand decides to give to us, if they give us third or fourth grade meat, and its cheap for us here, we buy that, so that is one which trade will affect our diet or our nutritional level"

Indications from research suggest that there is an element evident in which this position of lack of choice for Fijians, and inadequate regulation of exports from New Zealand is taken advantage of in some cases. New Zealand exporters have been associated with dumping of products which would not be accepted by wealthier countries. $\mathrm{KI}(5)$ stated: "we've sometimes sent exports there that we would find difficult to send elsewhere". Interviews suggested that sub-standard products are being sent to the Pacific as it is viewed by some New Zealand manufacturers as a permissive market. KI(Matheson) explained: "some manufacturers view the Pacific as a soft touch so they send the low quality products to the Pacific cause they can get a price for it". The 'Pacific cut' as it has come to be known represents a situation, whereby 
a country sends its best cuts to wealthier countries and poorer cuts to poorer countries. As $\mathrm{KI}(1)$ stated "the third grade meat will always go to the third world country".

Perhaps ironically, it was clear from interviews that a great amount of faith and trust is held in the quality of New Zealand products and the intentions of New Zealand exporters, as is evident by the following statement by KI(Yabaki):

"I think that they export food that is genuine, that will be good for Pacific Islanders ...there is no question about us questioning New Zealand about the genuineness that is in there in the food imports to Fiji”.

It is also this belief in New Zealand integrity that contributes to the strong hold New Zealand maintains in the Fijian market, in spite of increased imports from other countries in recent years: "I think New Zealand products have gained quite a bit of loyalty and trust from Fijians. That's why they have gained a hold on the market..." KI(Namoce). Thus, there is an association between New Zealand products and 'quality' leading consumers to choose New Zealand products. This research questions whether this degree of faith in New Zealand is warranted.

The situation whereby poor quality foods are exported to poor countries highlights the inequality between individuals within and across country lines. They also display an element in which New Zealand has a degree of choice over the decision to export certain foods, and a lack of choice for consumers in Fiji, due to restricted incomes and availability of affordable nutritional foods. Further, it points to the wider structure of inequality globally which means poor people, especially those in poor countries, are not able to access basic rights such as sufficient food to prevent disease and maintain an active, healthy and productive life.

There is globally an environment of inequality and New Zealand is complicit in this. The environment that has been created in part by New Zealand government and business actions contributes to food insecurity. Egger and Swinburn (1997) have suggested a paradigm shift in the way obesity is viewed, from one where the pathology lies with individuals to one where obesity is "normal physiology within a pathological environment". The New Zealand government is supporting an environment conducive to food insecurity (and at the same time paying for it in aid). As Crocombe states "creating artificial demands for unnecessary goods and services, irrespective of their use or value, makes people worse off" (Bellam, 1980, p. 
24). The environment that is leading to over-nutrition in the Pacific, is one in which New Zealand contributes through exporting items that contribute to obesity and poor health, and at the same time supporting the exportation of local produce, through supporting export led models of development, and also receiving those goods, which takes away from local availability of nutritious foods.

Based on the above it can be argued that the New Zealand government has a degree of responsibility to account for its actions in contributing to food insecurity in Fiji on a number of counts. There is indeed a moral argument for addressing the trade-food security relationship. Peter Singer, a prominent ethicist argues "if it is within our power to prevent something from happening without thereby sacrificing anything of comparable moral importance we ought, morally, to do it" (Singer, 1972, p. 231). The point that New Zealand has an element of social responsibility was supported by KI(Kumar) who stated:

"The New Zealand exporters are doing, legally, nothing wrong, but, from a social responsibility point of view I believe the New Zealand government can stand up because after all we are one big community that lives in the Pacific Ocean”.

The World Trade Organization is the primary governing body in international trade matters. Under the WTO, the actions of New Zealand as described in this chapter are permissible. However there is another framework which ultimately takes precedence over the WTO framework and that is the Universal Declaration of Human Rights. This framework protects individual rights including the basic right to adequate food. The rights protected under the declaration are enshrined in international law. The right to adequate food and the extraterritorial obligations associated with this further provide the basis for the New Zealand government to address New Zealand's role in food security concerns in Fiji. New Zealand has an obligation to respect individuals' rights to access to nutritional food and to protect them also from third parties who may also be undermining this right. Although in its infancy, extraterritorial application of human rights is gaining strength, and with the challenges presented by globalisation, will likely become only more important.

Although this research does not wish to draw too heavily on this point, as it is not the motivation from which it stems, nonetheless from a self-interested point of view, an economic argument could also be made for New Zealand taking greater action on its role through trade to ensure that it is not contributing to food insecurity in the Pacific. New Zealand contributed 
around six and a half million dollars in aid to Fiji in the 2009/2010 calendar year (NZAID, 2010) and one of the keys areas New Zealand aid is directed towards is reducing noncommunicable diseases. In the words of one participant KI(Matheson) "if food is killing people it is not in our interests". This argument loses some strength, however, when one takes into account the amount received from trade with Fiji, with food exports equating to around NZ\$104 million in 2010.

\subsection{CONCLUSION}

The relationship between New Zealand trade and food security in Fiji is complex. Trade with New Zealand unequivocally has some benefits. However, this needs to be reflected upon in terms of the impact of trade holistically. This chapter has found that there are aspects of the relationship which at best are not conducive to a food secure Fiji, and at worst are actively undermining the health, nutrition, and livelihoods of people in Fiji. In particular, some of the primary commodities exported from New Zealand are considered widely to be detrimental to health. Further, some products exported are undermining local consumption choices and local production, thus contributing to food insecurity in Fiji by affecting local access to nutritional food. Given this, it is essential to consider carefully how trade proceeds from here on. There will need to be careful balance between trade and local food production. How New Zealand acts and whether or not the manner in which they trade supports Fiji and other Pacific Islands to achieve this balance is critical to food security. It is not clear that New Zealand at present is doing this. Importantly, too, with the present renegotiation of trade relations through PACER Plus there is potential for supporting food security in the Pacific Islands through trade. This will in part be determined by the approach the New Zealand government takes in negotiations. For trade to be undertaken in a way that does not undermine food security in Fiji, food security concerns must be taken into account in the development of New Zealand policy. An important lever in the realisation of food access is the right to adequate food. What is New Zealand's policy on food security and the right to food? How is this accounted for in trade policy? These questions are critical if New Zealand is to affect its position so as to ensure best practice in supporting food security in Fiji. These will be reviewed in the subsequent chapter. 


\title{
Chapter 8: The New Zealand Government's Approach to Food Security \& the Right to Food
}

\author{
"When it comes to policy-making, and especially to international policy making, the \\ consequences of action are not clearly defined, nor are the relationships between actions and \\ consequences well understood" \\ (Tutwiler \& Straub, 2007, p. 237)
}

\subsection{INTRODUCTION}

One of the key messages from State of Food Insecurity in the World (FAO, 2009) was that food security will not be achieved by following the present path and a new approach is needed, one in which the right to food plays a vital role. This is not just a matter for food insecure states alone. With increased global interconnectedness, the right to food is increasingly being understood to carry extraterritorial obligations; all states have an obligation to ensure that acts taken by those within their jurisdiction do not undermine the fundamental rights of those in other parts of the world. Both trade policy and transnational corporate activity have been highlighted as areas in which this is especially important. On this basis, this chapter reviews the New Zealand government's approach to food security and the right to food. In doing so it aims to assess the extent to which the New Zealand government takes right to food and food security concerns into account in the development of international policy, and the extent to which extraterritorial impacts of territorial actions are accounted for. Finally, barriers for international trade policy to take into account Pacific food security and right to food concerns are considered. The chapter begins by analysing government documents and statements on the right to food and food security. Following this, the degree to which the policy positions identified are applied in practice are discussed, based on findings from interviews. Finally, some conclusions are drawn.

\subsection{FOOD SECURITY AND THE RIGHT TO FOOD IN GOVERNMENT POLICY}

New Zealand's Pacific trade policy was discussed in chapter six. Building on this, this chapter focuses on New Zealand trade policy in regards to the manner in which the right to food and food security are included within this. Inclusion of food security and right to food concerns is closely linked to their treatment more broadly within the New Zealand government, and in 
particular those teams responsible for advocating those positions. On this basis, the approach taken by the International Development Group and the Human Rights and Commonwealth division is also referred to.

\section{Committed globally to the right to food and addressing food security concerns}

The state of New Zealand has accepted the right to adequate food as a basic human right. New Zealand is party to both the Universal Declaration of Human Rights (1946) as well as a party to the International Covenant on Economic, Social and Cultural Rights (1966). Both instruments enshrine the right to adequate food and by virtue of being signatories to these New Zealand's obligation to support this right is firmly established. New Zealand has also displayed its commitment to the right to adequate food through its support of the 1996 Rome Declaration on World Food Security and the 2000 Millennium Declaration, both of which recognise the importance of the right to adequate food. Reaffirming its commitment, in a statement in November 2008 New Zealand stated "As a State Party to ICESCR since 1976, New Zealand is fully committed to the progressive realization of economic, social and cultural rights" (MFAT, 2009b, para.1). These rights entail the right to adequate food.

\section{Recognises obligations associated with the right to food but in an extraterritorial context?}

Of key importance is how are these obligations are interpreted. Further insight into New Zealand's position on the right to food can be drawn from a recent brief developed by the Ministry of Foreign Affairs and Trade (MFAT). Updated in 2010, this brief represents the most current position at the time of writing this thesis. For the purposes of this research four points are worth highlighting. First, the brief states "it is important that states create an enabling environment where everyone can enjoy the right to food as a priority". The brief further states that "the state must respect and protect the rights of individuals to feed themselves" (MFAT, 2010b, p. 2). These positions are consistent with international positioning on the right to food. By restating these points, New Zealand displays an awareness of these as responsibilities in the right to food. Drawing attention to identification of an environment in which individuals can enjoy the right to food, and further that the state must both respect, but importantly protect this right, the obligation associated with this is that where third parties, for example, individuals or businesses, are undermining an environment in which the right to food can be realised, the government has identified that it has a duty to act. On this point, the brief emphasises that the right to food is progressively realisable. While 
this provision allows states time to work towards full realisation of the right to food, the corollary of this is that a state must be taking action within its ability on this right.

Unwillingness to do so does not constitute an inability to act (A. Eide, 2002). Where the state has an ability to act but does not do so, this constitutes a violation of the obligation to satisfy others' rights.

Critical to this research is the extent to which the New Zealand government recognises extraterritorial application of the right to adequate food. Where an environment in which individuals can enjoy the right to food is being undermined by New Zealand parties, what obligations does the New Zealand government view itself as having? There is no direct reference in the brief to extraterritorial obligations to protect against violations of the right to food. The brief does however refer to international aspects of the right to food. It states:

New Zealand is mindful of attempts by some States to broaden the nature and scope of provisions of Article 2(1) of ICESCR. In the context of the right to adequate food, there is only a requirement for States to pursue international cooperation if they have been unable, due to resource constraints, to provide access to food to those individuals or groups within their jurisdiction who have been unable to secure such access themselves. (Author's emphasis) (MFAT, 2010b, p. 1)

In Article 1 and Article 55 of the United Nations Charter it sets out as a primary goal the promotion of higher standards of living and universal respect for and observance of human rights (Eide, 2002). Given that developing states are often in a position of being unable to fulfil obligations to the full extent of the right to food, in accordance with the UN Charter Eide argues states have a shared responsibility to assist as is recognised indirectly in the statement above. This is true even where absence of the right to food is due to no action of the other state. However this can be seen as distinct from obligations for self-mediation. In addition to the above, Eide further points out in protecting the right to food states "should monitor the impact of their external aid and trade, as well as the impact of transnational corporations under their jurisdiction...and take correlative measures where a negative impact can be shown" (Eide, 2002, p. 44). There is little indication within the brief of the New Zealand government recognising itself as having an obligation to act to protect those outside its territory from acts taken within its own territory where those actions undermine the right to food. 


\section{Committed to addressing food security}

Turning to food security more broadly, at the time of writing, the New Zealand government was in the process of reviewing its policy position on food security and thus no formal document was available to comment on. Some conclusions can be drawn from other areas, however. New Zealand is on record as committing to "immediate action to address food security issues nationally and, where possible, regionally through a range of measures across key sectors such as agriculture, fisheries, trade and transport" through a statement made on the part of all Pacific Islands Forum leaders at the Pacific Food Summit in April 2010 (Pacific Islands Forum Secretariat, 2010, para. 2). Additionally, New Zealand displays a commitment to food security globally through the millions of dollars of financial support it provides to international projects working to achieve greater global food security, such as the World Food Programme.

\section{Food security and human rights identified as priorities in international development policy}

As the government department responsible for international development assistance, the International Development Group (IDG) provides a point of reference to identify New Zealand's approach to food security at an international level. At the time of writing, these policies were under review following the changes in 2009 to the mandate of IDG, formerly NZAID. Until replaced, however, they represent standing policy. In addition to these, shortly prior to thesis completion a further policy was published by the Ministry of Foreign Affairs and Trade. All three are discussed below.

A key policy providing insight into the New Zealand government's approach to food security and the right to food is the "Economic Growth and Livelihoods" policy (2008). This outlines operating principles for the International Development Group. The policy establishes the department as taking a rights-based approach, displaying a commitment to human rights, citing the United Nations Office of the High Commissioner for Human Rights (2006) which stated "economic growth must be achieved in a manner consistent with human rights" (NZAID, 2008, p. 19). The policy further establishes food security as both a key priority and development objective. Additionally, the policy cites fairer trade rules and "a vibrant and appropriately regulated public and private sector" as additional priorities (NZAID, 2008, pp. 9-10). Interestingly though, while pointing out the link between imported foods and high incidence of non-communicable diseases; the contribution of 'convenience foods' to 
decreased consumption of traditional, healthier food; and competition faced by local products from imports; a link between trade and food security is not made (NZAID, 2008, pp. 13,33). These objectives are referred to in separate, rather than integrated accounts.

Harnessing Trade for International Development (2003) is a second key document providing insight into New Zealand's approach to food security and right to food concerns, particularly the relationship with trade. The policy document provides additional support for the notion that the New Zealand government is aware of and is incorporating food security into policy development - citing food security as a serious and legitimate concern deserving of special attention in negotiation and development assistance (NZAID, 2003, p. 16). In regards to the right to food, the policy states as an operating principle that protecting and promoting human rights are 'integral' concerns in the development of trading systems. Yet, despite addressing trade governance, international trade obligations and human rights, these make no reference to the right to food or governance of New Zealand's trade relationship from the New Zealand side in relation to the Pacific.

In April 2011 the Ministry of Foreign Affairs and Trade released "International Development Policy Statement - Supporting Sustainable Development” which represents the Ministry’s overarching policy on international development assistance and engagement in international development issues. In line with the previous two policies, it identifies human rights principles as being a 'cross-cutting' and 'thematic issue'. It adds the Ministry "consider[s] the human rights implications of what we do" and in respect of aid initiatives this will be monitored "to ensure good development outcomes and to manage risks, including the risks of negative unintended impacts" (MFAT, 2011b, pp. 2, 9). Food security is referred to stating simply that it will be 'promoted'. Separately the policy identifies non-communicable diseases as an area for targeted intervention. Worth noting is that at the same time there is a clear and strong emphasis on (sustainable) economic growth as a core focus of the Ministry's approach to international development. Improved trade facilitation, increased and open trade, export-led development, and 'cutting red tape for businesses' are identified as components of this approach. While under certain conditions these have potential to support development, at the same time, without mediation, they can also prove detrimental to food security ${ }^{27}$. A point of concern with implications for food security is the policy's statement of alignment of aid and foreign and trade policy: "New Zealand's Official Development Assistance outcomes should

${ }^{27}$ See chapter seven 
be consistent with, and support, New Zealand's foreign policy and external relations outcomes" (MFAT, 2011b, p. 9). The implication from this statement is that international development measures should fit in line with foreign policy on trade. This runs in conflict with international application of the right to food, which commands review of trade and foreign policy in respect of the human right to adequate food, rather than the other way round.

It seems while the right to food is well supported at an international level by the New Zealand government, in practice it has yet to extend to application in its international policy. Food security on the other hand, at least until recently, appears to have been attributed a much larger prominence in policy. It is worth noting that the right to food, unlike food security, carries obligations. Whether food security will maintain the attention it has thus far been afforded when the formerly discussed policies are reviewed is doubtful if the latest policy is anything to go by.

\section{Food security and the right to food absent in trade policy}

Looking more at the food security and trade interface, it seems the approach by the New Zealand government to the role of trade in food security is unidirectional. Trade plays a central role in overseas development assistance aimed at reducing poverty and food insecurity. But to what extent are food security and right to food concerns evident in the development of New Zealand trade policy?

There is little to suggest the inclusion of either food security concerns or the right to food in New Zealand's Pacific trade agenda. At the commencement of PACER Plus negotiations in 2009 a cabinet paper presented to government by the Minister of Foreign Affairs and Trade and the Minister for Trade was devoid of any reference to either the right to adequate food or food security (MFAT, 2009a). The Ministry does, however, refer to the importance of agriculture to food security in developing countries (MFAT, 2011a). Additionally, reference was made to trade in the context of food security by the New Zealand government at the Special Meeting of the Economic and Social Council on the Global Food Crisis in 2008. There, New Zealand Permanent Representative to the United Nations H.E. Ms Rosemary Banks, speaking on behalf of New Zealand, stated: "Turning to trade, New Zealand sees both tariff reductions and continued reform of agricultural markets as essential elements of a long term solution [to global food insecurity]". The approach from New Zealand to global food security thus appears to be one of more and more liberal trade. It is, however, unclear that 
greater liberalisation is in the interests of Pacific Island countries, and on the contrary will likely be detrimental to the regions food security (PANG, 2009a). While there has been recognition from the government that the process of liberalisation for developing countries may take time (MFAT, 2011a) the implication of this is, however, that it is a matter of when, not if full liberalisation ought to occur. There appears little evidence of analysis of the impact of New Zealand's trade policy on the right to food in the Pacific, as is deemed by experts both necessary and critical to the realisation of this right (A. Eide, 2002; Ziegler, 2009).

\subsection{FOOD SECURITY AND THE RIGHT TO FOOD IN PRACTICE}

Recent changes in the direction of New Zealand development assistance means key policies relating to food security, aid delivery and trade policies are yet to be formally determined. As such, interviews with key informants with knowledge of New Zealand government affairs provided an important avenue in obtaining greater clarity on the inclusion of food security and the right to food in the development of international policy and application thereof. Through the interviews, a number of key points came to light. In sum, there is an awareness of challenges in food insecurity for the Pacific, however, these are not, in practice, prioritised as a matter of New Zealand government policy in trade or international development assistance. Given the sensitive nature of the topic, individual informants and their roles are not always identified, as to do so would place them in a vulnerable position. In accepting these findings, the researcher thus relies on the reader to have faith in the process of research and in the researcher conducting $\mathrm{it}^{28}$.

\section{New Zealand's role in food security raised indirectly by Pacific Island nations}

To address a problem, one must first be aware that a problem exists. The point was made that food security has not been raised by Pacific Islands in trade discussions: "Food security hasn't been raised with us in terms of our trade policy and PACER Plus...if they raised it absolutely we would have to talk about it" $\mathrm{KI}(2)$. However, that food security is a key issue for the Pacific was known across informants. Although not necessarily raised in food security terms, concerns that have food security implications have been raised by Pacific Island nations with MFAT.

\footnotetext{
${ }^{28}$ See chapter two for elaboration on this point
} 
"it's often framed in terms of economic development, they want to sometimes increase domestic food supply sometimes... or they want to increase incomes of farmers, or they want to increase exports so there's different streams in there that all have food security implications negative or positive” KI(4)

Interviews conveyed an awareness within the Ministry of challenges for Pacific Island countries in agriculture and trade which have links to food insecurity. Additionally, there was awareness displayed of aspects of New Zealand exports and trade policy which are having negative impacts in the Pacific Islands. These included the export of poor quality products and the competition for domestic producers from New Zealand imports, two key factors that were identified in chapter seven as undermining access to nutritional food for people in Fiji.

A key way in which New Zealand can be seen to interact negatively with food security in Fiji is through the export of products with little to no, or negative nutritional value. This was seen particularly in the quality of meat New Zealand exports to the Pacific. Interviews established that quality concerns over the exports of New Zealand meat are widely acknowledged across different sections of the Ministry. The following quotes came from three separate sections of the Ministry:

"there have been some concerns about our trade in sheep meat to the Pacific so we are certainly not blind to that" KI(2)

"Export of lamb flaps to the Pacific is an issue that several Pacific countries at times have expressed concerns about and some people have said why doesn't New Zealand do something to stop these lamb flaps being exported" KI(3)

"this has been a subject of discussion and debate for quite a while and there isn't really an easy answer to that problem" KI(McBryde).

A further area in which New Zealand trade can undermine food security in Fiji is through the displacement of local industries. Competition faced by local producers in the Pacific from New Zealand exports was also acknowledged by an informant within the Ministry:

"a lot of the local industries aren't that developed and I suppose there is a case of we are exporting something and it arguably does take away from a local producer but that is certainly something that has been raised with us in PACER Plus talks about 
certain provisions around protecting local industries ....we are certainly aware of it, and its an issue that Pacific Island countries have raised with us" KI(2)

From the above it is evident that the Ministry is both aware of concerns which are related to food security, and further that these concerns have been raised by Pacific Island nations. That concerns have not been raised under the banner of food security, should not preclude them being seen as issues of food security, and hence being so addressed.

\section{Food security not prioritised}

Ultimately, indications are that while the government asserts food security is a priority, it does not in practice prioritise food security. As was stated by $\mathrm{KI}(4)$ "where we are in terms of this government and the priorities, the lens that is being used, the way things have been framed is not in the food security way". As evidence of this, it was reported by one informant that while food security is 'considered' in country strategies for development assistance, it was acknowledged that a food security analysis is not undertaken:

[The ministry] "do[es]n't specifically do a food security analysis as part of joint commitments for development process" $K I\left({ }^{*}\right)^{29}$ and further that in regards to operational strategy there hasn't been a strong strategy on food security KI(*).

Not surprisingly then, it was considered by an informant within the Ministry that food security was also not viewed as a priority in international trade policy development with the Pacific: $\mathrm{KI}(3)$

"I don't think in general from a Pacific trade policy perspective it's been a priority for discussion on trade policy vis-a-vis the Pacific and the food security and trade work has been in a slightly separate channel and that's not to say that they don't intersect at times but my sense is that for the Pacific it hasn't been the highest priority from a trade issue"

In the final analysis, it seems clear that food security and right to food concerns are yet to be addressed in a manner that would see real movement for food insecure people in Fiji. This is not for lack of awareness of challenges faced by the Pacific.

\footnotetext{
${ }^{29}$ Interviewees identification withheld for confidentiality reasons
} 
Gap between New Zealand practice and international best practice on the right to food and food security

Special Rapporteur on the right to food, Asbjorn Eide, (2002, p. 44) has stated "Donor states should increase their awareness of the importance of the effective enjoyment of the right to food, and make it a major concern in their development assistance". The New Zealand government has committed to the right to food and through programmes designed to support food security can be viewed to be acting on that commitment. This notion was supported by KI(McBryde):

"through our aid programmes we are accepting an obligation to promote development and sustainability and the ability of countries to produce their food and enhance the standard of living of their peoples"

However, there is an absence of evidence to indicate that New Zealand international programmes in development or trade recognise New Zealand as having obligations beyond this which would create space for deeper reflection on New Zealand practices. Eide has also stated the imperative for states to account for the universal right to food in the development of their external aid and trade for the right to food to be realised globally. States are increasingly being expected to take due diligence in this regard, to both monitor and amend policy where negative impacts are found (Eide, 2002). The recent International Development Policy Statement from MFAT (2011) indicates a plan to introduce this in respect of aid but there is no evidence of this happening at present in areas of external trade. That is not to say that New Zealand does not take action to support the right to food of extraterritorially, but that a key element, that of protecting other nations against actions within their territory, remains lacking. For global food security to be realised attention must be paid to the global impacts of our nation's actions. For food security and the right to food to be realised it will require a deeper understanding of the right to adequate food, and what constitutes violation of this right.

\subsection{BARRIERS TO GREATER PRIORITISATION OF FOOD SECURITY AND THE RIGHT TO FOOD IN} PRACTICE

What might prevent the New Zealand government from placing greater priority on the right to food and food security concerns in their international policies? It seems from interviews there are some key tensions that prevent food security taking a greater presence in development of 
trade policy. These are centred primarily around two key issues, sovereign self-interest, and narrow interpretation globally of trade and economic frameworks - interpretations, which are not without their own element of self-interest. As Spitz (2002, p. 74) opines "Liberalism, indeed, seems to have flexible interpretations, which strangely enough seem to fit the interests of the most powerful rather than those of the less powerful."

\section{Sovereign interests prioritised over global rights}

In the development of policy there are many things to take into account. As KI(3) stated "there will be many things at play, some of them will be political interests, some of them will be commercial interests, some of them might be foreign policy and development objectives". It is evident in discussion with both participants in New Zealand and Fiji that there are some underlying tensions that prevent food security issues for Fiji, of which New Zealand has a part in, being included in the development of New Zealand's trade policy.

Protecting national interests is clearly evident in the development of trade policy. Agricultural exports form a critical part of New Zealand's economy. Production and processing of agricultural products generates approximately 16 percent of New Zealand's Gross Domestic Product annually and accounts for 15 percent of jobs nationally (MFAT, 2011a). Meat and dairy sectors in particular are major earners for New Zealand. Concern for the protection of New Zealand industries was clearly evident in interviews: "I think it's a really tough issue, because let's say we go down that track [of banning exports]...I think about the jobs domestically" KI(2); "some people have advocated that New Zealand should ban the export of lamb flaps, I think the meat industry wouldn't be very happy about" KI(3). This point was evident again in regards to New Zealand quarantine standards, an area that has been identified as a major barrier to Pacific exports: $\mathrm{KI}(2)$ "that's quite a tough one because our economy is based on commodities and we need to protect our exports too". Hence, a tension exists in the development of international policy between protection of domestic interests and development priorities abroad.

Ultimately, the New Zealand government is responsible for managing the tension between obligations to New Zealand citizens and those to the global community. Where interests are not compatible, this requires a prioritisation of interests. On this point: $\mathrm{KI}(5)$ stated 
"the businesses that have interests in the Pacific have an interest in the New Zealand government protecting their interests and advancing them, so I think that's where it can come down to an interplay of interests".

It is seems evident from the above discussion that when it comes down to interplay of interests between New Zealand trade and Pacific food security, the New Zealand government places priority on its domestic interests. This is perhaps neither unique nor surprising. However if human rights are to be realised for all, it is unlikely to occur under this approach. In the development of trade agreements the New Zealand government is highly conscious of not giving up anything in the process. MFAT, in both its aid and trade programmes, has talked of addressing the trade imbalance. This is to be achieved through support to the Pacific in the development of local infrastructure and support for exports and through the focus on economic development. At the same time, the New Zealand government is highly conscious of maintaining at a minimum its current export positioning. KI(Halavatau) points to the situation whereby "some of the countries bring in their aid try to help you improve your agriculture, but then in the final analysis they try to ensure that you don't export to where they export also". From the New Zealand side, the protection of New Zealand exporters is not denied: $\operatorname{KI}(3)$ "we need to be mindful of any New Zealand exporters that might be undercut"; nor is protecting New Zealand market access in the Pacific: KI(3) "from an exporter point of view in New Zealand it is just to ensure that we have the same kind of access as any other developed country has into the Pacific". Both of these arguments are evident in the New Zealand government position on PACER Plus. While the New Zealand government continues to focus on protecting New Zealand industries without concern for the impacts of this on others, this undermines Pacific Island abilities to realise the right to food, and move towards greater food security.

To prioritise global human rights over sovereign interests certainly represents a challenge. As $\mathrm{KI}(5)$ stated "the question is can New Zealand separate its own domestic interests in the outcome of those decisions". The New Zealand government advocates strongly for greater liberalisation of agriculture (MFAT, 2011a). However it is not clear that full liberalisation is in the interests of the Pacific Islands, now or indeed ever (Connell, 2007; Kelsey, 2005). The last two decades of moves towards trade liberalization in Fiji has not seen the benefits occur that have been espoused globally and supported by the New Zealand government. 
KI(5) "I think that New Zealand does have difficulty in separating its domestic interest from the Pacific's interest, so generally as far as agriculture is concerned, internationally, New Zealand takes this stance well we have opened our agriculture, we don't support providing any kind of subsidies for farmers, everybody else should do the same thing...so it takes the position that that is what the Pacific should do as well...the difference being that many have a very small commercial agricultural sector"

As is evident in this quote, there is question over the New Zealand government's ability to step outside itself to fully appreciate what is in the best interests of other countries. Another area in which this is present is in the way the New Zealand government interprets food security. The New Zealand government has been outspoken about the kind of language surrounding the right to food, which have been anti-food self-sufficiency so as to prevent agricultural protection. As Anderson (2006, p. 1) identifies "different approaches to 'food security' are linked to distinct interests". Protected agricultural markets are not in the interests of New Zealand exporters. As an export driven economy and advocate for open trade, New Zealand is particularly wary of arguments for food self-sufficiency. $\mathrm{KI}(5)$ explains:

"what New Zealand is very wary of is countries using food security to advance protectionist arguments or argument to protect the agricultural sector basically saying that food security means we have to produce our own food so therefore we have to protect our agriculture"

However, this stance has implications for Pacific islands, as KI(5) identifies "our trade policy tends to be defined outside the Pacific but applied to the Pacific so that's where it becomes a problem...”. For Pacific islands, protection of infant industries may be necessary to support food security. There is strong argument for developing countries to be allowed levels of protection, particularly in a global context of trade rules that are viewed by many as neither free nor fair (Wolter, 2002). So as $\mathrm{KI}(5)$ states: we are taking this line as a trade line but then stop there and we assume that what we think is good for the EU and good for us is also good for least developed countries, which it isn't'. 


\section{National and global frameworks prioritise trade over food security and the right to food}

The Ministry of Foreign Affairs and Trade is the government department primarily responsible for New Zealand's international interactions. The Ministry is also guided by a focus on trade, more specifically, securing New Zealand trade access internationally. It states: "One of the Ministry's key trade responsibilities is to negotiate market access for New Zealand goods and services and to maintain and enforce that access" (MFAT, 2011c). International trade policy is hence formulated around this goal as was indicated by $\operatorname{KI}(2)$

"if people do raise concerns about PACER Plus social or economic or whatever, and it was a fairly strong concern we'll put up the recommendations based on what our emerging trade policy is in the Pacific, so if the focus is on improving their trade then it's around those objectives that we'll be formulating their objectives"

However, setting trade as the goal around which all other policies are formulated is problematic. As was highlighted by the United Nations Research Institute for Social Development "the pursuit of policies in one domain (economic, social or political) to the neglect of others is likely to undermine efforts to combat poverty and inequality" (UNRISD, 2010, para. 3). This opinion was also expressed by KI(Matheson): "trade as a goal is an inadequate goal on its own, it's a subset of things you need, when it becomes the whole purpose then you've got a problem". With the reintegration of NZAID into MFAT and the new mandate for sustainable economic development over poverty alleviation, the imperative for trade to be seen as secondary to raising global living standards and human rights is even more pertinent. Despite calls for a review of the goals of trade in the fight against world poverty, as Chopra et al. (2002) note, increased trade is currently driving global policy. Although New Zealand has said PACER Plus will not be a typical trade agreement, it nonetheless will likely have to be WTO compatible (PANG, 2009a). Adhering to common application of the WTO framework represents a potential barrier to global food security and the right to food.

The point that some of the actions that would support food security run counter to WTO operational regulations, was made on a number of occasions during interviews. Some of the key ways to support food security do not fit well with the present policy framework. As KI(Thaman) stated "we [Fiji] could possibly subsidise our own people for some of these things while at the same time increasing the duty a tiny bit, the problem is under the WTO 
that is kind of hard" . As indicated here, one tool to address the production aspect of food insecurity is protection of local industries, which would support small farmers to be able to develop their business in an environment which is at present too difficult to achieve otherwise. However, in an environment of increasing trade liberalisation, whether this will be acceptable is unclear. Regulation of products is another path that has been suggested, particularly by health professionals, to protect populations against influxes of foods detrimental for health (Wyber, et al., 2009). WTO regulations, however, present a challenge to this and have been used in the past in efforts to prevent such measures. The banning of mutton flaps is a case in point.

\section{Potential for recognition of Pacific needs in trade}

Whether the right to adequate food can be realised in the current economic framework has been questioned. This feeling was echoed by KI(1) "If New Zealand producers and suppliers are morally and socially responsible ...they will have to work outside the economic framework". Certainly, a dogmatic approach to economic growth and trade liberalisation within the New Zealand government and in approaching the WTO places limitations on realising the right to food and food security. However, there is potential for a more flexible agreement that can be argued to be compatible with WTO rules. Part (iv) of GATT states: "a contracting party, the economy of which can only support low standards of living and is in the early stages of development, shall be free to deviate temporarily from the provisions of the other Articles of this Agreement" (WTO, n.d., para. 4). Further, there is clear precedent of countries selectively maintaining protection over sensitive industries. An example of this is the EU agreements in 2000 with Poland and the Czech Republic; the EU offered duty-free, quota free access in the industrial sector, while the share of duty-free tariff lines in agriculture was between 27 percent for Poland and 32 percent for the Czech Republic (South Centre, 2008). The selective interpretation and application of WTO rules begs one to question the underlying motives and interests of such parties. If we are to work within the existing framework, it will require a reprioritisation of rights, and an ability to be both flexible and self-reflexive. 


\subsection{CONCLUSION}

"New Zealand needs to more strongly commit to food security than it does to trade, that it should see food security as the goal and trade a subset of that" KI(Matheson)

As has been presented in this chapter, at present food security and the right to food receives inadequate attention in the development of policy, both trade and international development assistance. This comes despite an awareness of challenges being faced by the Pacific which are intrinsically related to food security, as well as a degree of awareness of New Zealand actions which are impacting negatively on the welfare of those in the Pacific. New Zealand has expressed intentions to deliver a trade agreement which puts commercial interests aside. Yet New Zealand continues to put commercial interests first by neglecting to review and adjust New Zealand trade to the Pacific.

For food security and the right to food in the Pacific to be realised it will require a rethinking over the goals of trade and what is acceptable in the pursuit of trade. Further, while this research has focused on trade, as one informant pointed out "They are not just trade issues, they are much deeper than that" KI(5). Other issues relevant here are those of social protection and distribution of resources, both of which will need to be addressed for countries to achieve food security. This will require a re-examination of the values which New Zealand as a state and as a people wishes to possess, for behind governments, businesses, and policymakers are ordinary New Zealanders.

The failure of the New Zealand government to address this aspect of the right to food is not unique by any means. Nor is this to say that failure to take this position on board corresponds to a lack of concern in regard to the right to food in other countries. Nonetheless, argument for the imperative to acknowledge and address extraterritorial obligations in the right to food is growing amongst academics and international human rights advocates. New Zealand ought to take heed of this. It is likely with the failure of present systems to realise the right to food for much of the world's population the need to account for this position will become more pressing. 


\section{Chapter 9: Conclusion}

\subsection{INTRODUCTION}

Food security, whereby all people, at all times, have physical, social and economic access to sufficient, safe and nutritious food is not just an ideal state to which to strive towards, it is a basic fundamental right of all human beings. This is established by the Universal Declaration of Human Rights, to which all countries are bound. This should not just be a matter of law protecting this right goes to the core of humanity. In a world of global plenty and sophisticated technology, there is no justifiable excuse for the situation where half the world's population suffer from hunger and malnutrition because of a lack of access to basic healthy food.

Food insecurity has become a concern of primary importance for the Pacific. Trade is commonly purported to be supportive of food security, although as this research outlines, this is not always the case. This research has sought to look deeper into the relationship between New Zealand trade and Pacific food insecurity, using Fiji as a case study. This final chapter draws together the findings of the research, further outlining the implications of the research for wider policy and theoretical application. Areas for further enquiry stem from this and these are outlined.

\subsection{RESPONDING TO THE RESEARCH AIMS}

The research sought to examine New Zealand's role in food insecurity in Fiji through the items it trades and the manner in which it engages in trade. In order to achieve this, the research had three aims. These are addressed in turn below, along with the findings that came out in the process of research.

\section{Food insecurity in Fiji}

The first aim of the research was to establish the context for food insecurity in Fiji. Food insecurity globally is commonly associated with hunger and global approaches to food insecurity mirror this. Malnutrition, particularly over-nutrition, features little amongst these. However, the presentation of food insecurity in parts of Africa and Asia, are very different from that in the Pacific; the former typically characterised by under-nutrition while for the latter, malnutrition, in particular, over-nutrition presents a more common problem. The 
impacts of malnutrition on individuals, families, and communities are severe. It impairs physical and cognitive development, the effects of which are carried throughout one's life, impacting on the health and wellbeing of future generations and the community as a whole. Importantly too though, within the Pacific there is diversity. Thus, to properly understand the relationship between New Zealand trade and Fijian food insecurity, it is necessary to establish a foundation in the presentation and causes of food insecurity in Fiji.

Food insecurity in Fiji presents differently to common conceptions of food insecurity. While, Fiji displays all aspects of food insecurity, under-nutrition, malnutrition, and over-nutrition, it is primarily represented by over-nutrition. The primary cause of death in Fiji in 2009 was from non-communicable diseases. A key risk factor in non-communicable diseases is obesity. Around 60 percent of the population is estimated to be overweight or obese and this is thought to be on the rise. Anaemia and other vitamin deficiencies are also a problem for Fiji and likely to increase. Although less prevalent, under-nutrition is also evident in Fiji. Some people on a regular basis are going without meals. Anecdotal evidence from this research suggests the number is higher than previous estimates. Importantly, for Fiji, food insecurity is not a matter of national availability of calories. Accessing nutritional food is, however, a key problem for individuals. As a result, the food that people are eating is not supportive of healthy living, and is leading to the poor health outcomes as described above.

\section{Factors creating food insecurity in Fiji}

Food insecurity in the region has historical origins but is perpetuated by contemporary factors. The immediate cause of food insecurity is primarily over consumption of highly refined and processed foods, which are typically high in salt, sugar and fat. These have been linked to obesity and non-communicable diseases. These are also, for the most part, imported. Changes in food security have coincided with global integration. Fiji, as with the rest of the Pacific, has a well-established history of exceptional nutrition. However, 2000 years of positive nutrition has been shifted within the last century. This period has experienced great changes in local food production and consumption, stemming in large part from colonial influence, which saw the introduction of commercial production and with it rural to urban migration. This period also saw the introduction of imported foods. Resulting from this has been a decline in use of traditional agriculture systems and availability and consumption of traditional foods, which were key in the maintenance of food security. The role of imported foods in the Fijian diet 
has overtaken that of traditional foods. This has seen a decline in overall health and wellbeing of Fijians.

This research found that while products are imported that would support nutrition, most of these are beyond the means of the majority of Fijians. High quality foods, and those that offer nutritional value, go primarily to the tourist industry or a small group of relatively wealthy people. Importantly, cost plays a determinant role, leading individuals to purchase items which are not good for them. While people may wish to purchase healthy options, in many cases they are simply not able to afford the more nutritious items. Further compounding the situation, local systems, which in the past have provided access to nutritional food, have declined. Some do not have the space, particularly in urban areas, which are growing rapidly; others are selling home production to pay for demands in a now monetised society. In order for individuals and their families not to go hungry, people are purchasing products that are nutritionally poor. This equates to an inability to access food for a healthy and active life, as dictated by the definition of food security and the right to food, and the element of access that is defined within these.

\section{New Zealand's role in food insecurity in Fiji}

With it established that imported products have a role to play in food insecurity in Fiji, and with New Zealand a major exporter to Fiji, the second aim of the research was to describe and analyse the trade relationship with respect to food between New Zealand and Fiji. In response to this aim, the research sought to describe and analyse trends in trade between New Zealand and Fiji, with a focus on food. It concluded that, Fiji and New Zealand have a well-established relationship, one that is valuable for both parties. The relationship, however, is not a balanced one. The balance of trade is overwhelmingly in New Zealand's favour. The trend for Fiji over time has been one of increasing imports from New Zealand. Over the same period, exports from Fiji to New Zealand have remained relatively flat, and well below trade to Fiji from New Zealand, leading to a negative trade balance close to NZ\$2 million for Fiji in 2010. The capacity for agricultural trade is also at odds. New Zealand has a well-developed agricultural sector, particularly in meat and dairy, which represent the greatest exports to Fiji from New Zealand. Despite historic efforts to commercialise Fiji's agriculture sector, stemming from colonial influence, it remains relatively undeveloped. The barriers to development faced by Fiji as a small island state make being in a position to compete with New Zealand unlikely, if 
possible at all. Despite this, New Zealand is continuing to pursue a policy of more and more open trade, the result of which will likely see fundamental, irrevocable hardship for many in Fiji, further undermining food security.

While Fiji on some levels benefits through its trade relationship with New Zealand, this research finds that, as it is currently practiced, it is undermining access to nutritional food for people in Fiji. New Zealand exports an array of products to Fiji, of varying nutritional value, some of which have strong links to obesity and non-communicable diseases. High fat and bone meat cuts have most often been identified in this scenario, but the export of other foods such as butter, and milk, to a country where diabetes and hypertension are among the major causes of death, can also arguably be seen to be contributing to this outcome. Additionally, products that are of potential nutritional value, such as potatoes, are replacing and displacing local products that are more nutritional. Additionally, exports to New Zealand from Fiji are decreasing local access to nutritional food, as the best quality produce is sent out of the country, only to be replaced by poorer quality foods coming in, some of which are from New Zealand. Added to this are the wider impacts of New Zealand trade on local production, and hence local access. Changes in consumption habits influenced by imports have led to a decline in production and availability of traditional crops. As local producers struggle to compete in the face of imports, this in turn affects economic access to foods as well as domestic availability. The combined impact of the aforementioned ways in which Fiji food security is affected by New Zealand trade is thus great and warrants attention.

\section{Potential for New Zealand to food security and the realisation of the right to food in Fiji}

A final aim of this research was to evaluate the New Zealand government's approach to food security in the Pacific and the right to food based on extraterritorial application of these. This aim is based on two positions - first, that food security is unlikely to be realised without a right to food approach, and secondly, that the right to food entails extraterritorial obligations, and that countries ought to take the impact of their trade and aid policies in other countries into account when developing policy.

Findings from this research suggest that while the New Zealand government identifies food security as a priority, in practice it does not prioritise food security. Within New Zealand's trade policy with the Pacific, there is little reference to food security and no indication of recognition of right to food concerns. The New Zealand government's approach to food 
security appears to be driven by sovereign interests. Further the politico-economic environment which adheres strongly to narrow neoliberal orthodoxy and WTO doctrine makes greater realisation of the extraterritorial right to food unlikely. The extent to which future New Zealand trade with Fiji will better support food security in Fiji hinges on whether or not New Zealand comes through with its promises in the upcoming PACER Plus negotiations. Even so, without a meaningful look at the ways in which existing New Zealand trade impacts on Fiji, it is likely New Zealand trade will continue to undermine Fijian prospects for food security.

\subsection{RESEARCH IMPLICATIONS}

The above findings raise some important implications - both for New Zealand policy and wider theoretical considerations.

\section{New Zealand government policy}

What do the findings of this research mean for the New Zealand government in approaching food insecurity and its trade relationship with Fiji? As the world fails to address the issue of global hunger and malnutrition, the right to food and obligations associated with this are gaining strength internationally. Under this premise, New Zealand has clear obligations to account for the impact of its trade on the right to food of those in other countries. Greater attention must be paid to what and how trade is undertaken. For trade to be harnessed so as to support health and life rather than contribute to poor health and poverty in Fiji it will require the right to food of all people, regardless of territorial boundaries, to receive greater priority. However, the present approach adopted by the Ministry of Foreign Affairs and Trade, in which foreign policy is formed around a primary goal of trade makes this unlikely. A reevaluation of the role of trade within the Ministry is required. It ought be remembered that trade is a means to a greater goal of raising global living standards, not an end in itself.

The negotiation of PACER Plus, in which the New Zealand government has said it will set aside its commercial trade interests, holds potential for a step in this direction. This will necessitate a review of and changes to current New Zealand trade with the Pacific. A major challenge to this will be the rules of the WTO, and how they have been practically applied thus far. However, the New Zealand government can draw on the precedence of the human rights framework and the right to food. 
The idea that New Zealand could be violating human rights will likely sit uncomfortably for many; New Zealand is often considered a champion in upholding human rights. New Zealand gave women the right to vote before any other country in the World. New Zealand has been a champion for the rights of the disabled, playing a leading role in the negotiation of the Convention on the Rights of Persons with Disabilities (MFAT, 2008). New Zealand's treatment of indigenous rights, although still a long way to go, can be considered generally to be better than most if not all other colonial-indigenous relationships. New Zealand has also taken a strong stance on international issues against dominant powers on anti-nuclearism. Hence, New Zealand is not a stranger to taking the lead on matters of primary importance. To put human rights ahead of trade will require the New Zealand government to take a leading step internationally, but it can be done, if it is willing.

\section{Theoretical Implications}

International discourse on food security and the right to food remains primarily focused on hunger; malnutrition receives comparatively insufficient attention. Situations, such as that in Fiji, and the Pacific are for the most part neglected in international discussions on food security. The situation in Fiji, however, highlights the need for greater attention to be placed on the full meaning of food security. Malnutrition, particularly over-nutrition, where individuals have sufficient calories but cannot access that which would support a healthy and active life represents a violation of the right to food. The consequences of malnutrition are severe; it impairs life quality and opportunity. Further, affecting globally more than two billion people, it is a problem of significant proportions. Global approaches to food insecurity need to give greater attention to this. The present trade framework prohibits regulation of foods which consumed on a regular basis are harmful (Evans, et al., 2001). Based on this, more attention needs to be given to foods and their relationship to health. As was raised by this research, foods which are not associated with poor nutrition can undermine nutrition, where these foods are displacing healthier alternatives, and local access via displacement of livelihoods. Access has also been a key issue highlighted in this research. Fiji has an excess of calories, however many people there are not able to access nutritional food.

The points raised in this research are not just a matter for 'developing' countries, or currently classified food insecure countries, but for 'developed' countries also. The issue of access to nutritional food is one which many, if not all countries face. Access to nutritional food is 
intrinsically linked to economic poverty. Friel and Baker (2009) refer to a social gradient in health where the lower an individual's socioeconomic status the worse their health. New Zealand must reflect on within its own territory also. With global food and oil price rises, it is becoming increasingly harder for the average family to access nutritional food for the family and there are at present those in New Zealand for whom the right to food is not a reality. The challenges faced by Fiji highlight lessons for the full realisation of the right to food for many countries in a climate of rising food prices and an overreliance on the market to provide social goods. The issue of ensuring that nutritional food is accessible to all applies to all countries and will require a serious rethink in the way that we produce, supply and regulate food.

Findings of this research lead to a questioning over prioritisation of rights. The situation whereby the economic concerns of some are prioritised over basic rights, such as food and health, points to a rights-economics tension. Rights are equal to all, but it may not be that all rights are equal. The way the WTO framework is applied at present appears to value some rights over others, such as private ownership over access to basic rights such as food and water. Under international law, the UDHR and related treaties take precedence over WTO rules and regulations, however, in practice this is often not played out. There is some evidence to suggest that the WTO is strengthening in areas of human rights however, progress in this regard appears limited and slow. Whether change can be achieved within the current economic framework is questionable. For rights such as the right to food to be realised it will likely require a re-prioritisation of basic human rights.

Further, in the current global climate of greater interconnectedness, extraterritorial application of the right to food must receive greater acceptance and incorporation into national policies if food security for all is to be realised. By neglecting elements in which one country undermines another countries right to food, important factors in food insecurity will continue unabated. Only when all factors are addressed will the potential for food security and the right to food have hope of being fully realised. Dependency theories in the 1970 s drew attention to the interrelationship between nations, which rendered some poorer as a result. Application of this line of thinking, however, receives insufficient incorporation in donor approaches to development. Extraterritorial application of the right to food would make this an obligation. This will necessitate the New Zealand government to take a more reflexive approach to policy. This is particularly important in trade where sovereign and commercial interests tend to dominate. 
Finally, a strong role for the state is imperative in this process. Despite some opinion that the state no longer has a role in this globalised world, due to the fluidity of borders, the rise of corporate power and international institutions and regional relationships, the opposite is in fact true. The state is more important than ever in protecting the rights of not just citizens within their territory but citizens globally, for they have the power to regulate and to seek justice where rights are violated. States are answerable to their protection of those rights. Within the context of food security, state sovereignty has been eroded through the WTO and international trade regulations, disabling its power to protect those within its jurisdiction from harmful goods. This requires redress.

\subsection{AREAS FOR FURTHER RESEARCH}

Based on the above the following areas for further research can be identified. Given that food insecurity in the Pacific presents differently to common conceptions of food security, further empirical work is needed to understand the drivers and manifestations of food insecurity in the Pacific region. Based on the outcomes of this research further investigation is called for into the link between New Zealand trade and food insecurity in other islands of the Pacific. In particular, the impact of New Zealand trade on rural livelihoods in the Pacific Islands is critical. With the renegotiation of the terms of trade between New Zealand and the Pacific Islands underway at present, the product of which will be irrevocable, research into the impacts of PACER Plus on food security in the Pacific region is imperative.

More broadly, while the WTO framework continues to dominate trade relationships globally, there is a need for greater investigation into the potential for trade relations formed within the WTO framework to fully incorporate and place priority on recognition of the full spectrum of human rights, including the right to food. Additionally, there has been much question over the role of the state in recent times. At present, this research finds the role of states to be critical in the global realisation of human rights. This research has further highlighted the tension that exists between national sovereignty and realising global goals such as universal human rights. Further investigation is required to understand this tension, and what role national sovereignty ought to continue to play in an increasingly interconnected world. Eide (1984, p.154) remarks "How can the obligations of the state be made operative in a way that ensures the optimal balance between freedoms and satisfaction of demands". This question has yet to be satisfactorily answered and requires further exploration. 


\subsection{FINAL REMARKS}

The world is at present facing multiple crises in climate, food, and financial arenas. At their core, these are linked by a deeper crisis, one of values and of will. Globally, more than three billion people, or half the world's population, on a daily basis lack adequate access to food that would enable them to lead a life free from hunger and disease. This comes despite unprecedented levels of global wealth and an abundance of food globally. It also comes despite successive commitments on the part of states globally to respect and protect universal rights, including perhaps the most basic of all human rights, the right to adequate food. With sufficient resources at our disposal globally to feed the world today, the failure to act in order to do so equates to a lack of will. The decision not to underscores a global crisis of values.

While the role of the state has been a major focus of this research, this situation should concern everyone. It is important to remember that we define our world, in the actions we take, and equally those that we fail to take. The present path of globalisation based on neoliberal rhetoric on which the world is turning is based on an ideology, not fact. In the speed of change of the past century, it is necessary to take time to reflect on the path which we want to continue. What parts of the past do we want to carry forward, what parts of where we are now do we want to change, and how can we merge these to make a prosperous future for all. This will necessarily entail a deeper look at ourselves, and at the ideologies that inform us and the world at present, and to what degree achieving recognition of such a fundamental human right as access to healthy food can be achieved in that context. This will require the New Zealand government and the people of New Zealand to take a deep reflection on the core values it wishes to follow. It is the hope of this researcher, that those values will incorporate the basic right of all to adequate food.

There is no time left for promises, change requires action. 


\section{References}

Abbott, D., \& Pollard, S. (2004). Hardship and Poverty in the Pacific: Strengthening Poverty Analysis and Strategies in the Pacific. Manila: Asian Development Bank.

ACIAR (2002). Determinants of Food Choice. Canberra: Australian Centre for International Agricultural Research.

ADB (2006). Republic of the Fiji Islands - Country Gender Assessment Manilla: Asian Development Bank.

ADB (2008). Living with High Prices - A Policy Brief. Manila: Asian Development Bank.

Alston, P. (1984). International Law and the Right to Food. In A. Eide, W. Eide, S. Goonatilake, J. Gussow \& Omawale (Eds.), Food as a Human Right. Tokyo: United Nations University.

Alston, P., \& Tomasevski, K. (Eds.). (1984). The Right to Food. Dordrecht: Martinus Nijhoff.

Amin, A. (2004). Regulating Economic Globalization. Transactions of the Institute of British Geographers, 29(2), 217-233.

Amin, A., \& Thrift, N. (1994). Living in the Global. In A. Amin \& N. Thrift (Eds.), Globalization, Institutions and Regional Development in Europe (pp. 1-22). Oxford: Oxford University Press.

Anderson, T. (2006). Food Security and Agriculture in the Australia-East Timor Relationship. In D. Kingsbury \& M. Leach (Eds.), East Timor: Beyond Independence. Melbourne: Monash Asia Institute Press.

Annan, K. (2001). Nobel Lecture, from http://nobelprize.org/nobel_prizes/peace/laureates/2001/annan-lecture.html

Australian High Commission Fiji (2007). Fiji-Australia Business Forum Radisson, Denaru, 4 December 2007 Speech by HE James Batley Australian High Commissioner to Fiji Pacer Plus: What Business Needs to Know, from http://www.fiji.embassy.gov.au/suva/pacer.html

Balakrishnan, R., \& Narayan, U. (1996). Combining Justice with Development: Rethinking Rights and Responsibilities in the Context of World Hunger. In W. Aiken \& H. La Follette (Eds.), World Hunger and Morality (2 ed.). New Jersey: Prentice-Hall.

Barr, K., \& Naidu, V. (2002). Comment on Poverty for Fiji Update. Paper presented at the "Fiji Update 2002" Australian National University. 
Bellam, M. (1980). A Question of Balance: New Zealand Trade in the South Pacific.

Wellington: New Zealand Coalition for Trade and Development.

Bentz, V., \& Shapiro, J. (1998). Mindful Inquiry in Social Research. London: Sage Publications.

Berger, P. (1974). Pyramids of Sacrifice. New York: Basic Books.

Blouin, C., Chopra, M., \& Van Der Hoeven, R. (2009). Trade and Social Determinents of Health. Lancet, 373, 502-507.

Bose, I. (1996). Statement by the Honourable Mr Isimeli Bose to WTO Ministerial Conference Singapore 1996, from http://www.wto.org/english/thewto_e/minist_e/min96 e/st54.htm

Breining-Kaufmann, C., \& Foster, M. (2006). Introduction. In F. Abbot, C. BreiningKaufmann \& T. Cottier (Eds.), International Trade and Human Rights: Foundations and Conceptual Issues (pp. 3-18). Ann Arbor: University of Michigan Press.

Browne, C., \& Scott, D. (1989). Economic Development in Seven Pacific Island Countries. Washington: International Monetary Fund.

Cassels, S. (2006). Overweight in the Pacific: Links between Foreign Dependence, Global Food Trade and Obesity in the Federated States of Micronesia. Globalization and Health, 2(10).

Castells, M. (1996). The Rise of the Network Society (1st ed.). Oxford: Blackwell.

Castells, M. (2010). The Rise of the Network Society (2nd ed.). West Sussex, Oxford: WileyBlackwell.

Chopra, M., Galbraith, S., \& Darnton-Hill, I. (2002). A Global Response to a Global Problem: The Epidemic of Overnutrition. Bulletin of the World Health Organization(80), 952958.

CIA (2011). The World Fact Book, from $<$ https://www.cia.gov/library/publications/the-worldfactbook/geos/fj.html>

Cloke, P., Philo, C., \& Sadler, D. (1991). Approaching Human Geography: An Introduction to Contemporary Theoretical Debates. London: Paul Chapman Publishing Ltd.

Connell, J. (2007). Towards Free Trade in the Pacific? The Genesis of the 'Kava-Biscuit' War Between Fiji and Vanuatu. Geographical Research, 45(1), 1-12.

Connell, J., \& Lea, J. (2002). Urbanization in the Island Pacific: Towards Sustainable Development. London, New York: Routledge. 
Coomans, F. (2005). Progressive Development of International Human Rights Law: Extraterritorial Application of the International Covenant on Economic, Social and Cultural Rights. In M. Windfuhr (Ed.), Beyond the Nation State: Human Rights in Times of Globalization. Uppsala: Global Publications.

Coyne, T. (2000). Lifestyle Diseases in Pacific Islands Countries. Noumea: Secretariat of the Pacific Community.

Daniels, P. (2005). The Geography of the Economy. In P. Daniels, M. Bradshaw, D. Shaw \& J. Sidaway (Eds.), An Introduction to Human Geography: Issues for the 21st Century (2nd ed.). Essex: Pearson Education Limited.

Denoon, D. (1997). Pacific Edens? Myths and Realities of Primitive Influence. In D. Denoon, S. Firth, J. Linnekin, M. Meleisea \& K. Nero (Eds.), The Cambridge History of the Pacific Islanders. Cambridge: Cambridge University Press.

Denscombe, M. (2007). The Good Research Guide: For Small-Scale Research Social Research Projects Berkshire: Open University Press.

Denzin, N. (1970). The Research Act: A Theoretical Introduction to Sociological Methods. Chicago Aldine.

Dicken, P. (2007). Global Shift: Mapping the Changing Contours of the World Economy. London: Sage Publications.

Dierckxsens, W. (2000). The Limits of Capitalism: An Approach to Globalization Without Neoliberalism. London: Zed Books Ltd.

Dreze, J., \& Sen, A. (1989). Hunger and Public Action. Oxford: Clarendon Press.

Egger, G., \& Swinburn, B. (1997). An "Ecological" Approach to the Obesity Epidemic. BMJ, $315,477-480$.

Eide, A. (1984). Food as a Human Right. Tokyo: United Nations University

Eide, A. (2002). The Right to Food: From Vision to Substance. In M. Borghi \& L.

Blommestein (Eds.), For an Effective Right to Adequate Food. Agno: Editions Universitaires Fribourg Suisse.

Eide, W. (2005). From Food Security to the Right to Food. In W. Eide \& U. Kracht (Eds.), Food and Human Rights in Development: Legal and Insitutional Dimensions and Selected Topics (Vol. 1). Oxford: Intersentia.

Escobar, A. (1995). The Making and the Unmaking of the Third World. Princeton: Princeton University Press. 
Evans, M., Sinclair, R., Fusimalohi, C., \& Liava'a, V. (2001). Globalization, Diet and Health: An Example From Tonga. Bulletin of the World Health Organization, 79(9), 856-862. FAO (1983). World Food Security: A Reappraisal of the Concepts and Approaches. Rome: Food and Agriculture Organization of the United Nations.

FAO (1996). Rome Declaration on World Food Security and World Food Summit Plan of Action. World Food Summit 13-17 November 1996. Rome: Food and Agriculture Organization of the United Nations.

FAO (1998). The Right to Food in Theory and Practice. Rome: Food and Agriculture Organization of the United Nations.

FAO (2002a). The State of Food Insecurity in the World 2001. Rome: Food and Agriculture Organization of the United Nations.

FAO (2002b). World Agriculture 2030: Global Food Production Will Exceed Population Growth, from http:/www.fao.org/english/newsroom/news/2002/7828-en.html FAO (2003). Trade Reforms and Food Security: Conceptualizing the Linkages. Rome: Food and Agriculture Organization of the United Nations.

FAO (2006). The State of Food Insecurity in the World. Rome: Food and Agriculture Organization of United Nations.

FAO (2010). The State of Food Insecurity in the World. Rome: Food and Agriculture Organization of the United Nations.

Feeney, S. (2010). The Global Economic Crisis and the MDGs in the Pacific Pacific Economic Bulletin, 25(1), 136-150.

Fiji Government (2001). Health of Fijians More Important than New Zealand Threats [Press release 15 March]. Suva: Fiji Government.

Fiji Islands Bureau of Statistics (2009a). Overseas Merchandise Trade Statistics 2008 Suva: Fiji Islands Bureau of Statistics.

Fiji Islands Bureau of Statistics (2009b). 2007 Census of Population and Housing: Labour Force, Employment and Unemployment. Suva: Fiji Islands Bureau of Statistics.

Fiji Islands Bureau of Statistics (2010). Key Statistics: March 2010. Suva: Fiji Islands Bureau of Statistics.

Firth, S. (2000). The Pacific Islands and the Globalization Agenda. Contemporary Pacific, 12(1), 178-192.

Fisk, E. K. (1972). Motivation and Modernization. Pacific Perspective, 1(1). 
Fogel, R. (2004). The Escape from Hunger and Premature Death, 1700-2100: Europe, America, and the Third World. Cambridge: Cambridge University Press.

Friel, S., \& Baker, P. (2009). Equity, Food Security and Health Equity in the Asia Pacific Region. Asia Pacific Journal of Clinical Nutrition, 18(4), 620-632.

Fritsch, S. (2008). The UN Global Compact and the Global Governance of Corporate Social Responsibility: Complex Multilateralism for a More Human Globalisation? Global Society, 22(1), 1-26.

FSP Working Group (2009). A Pacific Food Summit 2010: Facilitating Action for a Food Secure Pacific, from http://www.foodsecurepacific.org/summit.html

FSP Working Group (2010). Towards a Food Secure Pacific: Framework for Action on Food Security in the Pacific, from http://www.foodsecurepacific.org/documents/FINAL $\% 20 \mathrm{TOWARDS} \% 20 \mathrm{~A} \% 20 \mathrm{FOO}$ D\%20SECURE\%20PACIFIC June1.pdf

Glipo, A. (2006). Achieving Food and Livelihood Security in Developing Countries: The Need for a Stronger Governance of Imports. Berlin: Heinrich Boll Foundation.

Goodman, D., \& Watts, M. (1997). Agrarian Questions: Global Appetite, Local Metabolism: Nature, Culture, and Industry in Fin-de-siecle Agro-food Systems In D. Goodman \& M. Watts (Eds.), Globalising Food: Agrarian Questions and Global Restructuring. London: Routledge.

Gow, N. (2007). New Zealand Government's Involvement in Agriculture: The Road to Nonsustainability. Paper presented at the 16th International Farm Management Association Congress: A Vibrant Rural Economy - The Challenge for Balance. from http://www.ifmaonline.org/pdf/congress/07N_Gow_etal.pdf

Habermas, J. (1978). Knowledge and Human Interests London: Heinemann.

Harvey, D. (2005). A Brief History of Neoliberalism. New York: Oxford University Press. Hawkes, C. (2006). Uneven Dietary Development: Linking the Policies and Processes of Globalization with the Nutrition Transition, Obesity and Diet-related Chronic Diseases. Globalization and Health 2(4).

Held, D., McGrew, A., Goldblatt, D., \& Perraton, J. (Eds.). (1999). Global Transformations: Politics, Economics and Culture. Cambridge: Polity Press.

Houghton, P. (1996). People of the Great Ocean. Cambridge: Cambridge University Press. Hughes, R. (2003). Diet, Food Supply and Obesity in the Pacific. Geneva: World Health Organization. 
Hughes, R., \& Lawrence, M. (2005). Globalisation, Food and Health in Pacific Island Countries. Asia Pacific Journal of Clinical Nutrition, 14(4), 298-306.

Ilbery, B. (2005). Changing Geographies of Global Food Production. In P. Daniels, M. Bradshaw, D. Shaw \& J. Sidaway (Eds.), An Introduction to Human Geography in the 21st Century (2nd ed.). Essex: Pearson Education Limited.

Institute for International Trade (2008). Research Study on the Benefits, Challenges and Ways Forward for PACER-Plus. Adelaide: Institute for International Trade.

Jackson, J. (2006). Reflections on the Possible Research Agenda for Exploring the Relationship between Human Rights Norms and International Trade Rules. In F. Abbot, C. Breining-Kaufmann \& T. Cottier (Eds.), International Trade and Human Rights: Foundations and Conceptual Issues (pp. 19-28). Ann Arbor: The University of Michigan Press.

Kanbur, R., \& Shaffer, P. (2005). Epistomology, Normative Theory and Poverty Analysis: Implications for Q-Squared in Practice. World Development, 35(2), 183-196.

Kelsey, J. (2004a). Big Brothers Behaving Badly: The Implications for the Pacific Islands of the Pacific Agreement on Closer Economic Relations. Suva: Pacific Network on Globalisation

Kelsey, J. (2004b). A People's Guide to PACER. Suva: Pacific Network on Globalisation. Kelsey, J. (2005). World Trade and Small Nations in the South Pacific region. Kansas Journal of Law and Public Policy, 14, 247-306.

Kelsey, J. (2009a). The Legality of Excluding Fiji From PACER-Plus Discussions. Suva: Pacific Network on Globalisation.

Kelsey, J. (2009b). Submission to the New Zealand Ministry of Foreign Affairs and Trade on the Proposal to Negotiate a 'PACER-Plus' Free Trade Agreement Among the Parties to the Pacific Agreement on Closer Economic Relations, from http://www.mfat.govt.nz/downloads/foreignrelations/pacific/Submissions/PACER_Plus_public_submission_Jane_Kelsey.pdf

Kennedy, G., Nantel, G., \& Shetty, P. (2004). Globalization of Food Systems in Developing Countries: A Synthesis of Country Case Studies Globalization of Food Systems in Developing Countries: Impact on Food Security and Nutrition. Rome: Food and Agriculture Organization of the United Nations.

Kent, G. (2005). Freedom From Want: The Human Right to Adequate Food. Washington D.C.: Georgetown University Press. 
Kitchin, R., \& Tate, N. (2000). Conducting Research into Human Geography: Theory, Methodology and Practice. Essex: Pearson Education Limited.

Knuth, L., \& Vidar, M. (2011). Constitutional and Legal Protection of the Right to Food Around the World. Rome: Food and Agriculture Organization of the United Nations. Lancet (2009). The Undernutrition Epidemic: An Urgent Health Priority. Editorial. The Lancet, 375(9711), 1473.

Maddison, A. (2001). The World Economy: A Millenial Perspective. Paris: Organisation for Economic Co-operation and Development.

Malthus, T. (1992). An Essay on the Principle of Population (5th ed.). London: J. Murray.

Marinoff, L. (2007). Ethics, Globalization and Hunger: An Ethicist's Perspective. In P. Sandoe \& P. Pinstrup-Andersen (Eds.), Ethics, Hunger and Globalization: In Search of Appropriate Policies (pp. 29-49). Dordrecht: Springer.

May, T. (1997). Social Research: Issues, Methods and Process (2nd ed.). Buckingham: Open University Press.

McCullough, E., Pingali, P., \& Stamoulis, K. (2008). Small Farms and the Transformation of Food Systems: An Overview. In E. McCullough, P. Pingali \& K. Stamoulis (Eds.), The Transformation of Agri-food Systems: Globalization, Supply Chains and Smallholder Farmers. London: Food and Agriculture Organization of the United Nations.

McGee, T. (1975). Food Dependency in the Pacific: A Preliminary Statement. Canberra: Socpac Printery.

McGrew, A., \& Lewis, P. (1992). Global Politics: Globalization and the Nation State. Cambridge: Polity Press.

McKee, H. (1957). Some Food Problems in the Pacific Islands. Noumea New Caledonia: South Pacific Commission.

McMichael, A., \& Beaglehole, R. (2000). The Changing Global Context of Public Health. The Lancet, 356, 495-499.

McMichael, P. (1994). Agro-Food System Restructuring - Unity in Diversity. In P. McMichael (Ed.), The Global Restructuring of Agro-food Systems. New York: Cornell University.

McMichael, P. (1996). Globalization: Myths and Realities. Rural Sociology, 61(1), 25-55. Mechlem (2006). Harmonizing Trade in Agriculture and Human Rights: Options for the Integration of the Right to Food in the Agreement on Agriculture. In A. Von 
Bogdandy \& R. Wolfrum (Eds.), Max Planck Yearbook of United Nations Law (Vol. 10, pp. 127-190): Koninklijke Brille.

MFAT (2008). New Zealand Handbook on International Human Rights. Wellington: Ministry of Foreign Affairs and Trade.

MFAT (2009a). Cabinet External Relations and Defence Committee Minute of Decision: PACER Plus: Commencement of Negotiations Wellington: Ministry of Foreign Affairs and Trade.

MFAT (2009b). Ministry Statements and Speeches 2008, from http://www.mfat.govt.nz/Media-and-publications/Media/MFAT-speeches/2008/0-18November-2008.php

MFAT (2010a). Foreign Relations: Pacific, from http://www.mfat.govt.nz/Foreign$\underline{\text { Relations/Pacific/Trade/index.php }}$

MFAT (2010b). The Right to Adequate Food. Wellington: Ministry of Foreign Affairs and Trade.

MFAT (2011a). Improving Access to Markets, from http://www.mfat.govt.nz/Trade-and-

Economic-Relations/NZ-and-the-WTO/Improving-access-to-markets/0agriculturenegs.php\#news

MFAT (2011b). International Development Policy Statement. Wellington: Ministry of Foreign Affairs and Trade.

MFAT (2011c). Market Access, from http://www.mfat.govt.nz/Trade-and-EconomicRelations/1-Market-access/index.php

Ministry of National Planning Fiji (2010). Millennium Development Goals: 2nd Report, 1999 - 2009: Report for the Fiji Islands, from http://www.undp.org.fj/pdf/Millennium\%20\%20Development\%20Goals.pdf

MOH (2002). Fiji Non-communicable Diseases (NCD) Steps Survey 2002. Suva: Ministry of Health

Morgan, W. (2010). Putting Development on the Agenda: Negotiating a Regional Trade Agreement for the Pacific Islands Forum. Paper presented at the Australian Political Studies Association Conference 2010 - 'Connected Globe: Conflicting Worlds'. from http://apsa2010.com.au/full-papers/pdf/APSA2010 0076.pdf

Murphy, S., \& Paasch, A. (Eds.). (2009). The Global Food Challenge: Towards a Human Rights Approach to Trade and Investment Policies. Bern: Brot Fur Alle [Bread For All]. 
Murray, W. (2006). Geographies of Globalization. New York: Routledge.

Murray, W. (2008). Neoliberalism, Rural Underdevelopment and Geographies of the Global South. Human Geography, 1(1), 33-38.

Murray, W. (2009a). Neoliberalism and Development. In N. Turitt \& N. Cotree Check (Eds.), International Encyclopedia of Human Geography. London: Elsevier Ltd.

Murray, W., \& Overton, J. (2003). Designing Development Research. In R. Scheyvens \& D. Storey (Eds.), Development Fieldwork: A Practical Guide (pp. 17-36). London: Sage Publications.

Narayan, P. (2009). Social Policies in Small Island States: A Case Study of the Fiji Islands.

Geneva: United Nations Research Institute for Social Development.

Narsey, W. (2006). Report on the 2002-03 Household Income and Expenditure Survey. Suva: Fiji Islands Bureau of Statistics.

National Food and Nutrition Centre (2007). 2004 Fiji National Nutrition Survey: Main Report. Suva: National Food and Nutrition Centre.

Niumataiwalu, A. (2009, October 15). Fiji makes top 4 obese list. The Fiji Times ONLINE,

Nutzenadel, A., \& Trentmann, F. (2008). Introduction: Mapping Food and Globalization. In A. Nutzenadel \& F. Trentmann (Eds.), Food and Globalization: Consumption, Markets and Politics in the Modern World (pp. 1-20). Oxford: Berg.

NZAID (2003). Harnessing Trade for International Development. Wellington: New Zealand Agency for International Development

NZAID (2008). Economic Growth and Livelihoods Wellington: New Zealand Agency for International Development

NZAID (2010). Where NZAID Works: Fiji, from http://www.nzaid.govt.nz/programmes/cfiji.html

Overton, J., \& Dierman, P. (2003). Using Quantitative Techniques. In R. Scheyvens \& D. Storey (Eds.), Development Fieldwork: A Practical Guide (pp. 37-56). London: Sage Publications.

Oxfam New Zealand (2009). Submission to the Ministry of Foreign Affairs and Trade on PACER Plus the proposed free trade agreement between New Zealand and Australia and the Pacific Forum Island Countries Provided for Under the Pacific Agreement on Closer Economic Relations (PACER). Auckland: Oxfam New Zealand. 
Paasch, A., Garbers, F., \& Hirsch, T. (2007). Trade Policies and Hunger - The Impact of Trade Liberalisation on the Right to Food of Rice Farming Communities in Ghana, Honduras and Indonesia. Geneva: Ecumenical Advocacy Alliance.

Pacific Islands Forum Secretariat (2010). Final Outcomes of Food Summit, from http://www.forumsec.org.fj/pages.cfm/newsroom/press-statements/2010/finaloutcomes-of-food-summit-1.html

Panagariya, A. (2002). Trade and Food Security: Conceptualizing the Linkages. Paper presented at the Conference on Trade, Agricultural Development and Food Security: The Impact of Recent Economic and Trade Policy Reform. from http://129.3.20.41/eps/it/papers/0308/0308012.pdf

PANG (2008). Making Waves: Opportunities for Reclaiming Development in the Pacific. Suva: Pacific Network on Globalisation.

PANG (2009a). New Trading Agreements with New Zealand and Australia: What Options for Development? Suva: Pacific Network on Globalisation.

PANG (2009b). What's the Rush? - PACER-Plus: Let's get it Right, from http://pactrade.wordpress.com/2009/10/21/what $\%$ E2\%80\%99s-the-rush$\% \mathrm{E} 2 \% 80 \% 93$-pacer-plus-let $\% \mathrm{E} 2 \% 80 \% 99$ s-get-it-right/

Parkinson, S. (1973). Some Observations on the Causes of Malnutrition in Pacific Island Urban Communities. In J. Harre (Ed.), Living in Town: Problems and Priorities in Urban Planning in the South Pacific (pp. 85-92). Suva: South Pacific Social Sciences Association and the University of the South Pacific.

Parry, J. (2010). Pacific Islanders Pay Heavy Price for Abandoning Traditional Diet. Bulletin of the World Health Organization, 88, 484-485.

Penjueli, M., \& Morgan, W. (2010). Putting Development First: Concerns about a Pacific Free Trade Agreement. Pacific Economic Bulletin, 25(1), 211-221.

Pingali, P. (1997). From Subsistance to Commercial Production Systems: The Transformation of Asian Agriculture. American Journal of Agricultural Economics, 79(2), 628-634.

Pinstrup-Andersen, P., \& Pandya-Lorch, R. (2001). Putting the Knowledge to Work for the Poor: Required Policy Action. In P. Pinstrup-Andersen \& R. Pandya-Lorch (Eds.), The Unfinished Agenda: Perspectives on Overcoming Hunger, Poverty and Environmental Degredation (pp. 269-276). Washington, D.C. : International Food Policy Institute. Pinstrup-Andersen, P., \& Sandoe, P. (Eds.). (2007). Ethics, Hunger and Globalization: In Search of Appropriate Policies. Dordrecht: Springer. 
Pollock, N. (1992). These Roots Remain: Food Habits in the Islands of the Central and Eastern Pacific Since Western Contact. Honolulu: University of Hawaii Press.

Rae, I., Thomas, J., \& Vidar, M. (2007). The Right to Food as a Fundamental Human Right: FAO's Experience. In B. Guha-Khasnobis, S. Acharya \& B. Davis (Eds.), Food Insecurity, Vulnerability and Human Rights Failure. Hampshire: Palgrave Macmillan.

Rahnema, M. (1997). Towards Post-Development: Searching for Signposts, a New Language and New Paradigms. In M. Rahnema \& V. Bawtree (Eds.), The Post-Development Reader (pp. 377-404). London: Zed Books.

Regmi, A., \& Dyck, J. (2001). Effects of Urbanization on Global Food Demand. In A. Regmi (Ed.), Changing Structures of Global Food and Consumption and Trade. Washington D.C.: Economic Research Service, United States Department of Agriculture.

Reutlinger, S. (1987). Food Security and Poverty in Developing Countries. In J. Gittinger, J. Leslie \& C. Hoisington (Eds.), Food Policy: Integrating Supply, Distribution and Consumption (pp. 205-214). Baltimore: The John Hopkins University Press.

Robinson, M. (2007). Social Justice, Ethics and Hunger: What are the Key Messages. In P. Pinstrup-Andersen \& P. Sandoe (Eds.), Ethics, Hunger and Globalization: In Search of Appropriate Policies (pp. vii-xv). Dordrecht: Springer.

Rodrik, D. (2001). The Global Governance of Trade: As if Development Really Mattered. New York: United Nations Development Programme.

Rody, N. (1978). Consumerism in Micronesia. South Pacific Bulletin, 28, 9-14.

Ruggie, J. (2008). Protect, Respect and Remedy: A Framework for Business and Human Rights, from http://www.reports-and-materials.org/Ruggie-report-7-Apr-2008.pdf

Ruggie, J. (2009). Opening Statement to the United Nations Human Rights Council, from http:/www.unglobalcompact.org/docs/news_events/9.6/Ruggie_Remarks 5 Oct2009. pdf

Runge, C., Senauer, B., Pardey, P., \& Rosegrant, M. (2003). Ending Hunger in Our Lifetime: Food Security and Globalization Baltimore: John Hopkins University Press.

Sandoe, P., Jensen, K., \& Pinstrup-Andersen, P. (2007). Concluding Reflections on the Role of Ethics. In P. Pinstrup-Andersen \& P. Sandoe (Eds.), Ethics, Hunger and Globalization Dordrecht: Springer.

Sarris, A. (2009). Evolving Structure of World Agricultural Trade and Requirements for New World Trade Rules. Paper presented at the Expert Meeting on How to Feed the World in 2050 . 
Scheyvens, R., \& Storey, D. (2003). Introduction. In R. Scheyvens \& D. Storey (Eds.), Development Fieldwork: A Practical Guide. London: Sage Publications Ltd.

Schultz, J. (2004). Globalization, Urbanisation and the Nutrition Transition in Developing Island Country: A Case Study in Fiji. In FAO (Ed.), Globalization of Food Systems in Developing Countries: Impact on Food Security and Nutrition (pp. 195-214). Rome: Food and Agriculture Organization of the United Nations.

Sharma, K. L. (2007). Food Security in the South Pacific Island Countries with Special Reference to the Fiji Islands. In B. Guha-Khasnobis, S. Acharya \& B. Davis (Eds.), Food Insecurity, Vulnerability and Human Rights Failure. Hampshire: Palgrave Macmillan.

Shaw, B. (1995). Contradictions between Action and Theory: Feminist Participatory Research in Goa, India. Antipode, 27(1), 91-99.

Shaw, D. (2005). The Making of the Twentieth-century World. In P. Daniels, M. Bradshaw, D. Shaw \& J. Sidaway (Eds.), An Introduction to Human Geography: Issues for the 21st Century (2nd ed.). Essex: Pearson Education Limited.

Shetty, P. (2011). Addressing Micronutrient Malnutrition to Achieve Nutrition Security. In B. Thompson \& L. Amoroso (Eds.), Combating Micronutrient Deficiencies: Food-based Approaches (pp. 28-40). Rome: Food and Agriculture Organization of the United Nations.

Simatupang, P., \& Flemming, E. (2001). Food Security Strategies for Selected South Pacific Island Countries: Proceedings of a Workshop Held in Sydney, Australia December 12-13 2000. Sydney: CGPRT Centre.

Singer, P. (1972). Famine, Affluence, and Morality. Philosophy and Public Affairs, 1(1), 229243.

Snowden, W., \& Swinburn, B. (2008). Improving Diets and Controlling Noncommunicable Diseases: Ways Forward for the Pacific Islands (Draft Background Paper). Melbourne: WHO Collaborating Centre for Obesity Prevention Deakin University.

Soubbotina, T., \& Sheram, K. (2000). Beyond Economic Growth: Meeting the Challenges of Global Development Washington D.C.: The World Bank.

South Centre (2008). Article XXIV and RTAs: How Much Wiggle Room for Developing Countries. Geneva: South Centre.

SPC (2009a). Our Increasing Population Demands Greater Food Production, from http://www.spc.int/lrd/index.php?option=com_content\&view=article\&id=380:our- 
increasing-population-demands-greater-food-production-\&catid=117:training-andworkshops\&Itemid=19

SPC (2009b). Pacific NCD Forum Meeting Report. New Caledonia: Secretariat of the Pacific Community.

Spitz, P. (2002). The Right to Food and Food Security: Crucial Issues of the Twenty-first Century. In M. Borghi \& L. Blommestein (Eds.), For an Effective Right to Adequate Food. Agno: Editions Universitaires Fribourg Suisse.

Statistics New Zealand (2010). Global New Zealand: Year Ended June 2010. Wellington: Statistics New Zealand.

Sumner, A., \& Tribe, M. (2008). International Development Studies: Theories and Methods in Research and Practice. London: Sage Publications Ltd.

Tashakkori, A., \& Teddlie, C. (2003). Handbook of Mixed Methods in Social and Behavioural Research. Thousand Oaks: Sage Publications, Inc.

Thaman, R. (1982). The Foods That Came First. Alafua Agricultural Bulletin, 7(3), 105-116.

Thaman, R. (1984). Food Dependency and Malnutrition: Deterioration of Traditional Pacific Food Systems. In E. Utrecht (Ed.), Fiji: Client State of Australasia? Sydney:

Transnational Corporations Research Project University of Sydney.

Thaman, R. (1988a). Consumerism, The Media, and Malnutrition in the Pacific Islands. The Journal of Pacific Studies, 14, 68-96.

Thaman, R. (1988b). Health and Nutrition in the Pacific Islands: Development or Underdevelopment? Geojournal, 16(2), 211-227.

Thaman, R. (1990). The Evolution of the Fiji Food System. In A. Jansen, S. Parkinson \& A. Robertson (Eds.), Food and Nutrition in Fiji: Food Production, Composition and Intake (Vol. 1). Suva: Fiji School of Medicine, The University of the South Pacific.

Thaman, R. (2005). Biodiversity is the Key to Food Security. Spore, 117, 16.

Thaman, R. (2009). Sustainability. In R. Gillespie \& Clague (Eds.), Encyclopedia of Islands (pp. 888-896). Berkeley: University of California Press.

Thow, A., Heywood, P., Schultz, J., Quested, C., Jan, S., \& Colagiuri, S. (2011). Trade and the Nutrition Transition: Strengthening Policy for Health in the Pacific. Ecology of Food and Nutrition, 50(1), 18-42.

Thow, A., \& Snowden, W. (2010). The Effect of Trade and Trade Policy on Diet and Health in the Pacific Islands. In C. Hawkes, C. Blouin, S. Henson, N. Drager \& L. Dube 
(Eds.), Trade, Food, Diet and Health: Perspectives and Policy Options (pp. 147-168). West Sussex: Blackwell.

Tuiketei, T., Snowdon, W., Waqa, G., Kremer, P., Schultz, J., \& Vanualailai, N. (2010). Pacific Obesity Prevention in Communities Project (OPIC) Fiji Country Report: Fiji School of Medicine, Deakon University.

Tutwiler, M., \& Straub, A. (2007). Reforming Agricultural Trade: Not Just for the Wealthy Countries. In P. Pinstrup-Andersen \& P. Sandoe (Eds.), Ethics, Hunger and Globalization. Dordrecht: Springer.

UNDP (2006). Trade on Human Terms: Transforming Trade for Human Development in Asia and the Pacific. Colombo: Macmillan India Ltd.

UNESCAP (2009). Sustainable Agriculture and Food Security in Asia and the Pacific. Bangkok: United Nations Economic and Social Commission for Asia and the Pacific.

UNICEF (2004). Vitamin and Mineral Deficiency: A Global Progress Report: United Nations Children's Fund

UNICEF (2010). Food and Nutrition Security In Pacific Island Nations and Territories. Suva: UNICEF Pacific Multi-Country Office.

UNICEF, WHO, UNESCO, UNFPA, UNDP, UNAIDS, et al. (2010). Facts for Life. New York: United Nations Children's Fund.

United Nations (1948). Universal Declaration of Human Rights from http://www.un.org/en/documents/udhr/index.shtml

United Nations (1975). Report of the World Food Conference, Rome 5-16 November 1974. New York: United Nations.

United Nations (1976). International Covenant on Economic Social and Cultural Rights from http://www2.ohchr.org/english/law/pdf/cescr.pdf

United Nations (1993). Vienna Declaration and Programme of Action. New York: United Nations.

United Nations (2010). The Right to Adequate Food. Geneva: Office of the High Commissioner for Human Rights.

UNRISD (2010). United Nations Research Institute for Social Development Press Release: Poverty Reduction Must Go Beyond Targeting the Poor, from http://www.unrisd.org/unrisd/website/newsview.nsf/54963870bfa2f33f80256b56005e 750d/554017d0f66983aec125779200442c36/\$FILE/PovRepPR.pdf

Vatucawaqa, P. (2009). Fiji Food Balance Sheet. Suva: National Food and Nutrition Centre. 
Visser, W., Matten, D., Pohl, M., \& Tolhurst, N. (Eds.). (2007). The A - Z of Corporate Social Responsibility: A Complete Reference Guide to Concepts, Codes and Organisations. Chichester: John Wiley and Sons Ltd

Walsh, C. (2010). Pacific Scoop: Melanesian Spearhead Group Plus...minus, divided and multiplied, from http://pacific.scoop.co.nz/2010/06/melanesian-spearhead-group-plusminus-divided-and-multiplied/

Warnock, J. (1987). The Politics of Hunger. New York: Methuen Publications.

Watters, R. (2008). Journeys Towards Progress: Essays of a Geographer on Development and Change in Oceania. Wellington: Victoria University Press.

Whatmore, S. (2002). From Farming to Agri-business: Global Agri-food Networks. In R. Johnston, P. Taylor \& M. Watts (Eds.), Geographies of Global Change. Oxford: Blackwell

WHO (2005). Preventing Chronic Disease: A Vital Investment. Geneva: World Health Organization.

WHO (2008). Closing the Gap in a Generation: Health Equity Through Action on the Social Determinants of Health. Geneva: World Health Organization.

WHO (2010). World Health Statistics. Geneva: World Health Organization.

Winters, A. (2000). Trade, Trade Policy and Poverty: What are the Links. London: CEPR Discussion Paper No. 2382.

Wolter, F. (2002). The WTO and the Right to Food. In M. Borghi \& L. Blommestein (Eds.), For an Effective Right to Adequate Food (pp. 119-130). Agno: Editions Universitaires Fribourg Suisse.

World Bank (2006). Not if but When: Adapting to Natural Hazards in the Pacific Islands Region. Washington D.C.: The World Bank.

World Food Programme (2011). Hunger Stats, from http://www.wfp.org/hunger/stats

World Hunger (2011). 2011 World Hunger and Poverty Facts and Statistics, from http://www.worldhunger.org/articles/Learn/world\%20hunger\%20facts\%202002.htm

WTO (2010). Principles of the Trading System, from http://www.wto.org/english/thewto_e/whatis_e/tif_e/fact2_e.htm

WTO (n.d.). The General Agreement on Trade and Tariffs (GATT 1947), from http://www.wto.org/english/docs_e/legal_e/gatt47_02_e.htm 
Wyber, R., Wilson, N., \& Baker, M. (2009). New Zealand's Impact on Health in the South Pacific: Scope for Improvement? The New Zealand Medical Journal 122(1291), 6068.

Ziegler, J. (2003a). United Nations Economic and Social Council Commission on Human Rights Fifty-ninth Session: Economic, Social and Cultural Rights - The Right to Food E/CN.4/2003/54, from http://www.righttofood.org/new/PDF/ECN4200354.pdf Ziegler, J. (2003b). United Nations General Assembly Fifty-eighth Session: Human Rights Questions A/58/330, from http://www.righttofood/new/PDF/A58330.pdf

Ziegler, J. (2006). United Nations Economic and Social Council Sixty-second Session Economic, Social and Cultural Rights: The Right to Food E/CN.4/2006/44, from http://www.righttofood.org/new/PDF/Human\%20Rights\%20Council\%202006.pdf

Ziegler, J. (2009). Preliminary Report to the Drafting Group of the Human Rights Council Advisory Committee on the Right to Food, from http://www2.ohchr.org/english/bodies/hrcouncil/.../A.HRC.AC.2.CRP.2.doc 


\title{
Appendix A: Interview Guide
}

\author{
$\mathrm{KI}=$ Key Informant
}

\begin{tabular}{|llll|}
\hline Reference & Name & Organisation & Area of Knowledge \\
\hline KI(Roberts) & Emma Roberts & Tagi Tuba Initiative & Conservation, food security \\
\hline KI(Moore) & Penelope Moore & Women's Action for Change & $\begin{array}{l}\text { Community } \\
\text { wellbeing/Informal } \\
\text { Settlements }\end{array}$ \\
\hline KI(Namoce) & Josua Namoce & Consumer Council of Fiji & Consumer Affairs \\
\hline KI(Kumar) & Premila Kumar & Consumer Council of Fiji & Consumer Affairs \\
\hline KI(Thaman) & Randy Thaman & University of the South Pacific & Pacific Ethnobiology \\
\hline KI(1) & Confidential & Confidential & $\begin{array}{l}\text { Economics (with reference to } \\
\text { Pacific island states) }\end{array}$ \\
\hline KI(Yabaki) & Tamarisi Yabaki & University of the South Pacific & Agriculture \\
\hline KI(Koto) & Camari Koto & University of the South Pacific & Informal Settlements \\
\hline KI(Larkan) & Hirday Larkan & $\begin{array}{l}\text { Independent, small holder dairy } \\
\text { farmer }\end{array}$ & Meat industry/agriculture \\
\hline KI(Seniloli) & Ratu Seniloli & Rewa Dairy Company Ltd & Dairy industry \\
\hline KI(Halavatu) & Dr Halavatu & Secretariat of the Pacific & Food security and agriculture \\
& & Community & Trade and agriculture \\
\hline KI(Morgan) & Wesley Morgan & $\begin{array}{l}\text { PANG/Oxfam } \\
\text { Australia/Independent }\end{array}$ & \\
\hline KI(McBryde) & Michael McBryde & $\begin{array}{l}\text { Ministry of Foreign Affairs and } \\
\text { Trade }\end{array}$ & Human rights \\
\hline KI(2) & Confidential & Ministry of Foreign Affairs and & Pacific Trade policy \\
\hline KI(3) & Confidential & Ministry of Foreign Affairs and & Economics/Aid and \\
& & Trade & Fovelopment \\
\hline KI(4) & Confidential & Confidential & Food security \\
\hline KI(5) & Confidential & Confidential & Public Health/Food security \\
\hline KI(Matheson) & Don Matheson & Massey University & \\
\hline & & & \\
\hline
\end{tabular}




\section{Appendix B: Consent Form}

\section{CONSENT TO PARTICIPATION IN RESEARCH}

Title of project: Food insecurity in the Pacific: New Zealand's Role - Past, Present and Future

I have been given and have understood an explanation of this research project. I have had an opportunity to ask questions and have them answered to my satisfaction. I understand that I may withdraw myself or any information I have provided from this project before January $15^{\text {th }} 2011$ (after which time the research will have been published) without having to give reason.

I understand that the interview will be electronically recorded and that any notes or recorded material from the interviews will be destroyed within 5 years of the completion of research. I understand that all information taken from the interviews will be safely stored and accessed only by the research and the research supervisor.

I understand that the information I have provided will be used only for this research project and that any further use will require my written consent. I understand that the results of this research will be included in a thesis and may be published in academic or professional journals, and or presented at academic or professional conferences.

$\mathrm{I}$, (name), agree to take part in this research.

Please tick as appropriate:

1) $\square$ I would like to receive a summary of this research when it is completed

2) $\square$ I consent to my name being used when my comments or opinions are used in this research

I request my name to be omitted and a pseudonym to be used if my comments or opinions are included in this research

3) $\square$ I consent to the name of the organisation I work for being used in this research

I request that the name of the organisation I work for be omitted from this research

Organisation:

Signed:

Date: 


\section{Appendix C: Interview Guides}

Please note: These are general guiding questions only. Interviewees were from a variety of backgrounds and questions were tailored towards each interviewee's individual area of knowledge.

\section{For Participants in Fiji}

1) How has the typical diet changed in Fiji over the course of your life?

2) How much of what is eaten is locally produced/imported, bought/grown?

3) Are you aware of situations where people/families/communities are without access to sufficient amounts nutritional food for a health life?

4) In your opinion, what are some of the causes of this?

5) What are the challenges facing Fiji in the provision of nutritional foods to the population?

6) What other social/economic changes have you witnessed in the past 50 years?

7) How does these relate to food production and consumption?

8) Do you think food trade with New Zealand has had a role to play in these changes?

9) From your experience what is the general attitude towards imported food? Locally produced food? Is there a preference?

10) What is the general attitude towards New Zealand's food trade (imports) with Fiji?

11) How could ensuring food security in Fiji best be addressed?

12) What is currently doing to this effect?

13) Would you/ the organisation like to see changes in the relationship between New Zealand and Fiji and the way we trade food and the items we trade?

For participants in New Zealand

1) To what degree are you aware of food insecurity in the Pacific

2) How does it present itself

3) What are some of the major factors contributing to food insecurity in the Pacific

4) What are the main concerns in the Pacific/Fiji in regards to food

5) Does New Zealand have a role in any of these factors?

6) Are you aware of any impacts stemming from NZs trade on local livelihoods, and people's ability to access nutritional food in sufficient quantities for health living

7) What role does New Zealand have in supporting food security in the Pacific? How, in your opinion, might New Zealand better support food security in the Pacific?

8) Are you aware or have you come across in your work the right to food as an approach to supporting food security in the Pacific, and in what sense?

9) How are the right to food and food security concerns taken into account in developing policy? 


\section{Appendix D: Guide to Harmonised System Categories}

\section{Section I Live Animals; Animal Products}

1. Live animals

2. Meat and edible meat offal

3. Fish and crustaceans, molluscs and other aquatic invertebrates

4. Dairy produce; birds' eggs; natural honey; edible products of animal origin, not elsewhere specified or included

5. Products of animal origin, not elsewhere specified or included

\section{Section II Vegetable Products}

6. Live trees and other plants; bulbs, roots and the like; cut flowers and ornamental foliage

7. Edible vegetables and certain roots and tubers

8. Edible fruit and nuts; peel of citrus fruit or melons

9. Coffee, tea, maté and spices

10. Cereals

11. Products of the milling industry; malt; starches; inulin; wheat gluten

12. Oil seeds and oleaginous fruits; miscellaneous grains, seeds and fruit; industrial or medicinal plants; straw and fodder

13. Lac; gums, resins and other vegetable saps and extracts

14. Vegetable plaiting materials; vegetable products not elsewhere specified or included

Section III Animal or Vegetable or Vegetable Fats and Oils and their Cleavage Products; Prepared Edible Fats; Animal or Vegetable Waxes

15. Animal or vegetable fats and oils and their cleavage products; prepared edible fats; animal or vegetable waxes

\section{Section IV Prepared Foodstuffs; Beverages, Spirits and Vinegar; Tobacco and Manufactured Tobacco Substitutes}

16. Preparations of meat, of fish or of crustaceans, molluscs or other aquatic invertebrates

17. Sugars and sugar confectionery

18. Cocoa and cocoa preparations

19. Preparations of cereals, flour, starch or milk; pastrycooks' products

20. Preparations of vegetables, fruit, nuts or other parts of plants

21. Miscellaneous edible preparations

22. Beverages, spirits and vinegar

23. Residues and waste from the food industries; prepared animal fodder

24. Tobacco and manufactured tobacco substitutes

25. Salt; sulphur; earths and stone; plastering materials, lime and cement 


\section{Appendix E: Foods exported from New Zealand to Fiji 2008-2010}

*Products in bold traded in excess of NZ $\$ 1,000,000$

\begin{tabular}{|c|c|c|c|}
\hline Description & Unit & Quantity & Value NZ\$M \\
\hline & & 3yr average & 3yr average \\
\hline Meat Of Bovine Animals, Fresh Or Chilled & KG & 22,247 & 0.265 \\
\hline Meat Of Bovine Animals, Frozen & KG & 599,258 & 2.753 \\
\hline Meat Of Swine, Fresh, Chilled Or Frozen & KG & 286 & 0.003 \\
\hline Meat Of Sheep Or Goats, Fresh Or Chilled Or Frozen & KG & $5,902,906$ & 19.149 \\
\hline Edible Offal Of Bovine Animals, Swine, Sheep, Goat & KG & $1,097,764$ & 2.310 \\
\hline Meat And Edible Offal, Of The Poultry Of Heading 0 & KG & $1,207,967$ & 2.583 \\
\hline Meat And Edible Meat Offal Nes, Fresh, Chilled Or Frozen & KG & 861 & 0.004 \\
\hline Meat \& Edible Meat Offal, Cured; Edible Flours And & KG & 1,422 & 0.003 \\
\hline Fish, Fresh Or Chd, Excl Fish Fillets \& Other Fish & KG & 1,242 & 0.023 \\
\hline Fish, Frozen, Excl Fish Fillets And Other Fish Mea & KG & 976,358 & $\mathbf{1 . 5 1 7}$ \\
\hline Fish Fillets And Other Fish Meat, W/N Minced, Fres & KG & 8,377 & 0.035 \\
\hline Fish, Cured; Smoked Fish W/N Cooked; Fish Meal Fit & KG & 11,211 & 0.094 \\
\hline Crust W/N In Shell, Live, Fr Etc; Crust In Shell C & KG & 15,076 & 0.201 \\
\hline Mol W/N In Shell, Live, Aqua Invert O/T Crust \& Mo & & $\ldots$ & 0.340 \\
\hline Milk And Cream, Not Concentrated Nor Sweetened & $\mathbf{L}$ & $6,398,567^{*}$ & 4.934 \\
\hline Milk And Cream, Concentrated Or Sweetened & KG & $2,243,902$ & 10.358 \\
\hline Buttermilk, Cream, Yogurt Etc, W/N Conc, Sweet Or & KG & 53,363 & 0.186 \\
\hline Whey, W/N Concentrated Or Sweet; Natural Milk Prod & KG & 53,858 & 0.173 \\
\hline Butter And Other Fats And Oils Derived From Milk ; & KG & $2,075,579$ & 10.801 \\
\hline Cheese And Curd & KG & 188,338 & 1.545 \\
\hline Birds' Eggs, In Shell, Fresh, Preserved Or Cooked & & $\ldots$ & 1.492 \\
\hline Birds'Eggs Unshelled,Egg Yolks,Fr Dried, Ckd By Wa & KG & 6,349 & 0.041 \\
\hline Honey, Natural & KG & 4 & $\ldots$ \\
\hline Potatoes, Fresh Or Chilled & KG & $17,954,618$ & $\mathbf{1 0 . 3 3 3}$ \\
\hline Tomatoes, Fresh Or Chilled & KG & 31,817 & 0.115 \\
\hline Onions, Shallots, Garlic, Leeks \& Other Alliaceous & & $\ldots$ & 5.150 \\
\hline Cabbages, Cauliflowers, Kohlrabi, Kale \& Sim Edibl & KG & 101,674 & 0.190 \\
\hline Lettuce And Chicory, Fresh Or Chilled & KG & 52,978 & 0.192 \\
\hline Carrots, Turnips, Salad Beetroot \& Sim Edible Root & KG & $2,369,958$ & 1.491 \\
\hline Cucumbers And Gherkins, Fresh Or Chilled & KG & 1,940 & 0.009 \\
\hline Leguminous Vegetables, Shelled Or Unshelled, Fresh & KG & 579 & 0.005 \\
\hline Vegetables Nes, Fresh Or Chilled & KG & 177,986 & 0.419 \\
\hline Vegetables (Uncooked Or Cooked By Steaming Or Boil & KG & 291,531 & 0.465 \\
\hline Vegetables Dried, Whole, Cut, Sliced, Broken Or In & KG & 2,485 & 0.015 \\
\hline Vegetables, Leguminous Dried, Shelled W/N Skinned & KG & 939,206 & 0.873 \\
\hline Manioc, Arrowroot, Salep, Etc \& Sim Roots \& Tubers & KG & 52 & 0.000 \\
\hline Coconuts, Brazil Nuts And Cashew Nuts, Fresh Or Dr & KG & 25,581 & 0.082 \\
\hline Nuts Nes, Fresh Or Dried, Whether Or Not Shelled O & KG & 8,157 & 0.089 \\
\hline Bananas, Including Plantains, Fresh Or Dried & KG & 1,476 & 0.005 \\
\hline Dates, Figs,Pineapples,Avocadoes, Guavas, Mangoes \& & KG & 22,440 & 0.061 \\
\hline Citrus Fruit, Fresh Or Dried & KG & 78,519 & 0.163 \\
\hline
\end{tabular}




\begin{tabular}{|c|c|c|c|}
\hline Grapes, Fresh Or Dried & KG & 68,292 & 0.268 \\
\hline Melons (Including Watermelons) \& Papaws (Papayas), & KG & 12,388 & 0.044 \\
\hline Apples, Pears And Quinces, Fresh & KG & $1,598,204$ & 2.076 \\
\hline Apricots, Cherries, Peaches, (Incl Nectarines), Pl & KG & 8,625 & 0.034 \\
\hline Fruits Nes, Fresh & KG & 15,844 & 0.059 \\
\hline Fruits \& Nuts,Uncook Or Cooked By Water, Frozen, W & KG & 21,105 & 0.113 \\
\hline Fruits \& Nuts Provisionally Presv But Unfit For Im & KG & 263 & 0.001 \\
\hline Fruits,Dried O/T Of Hds 08.01 To 08.06 Mx Of Nuts & KG & 12,428 & 0.075 \\
\hline Peel Of Citrus Fruit Of Melons (Water- Melons)Fres & KG & 3,355 & 0.012 \\
\hline Coffee W/N Roast Or Decaff; Coffee Husks \& Skins; & KG & 7,289 & 0.109 \\
\hline Tea & KG & 3,191 & 0.047 \\
\hline Pepper Of The Genus Piper; Dried,Crus Or Grd Fruit & KG & 1,329 & 0.026 \\
\hline Vanilla & KG & 4 & 0.001 \\
\hline Cinnamon And Cinnamon-Tree Flowers & KG & 23 & 0.000 \\
\hline Cloves (Whole Fruit, Cloves And Stems) & KG & 31 & 0.000 \\
\hline Nutmeg, Mace And Cardamons & KG & 26 & 0.000 \\
\hline Seeds Of Anise, Badian,Fennel,Coriander, Cumin, $\mathrm{Ca}$ & KG & 17 & 0.000 \\
\hline Ginger, Saffron, Turmeric (Curcuma), Thyme, Bay Le & KG & 2,914 & 0.014 \\
\hline Wheat And Meslin & KG & $3,459,510$ & $\mathbf{1 . 0 8 5}$ \\
\hline Rye & KG & 2,833 & 0.003 \\
\hline Barley & KG & 173 & 0.000 \\
\hline Oats & KG & 73 & 0.000 \\
\hline Maize (Corn) & KG & 2,406 & 0.001 \\
\hline Rice & KG & 9,090 & 0.022 \\
\hline Grain Sorghum & KG & 567 & 0.001 \\
\hline Buckwheat, Millet And Canary Seed; Other Cereals & KG & 48 & 0.000 \\
\hline Wheat Or Meslin Flour & KG & 13,368 & 0.018 \\
\hline Cereal Flours Other Than Of Wheat Or Meslin & KG & 255,054 & 0.262 \\
\hline Cereal Grouts, Meal And Pellets & KG & 679,508 & 0.633 \\
\hline Cereal Grn O/W Worked (Ex Hulled Etc)Exc Rice Hd 1 & KG & 49,273 & 0.076 \\
\hline Flour, Meal, Powder, Flakes, Granules And Pellets & KG & 250 & 0.001 \\
\hline Flour,Meal \& Pdr Of Veg Of Hd 07.13, Of Sago Or Of & KG & 32 & 0.003 \\
\hline Malt, Whether Or Not Roasted & KG & 7,167 & 0.018 \\
\hline Starches; Inulin & KG & 5,320 & 0.012 \\
\hline Wheat Gluten, Whether Or Not Dried & KG & 3,745 & 0.013 \\
\hline Ground-Nuts, Not Roasted Or Otherwise Cooked W/N S & KG & 8 & 0.000 \\
\hline Linseed, Whether Or Not Broken & KG & 192 & 0.000 \\
\hline Sunflower Seeds, Whether Or Not Broken & KG & 401 & 0.002 \\
\hline Oil Seeds And Oleaginous Frutis Nes, Whether Or No & KG & 4,408 & 0.011 \\
\hline Flour And Meals Of Oil Seeds Or Oleaginous Fruits & KG & 263 & 0.001 \\
\hline Seeds, Fruit And Spores, For Sowing & KG & 6,899 & 0.027 \\
\hline Plants \& Pts (Incl Seeds \& Fruits) For Perf, Pharm & KG & 107 & 0.002 \\
\hline Locust Beans Etc, Fr,Chd,Frz/ Drd, Nes; Fruit Ston & KG & 158 & 0.003 \\
\hline Cereal Straw \& Husks, Unprepared, W/N Chopped, Gro & KG & 6,667 & 0.040 \\
\hline Swedes, Mangolds, Fodder Roots, Hay, Lucerne (Alfa & KG & 1,225 & 0.002 \\
\hline Lac; Natural Gums, Resins, Gum-Resins \& Oleoresins & KG & 424,158 & 0.536 \\
\hline Veg Saps \& Extr(O/T Oleoresin Extr) Pec Tic Subs E & KG & 3,824 & 0.026 \\
\hline Vegetable Products, Nes & KG & 100,423 & 0.056 \\
\hline Bovine,Sheep \& Goat Fats, O/T Hd 15.03 & KG & $1,252,705$ & 1.387 \\
\hline
\end{tabular}




\begin{tabular}{|c|c|c|c|}
\hline Fish Or Marine Mammals,Fats,Oils \& Their Fract W/N & $\mathrm{L} / \mathrm{KG}$ & $\ldots$ & 0.001 \\
\hline Soya-Bean Oil And Its Fractions, W/N Refined, But & $\mathrm{L}$ & 5,427 & 0.004 \\
\hline Ground-Nut Oil And Its Fractions, W/N Refined But & $\mathrm{L}$ & 142 & 0.000 \\
\hline Olive Oil And Its Fractions W/N Refined, But Not C & $\mathrm{L}$ & 881 & 0.021 \\
\hline Oils \& Their Fract Nes, Obt From Olives, W/N Ref'D & $\mathrm{L}$ & 413 & 0.004 \\
\hline Palm Oil \& Its Fraction, W/N Refined But Not Chemi & $\mathrm{L}$ & 8,120 & 0.013 \\
\hline Safflower, Sunflower Or Cotton-Seed Oil \& Fraction & $\mathrm{L}$ & 8 & 0.000 \\
\hline Coconut (Copra), Palm Kernel Or Babassu Oil \& Frac & $\mathrm{L}$ & 86 & 0.001 \\
\hline Rape,Colza Or Mustard Oil \& Their Fract, W/N Ref'D & $\mathrm{L}$ & 5,893 & 0.014 \\
\hline Fixed Vegetable Fats \& Oils (Incl Jojoba Oil) \& Fr & $\mathrm{L}$ & 11,912 & 0.070 \\
\hline Animal Or Veg Fats, Oils \& Fract, Hydrog Etc W/N R & KG & 53,687 & 0.136 \\
\hline Margarine;Edible Mx Or Prep Of Animal Or Veg Fats & KG & $287,639^{*}$ & 0.703 \\
\hline Animal Or Veg Fats \& Oils \& Fract Boiled Oxid, Etc & $\mathrm{L}$ & 460 & 0.001 \\
\hline Waxes Veg (O/T Triglycerides) Beeswax, O Insect Wa & KG & 222 & 0.003 \\
\hline Degras; Residues From Fatty Substances Or Animal O & KG & 217 & 0.004 \\
\hline Sausages \& Sim Prod, Of Meat, Meat Offal Or Blood; & KG & 717 & 0.006 \\
\hline Prepared Or Preserved Meat, Meat Offal Or Blood, N & KG & 131,932 & 0.688 \\
\hline Prepared Or Preserved Fish; Caviar \& Caviar Subst & KG & 13,414 & 0.048 \\
\hline Crustaceans, Molluscs And Other Aquatic Invertebra & KG & 2,764 & 0.015 \\
\hline Cane Or Beet Sugar And Chemically Pure Sucrose, In & KG & 502,195 & 0.562 \\
\hline Sugars, Nes, Incl Chem Pure Lactose Etc; Sug Syrup & KG & 109,087 & 0.170 \\
\hline Sugar Confectionery (Incl White Choc), Not Contain & KG & 28,719 & 0.126 \\
\hline Cocoa Beans, Whole Or Broken, Raw Or Roasted & KG & 10 & 0.000 \\
\hline Cocoa Powder, Not Containing Added Sugar Or Other & $\mathrm{KG}$ & 5,198 & 0.025 \\
\hline Chocolate And Other Food Preparations Containing C & KG & 44,308 & 0.351 \\
\hline Malt Extract; Food Prep Of Flour $<40 \%$ Cocoa ; Foo & KG & 54,076 & 0.273 \\
\hline Pasta W/N Cooked/Stuffed, O/W Prep, Such As Spaghe & KG & 24,676 & 0.054 \\
\hline Tapioca \& Subst Prepr From Starch, In Flake, Grn, & KG & 4,433 & 0.005 \\
\hline Prepared Foods Obt By Swelling/Roasting Of Cereals & KG & 286,688 & 0.955 \\
\hline Bread,Pastry Etc W/N Cntg Cocoa;Comm Waf Empty Cac & KG & 143,941 & 0.496 \\
\hline Vegetable, Fruit, Nuts \& Edible Pts Of Plants Prep & KG & 8,342 & 0.025 \\
\hline Tomatoes Prepared Or Preserved O/W Than By Vinegar & KG & 92,355 & 0.189 \\
\hline Mushrooms \& Truffles, Prepr Or Presv O/W Than By V & KG & 858 & 0.004 \\
\hline Vegetables Nes, Prepr Or Presv O/W Than By Vinegar & KG & 879,479 & 1.221 \\
\hline Vegetables Nes,Prepr Or Presv O/T By Vi Negar, Ace & KG & 297,868 & 0.834 \\
\hline Veg,Fruits, Nuts,Fruit-Peel \& Pts Of P1 Ants Presv & KG & 608 & 0.004 \\
\hline Jams, Fruit Jellies, Marmalades,Fruit Or Nut Purée & KG & 54,181 & 0.229 \\
\hline Fruits, Nuts \& O Edible Pts Of Plants O/W Prepr Or & KG & 91,210 & 0.268 \\
\hline Fruit (Incl Grape Must) \& Veg Juices, Unferment, N & $\mathrm{L}$ & 600,760 & 0.827 \\
\hline Extr, Ess \& Conc Of Coffee, Tea Or Maté; Chic O Co & KG & 7,839 & 0.097 \\
\hline Yeasts; O Dead One Cell Micro-Organisms (O/T Vacci & KG & 14,040 & 0.060 \\
\hline Sauces \& Prep Nes;Condiments \& Seasoning Mxd; Must & 0 & $\ldots$ & 0.309 \\
\hline Soups, Broths \& Prep Thereof; Homo Composite Food & KG & 6,652 & 0.018 \\
\hline Ice Cream And Other Edible Ice, Whether Or Not Con & KG & 244,673 & 0.733 \\
\hline Food Preparations, Nes & $\mathbf{0}$ & $\ldots$ & 2.578 \\
\hline Waters, Incl Nat Or Arti Min Or Aerated Waters Not & $\mathrm{L}$ & 272,264 & 0.420 \\
\hline Waters,Min Or Aerated,Sweet Or Flav,Non- Alc Bev E & $\mathrm{L}$ & 346,108 & 0.776 \\
\hline Beer Made From Malt & LPA & $2,549^{*}$ & 0.080 \\
\hline Wine Of Fresh Grapes, Incl Fortified; Grape Must O & $\mathbf{0}$ & $\ldots$ & 2.096 \\
\hline
\end{tabular}




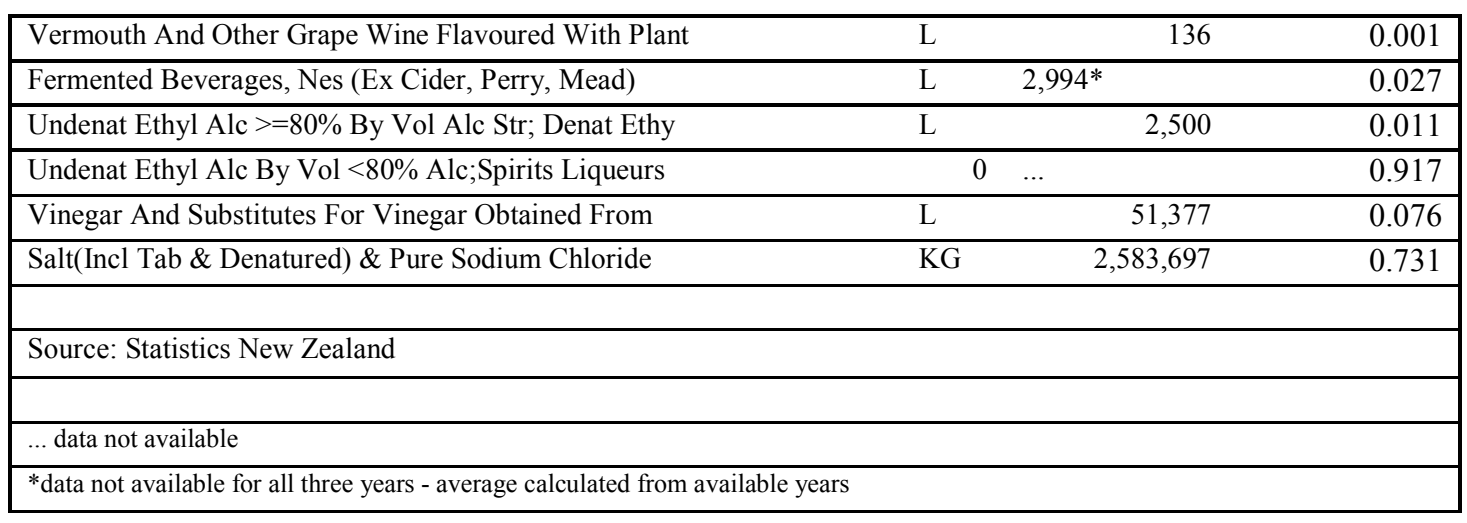




\section{Appendix F: Meat exports New Zealand to Fiji 2008 - 2010}

\begin{tabular}{|c|c|c|c|}
\hline Description & 2008 & 2009 & 2010 \\
\hline & NZ\$M & NZ\$M & NZ\$M \\
\hline Meat and edible meat offal (total) & $29,215,351$ & $28,665,171$ & $22,403,461$ \\
\hline \multicolumn{4}{|l|}{ Meat of bovine animals } \\
\hline fresh or chilled & 211,448 & 222,798 & 361,487 \\
\hline carcasses and half-carcasses, fresh or chilled & 28,806 & 0 & 64,590 \\
\hline $\begin{array}{l}\text { cuts with bone in (excluding carcasses and half-carcasses), fresh or } \\
\text { chilled }\end{array}$ & 0 & 0 & 24,300 \\
\hline boneless cuts, fresh or chilled & 182,642 & 222,798 & 272,597 \\
\hline frozen & $3,077,121$ & $2,633,816$ & $2,480,952$ \\
\hline cuts with bone in (excluding carcasses and half-carcasses), frozen & 69,159 & 73,220 & 130,487 \\
\hline Meat; of bovine animals, boneless cuts, frozen & $3,007,962$ & $2,560,596$ & $2,350,465$ \\
\hline \multicolumn{4}{|l|}{ Meat of swine } \\
\hline fresh, chilled or frozen & 7,718 & 0 & 0 \\
\hline carcasses and half-carcasses, frozen & 2,978 & 0 & 0 \\
\hline hams, shoulders and cuts thereof, with bone in, frozen & 2,331 & 0 & 0 \\
\hline n.e.c. in item no. 0203.2 , frozen & 2,409 & 0 & 0 \\
\hline \multicolumn{4}{|l|}{ Meat of sheep or goats } \\
\hline Meat of sheep or goats; fresh, chilled or frozen & $21,225,173$ & $21,097,270$ & $14,392,100$ \\
\hline Meat; of sheep, lamb carcasses and half-carcasses, fresh or chilled & 3,006 & 0 & $\overline{0}$ \\
\hline $\begin{array}{l}\text { Meat; of sheep (including lamb), cuts with bone in (excluding } \\
\text { carcasses and half-carcasses), fresh or chilled }\end{array}$ & 16,488 & 19,509 & 35,163 \\
\hline Meat; of sheep (including lamb), boneless cuts, fresh or chilled & 87,225 & 108,140 & 59,529 \\
\hline Meat; of sheep, lamb carcasses and half-carcasses, frozen & 9,104 & 2,774 & $\overline{0}$ \\
\hline $\begin{array}{l}\text { Meat; of sheep, carcasses and half-carcasses (excluding carcasses and } \\
\text { half-carcasses of lamb), frozen }\end{array}$ & 60,654 & 206,143 & 0 \\
\hline $\begin{array}{l}\text { Meat; of sheep (including lamb), cuts with bone in (excluding } \\
\text { carcasses and half-carcasses), frozen }\end{array}$ & $17,909,745$ & $17,367,506$ & $11,979,274$ \\
\hline Meat; of sheep (including lamb), boneless cuts, frozen & $3,066,028$ & $3,323,304$ & $2,292,542$ \\
\hline Meat; of goats, fresh, chilled or frozen & 72,923 & 69,894 & 25,592 \\
\hline
\end{tabular}




\begin{tabular}{|c|c|c|c|}
\hline Description & 2008 & 2009 & 2010 \\
\hline & NZ\$M & $\mathrm{NZ} \$ \mathrm{M}$ & NZ\$M \\
\hline $\begin{array}{l}\text { of bovine animals, swine, sheep, goats, horses, asses, mules or hinnies; } \\
\text { fresh, chilled or frozen }\end{array}$ & $1,765,261$ & $2,552,422$ & $2,533,744$ \\
\hline of bovine animals, tongues, frozen & 63,381 & 0 & 0 \\
\hline of bovine animals, livers, frozen & 166 & 0 & 0 \\
\hline of bovine animals, (other than tongues and livers), frozen & 318,511 & $1,131,256$ & $1,112,084$ \\
\hline of sheep, goats, horses, asses, mules or hinnies, fresh or chilled & 67,176 & 0 & 30,940 \\
\hline of sheep, goats, horses, asses, mules or hinnies, frozen & $1,316,027$ & $1,421,166$ & $1,390,720$ \\
\hline \multicolumn{4}{|l|}{ Meat and edible offal of poultry } \\
\hline $\begin{array}{l}\text { of the poultry of heading no. } 0105 \text {, (i.e. fowls of the species Gallus } \\
\text { domesticus), fresh, chilled or frozen }\end{array}$ & $2,920,726$ & $2,154,380$ & $2,627,258$ \\
\hline $\begin{array}{l}\text { of the poultry of heading no. } 0105 \text {, of fowls of the species Gallus } \\
\text { domesticus, (not cut in pieces), frozen }\end{array}$ & 996,216 & 590,101 & 477,012 \\
\hline $\begin{array}{l}\text { of the poultry of heading no. } 0105 \text {, of fowls of the species Gallus } \\
\text { domesticus, cuts and offal, fresh or chilled }\end{array}$ & 0 & 0 & 377 \\
\hline $\begin{array}{l}\text { of the poultry of heading no. } 0105 \text {, of fowls of the species Gallus } \\
\text { domesticus, cuts and offal, frozen }\end{array}$ & $1,584,765$ & $1,320,246$ & $2,064,528$ \\
\hline of the poultry of heading no. 0105 , of turkeys, (not cut in pieces), frozen & 67,204 & 30,884 & 32,287 \\
\hline of the poultry of heading no. 0105 , of turkeys, cuts and offal, frozen & 119,094 & 53,452 & 34,311 \\
\hline $\begin{array}{l}\text { of the poultry of heading no. } 0105 \text {, of ducks, geese or guinea fowls, (not } \\
\text { cut in pieces), fresh or chilled }\end{array}$ & 540 & 0 & 71 \\
\hline $\begin{array}{l}\text { of the poultry of heading no. } 0105 \text {, of ducks, geese or guinea fowls, (not } \\
\text { cut in pieces), frozen }\end{array}$ & 87,186 & 65,410 & 18,614 \\
\hline $\begin{array}{l}\text { of the poultry of heading no. } 0105 \text {, of ducks, geese or guinea fowls, fresh } \\
\text { or chilled, poultry cuts or offal (excluding fatty livers) }\end{array}$ & 0 & 0 & 58 \\
\hline of the poultry of heading no. 0105 , of ducks, geese or guinea fowls, frozen & 65,721 & 94,287 & 0 \\
\hline \multicolumn{4}{|l|}{ Other } \\
\hline Meat and edible meat offal n.e.c. in chapter 2, fresh, chilled or frozen & 4,270 & 3,713 & 3,569 \\
\hline $\begin{array}{l}\text { Meat and edible meat offal; salted, in brine, dried or smoked; edible flours } \\
\text { and meals of meat or meat offal }\end{array}$ & 3,634 & 772 & 4,351 \\
\hline $\begin{array}{l}\text { Meat, preserved; of swine, hams, shoulders and cuts thereof, with bone in, } \\
\text { salted, in brine, dried or smoked }\end{array}$ & 0 & 0 & 443 \\
\hline $\begin{array}{l}\text { Meat, preserved; of swine, salted, in brine, dried or smoked, n.e.c. in item } \\
\text { no. } 0210.1\end{array}$ & 3,634 & 772 & 1,429 \\
\hline Meat, preserved; of bovine animals, salted, in brine, dried or smoked & 0 & 0 & 479 \\
\hline $\begin{array}{l}\text { Meat and edible meat offal, preserved; salted, in brine, dried or smoked, } \\
\text { and edible flours and meals of meat or meat offal, other than of primates, } \\
\text { whales, dolphins and porpoises, manatees and dugongs, reptiles (including } \\
\text { snakes and turtles) }\end{array}$ & 0 & 0 & 2,000 \\
\hline \multicolumn{4}{|l|}{ n.e.c. not elsewhere categorised } \\
\hline & & & \\
\hline
\end{tabular}

